\title{
Using Thermal Imaging to Promote Independent Living
}

By

Ming Y. Yuan, B. Eng

A thesis submitted to the Faculty of Graduate Studies and Research in partial fulfillment of the requirements for the degree of

Master of Applied Science

In Biomedical Engineering

Ottawa-Carleton Institute for Biomedical Engineering

Department of Systems and Computer Engineering

Carleton University

Ottawa, Ontario, Canada

December 2008

Copyright $\odot$ Ming Y. Yuan, 2008 


$\begin{array}{ll}\begin{array}{l}\text { Library and } \\ \text { Archives Canada }\end{array} & \begin{array}{l}\text { Bibliothèque et } \\ \text { Archives Canada }\end{array} \\ \begin{array}{l}\text { Published Heritage } \\ \text { Branch }\end{array} & \begin{array}{l}\text { Direction du } \\ \text { Patrimoine de l'édition }\end{array} \\ \begin{array}{l}\text { 395 Wellington Street } \\ \text { Ottawa ON K1A 0N4 } \\ \text { Canada }\end{array} & \begin{array}{l}\text { 395, rue Wellington } \\ \text { Ottawa ON K1A 0N4 } \\ \text { Canada }\end{array}\end{array}$

Your file Votre référence ISBN: 978-0-494-47524-9

Our file Notre référence

ISBN: 978-0-494-47524-9

NOTICE:

The author has granted a nonexclusive license allowing Library and Archives Canada to reproduce, publish, archive, preserve, conserve, communicate to the public by telecommunication or on the Internet, loan, distribute and sell theses worldwide, for commercial or noncommercial purposes, in microform, paper, electronic and/or any other formats.

The author retains copyright ownership and moral rights in this thesis. Neither the thesis nor substantial extracts from it may be printed or otherwise reproduced without the author's permission.
AVIS:

L'auteur a accordé une licence non exclusive permettant à la Bibliothèque et Archives Canada de reproduire, publier, archiver, sauvegarder, conserver, transmettre au public par télécommunication ou par l'Internet, prêter, distribuer et vendre des thèses partout dans le monde, à des fins commerciales ou autres, sur support microforme, papier, électronique et/ou autres formats.

L'auteur conserve la propriété du droit d'auteur et des droits moraux qui protège cette thèse. $\mathrm{Ni}$ la thèse ni des extraits substantiels de celle-ci ne doivent être imprimés ou autrement reproduits sans son autorisation.
In compliance with the Canadian Privacy Act some supporting forms may have been removed from this thesis.

While these forms may be included in the document page count, their removal does not represent any loss of content from the thesis.
Conformément à la loi canadienne sur la protection de la vie privée, quelques formulaires secondaires ont été enlevés de cette thèse.

Bien que ces formulaires aient inclus dans la pagination, il n'y aura aucun contenu manquant.

\section{Canada}


The undersigned recommend to the

Faculty of Graduate Studies and Research acceptance of the thesis

\section{Using Thermal Imaging to Promote Independent Living}

Submitted by Ming Ye Yuan

in partial fulfillment of the requirements for

the degree of Master of Applied Science in Biomedical Engineering

Thesis Co-Supervisor

Dr. James R Green
Thesis Co-Supervisor

Dr. Rafik Goubran

Chair, Department of Systems and Computer Engineering

Dr. Victor Aitken

2008, Carleton University 


\section{Abstract}

The elderly segment of the population is experiencing rapid growth worldwide leading to increased demands on the health care system. One solution is to develop novel technologies to promote independent living, where users are able to continue to live safely in their own home rather than entering costly institutional care facilities. In North America, the stove is one of the most frequent causes of fire accidents in the home. Many of these fire accidents are caused by human error or forgetfulness, a problem which may be more serious with advanced age. An automated stove top monitoring system could significantly increase kitchen safety. In this thesis, a stove top monitoring system is developed that uses a thermal camera to detect dangerous situations and behaviours, and alert the user before a fire accident occurs. Monitoring systems such as the one developed here will serve to promote independent living among the elderly leading to increased quality of life and decreased health care costs.

The stove top monitoring systems consists of four subsystems: the burner status (active/inactive) detection system, the burner temperature detection system, the pot presence/absence detection system, and the human activity detection system. Twenty nine experiments were conducted using three different types of stove tops: 2-burner electrical coil, 4-burner electric ceramic top, and 5-burner natural gas. Each subsystem was thoroughly tested and robust performance was achieved in all cases. Lastly, data fusion algorithms were developed to combine the data gathered by the four subsystems, and to alert the user or caregiver when a dangerous situation occurs. 
A thermal camera is used in this thesis to quantify burner temperature. Although the problem could be simplified by also using a natural light camera, particularly to detect human activity, we restrict ourselves to using only a thermal imaging camera with a fixed narrow field of view to address privacy concerns and encourage adoption by the elderly population. Furthermore, no modifications to the stove top are required allowing this system to be retrofit on any stove top when deemed necessary by a caregiver, user, or their family. 


\section{Acknowledgements}

I would like to thank my supervisors, Professors James Green and Rafik Goubran, for their infinite support during my research. Without them, I could not finish my master degree.

I also need to thank my dear parents for their love, wisdom and guidance. I have been brave to live alone in Canada over the past six years all because of them.

To all my friends and family who help me to proceed my research. Special thanks to my roommate Anni, Zhu, you shared most of housework when I am working at home. Also Christophe Herry, I appreciate your suggestions of how to use thermal camera well. And Dr. Hua, Xiao, your useful suggestions for my thesis.

I gratefully acknowledge the financial support received from the Natural Sciences and Engineering Research Council of Canada. 


\section{Table of Contents}

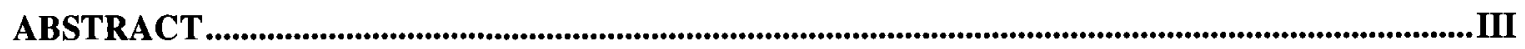

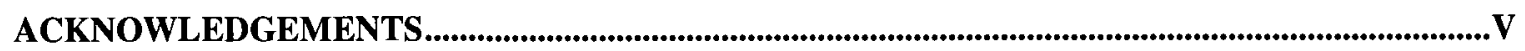

TABLE OF CONTENTS............................................................................................................................ VI

LIST OF FIGURES .......................................................................................................................................X

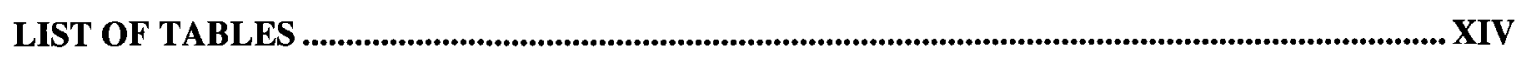

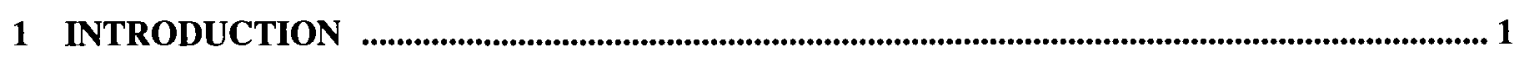

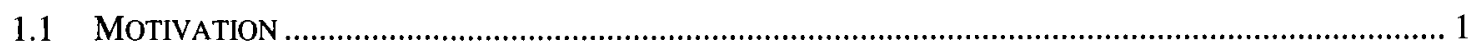

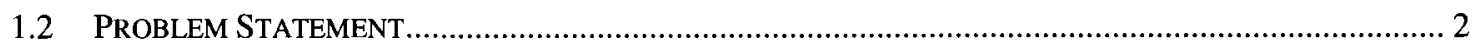

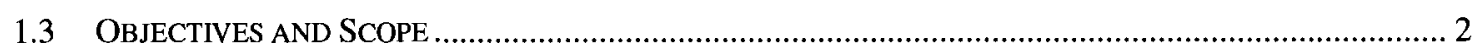

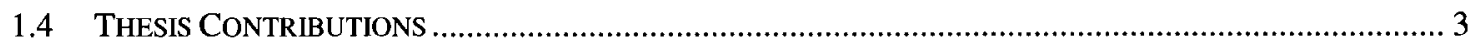

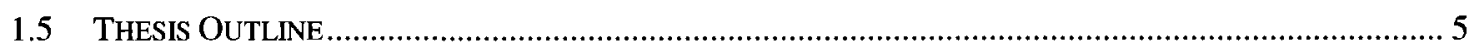

2 BACKGROUND REVIEW

2.1 PROMOTING INDEPENDENT LIVING VIA AUTOMATED MONITORING............................................... 7

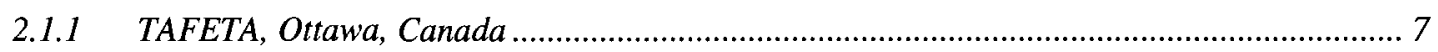

2.1.2 MARC, University of Virginia, United States................................................................. 8

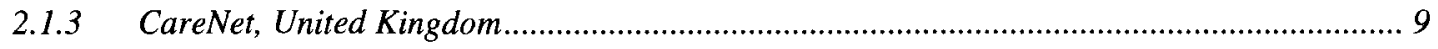

2.1.4 University of N.S.W., Sydney, Australia ………................................................................. 10

2.1.5 "Smart" care flats, Tonsberg, Norway ............................................................................. 11

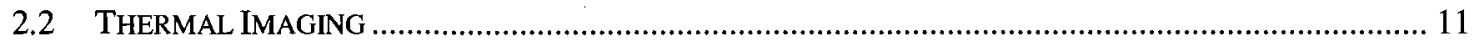

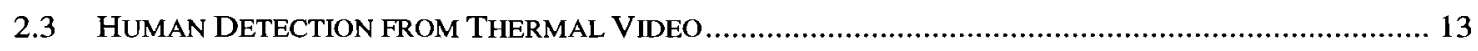

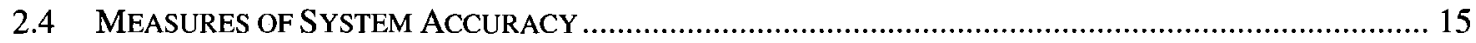

3 SYSTEM OVERVIEW .................................................................................................................................. 17

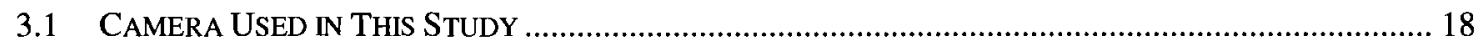




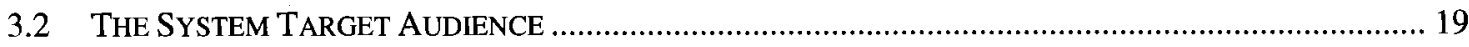

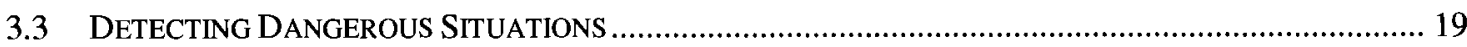

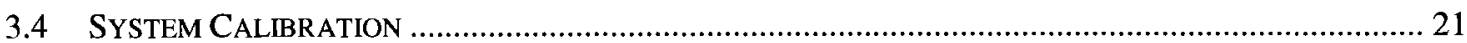

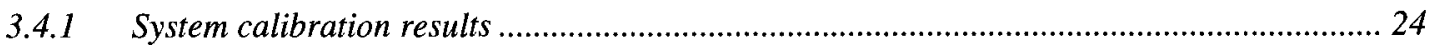

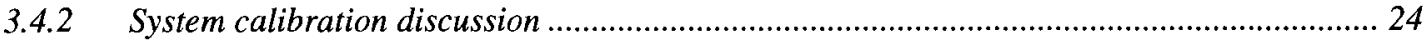

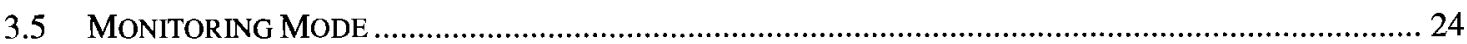

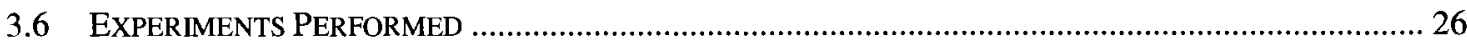

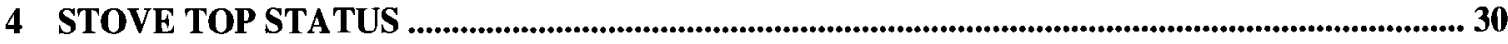

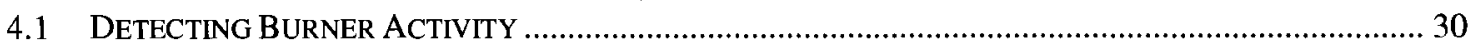

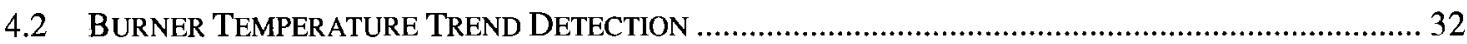

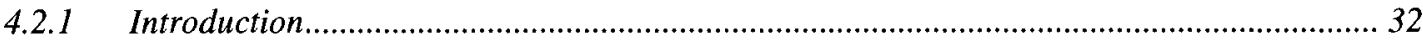

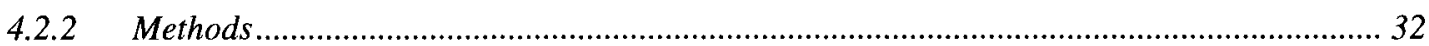

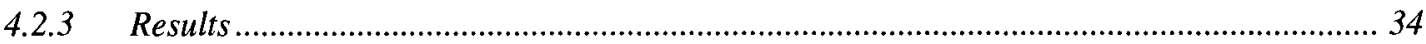

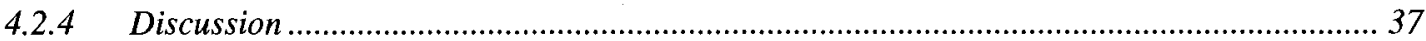

5 POT PRESENCE/ABSENCE DETECTION SYSTEM ...................................................................... 38

5.1 INITIAL Pot PRESENCE/AbSENCE DeTECTION SYSTEM .................................................................... 38

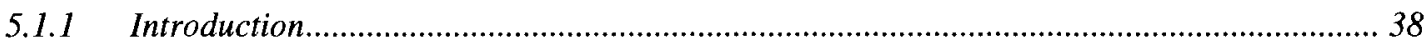

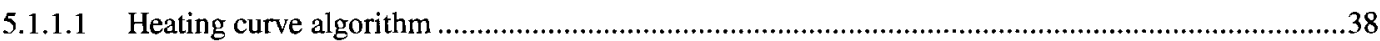

5.1.1.2 Percentage of max temperature pixels algorithm......................................................................40

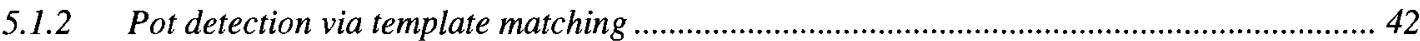

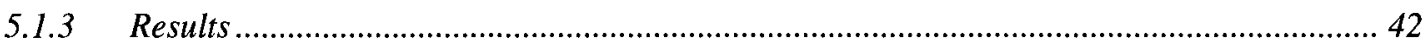

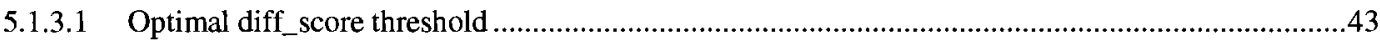

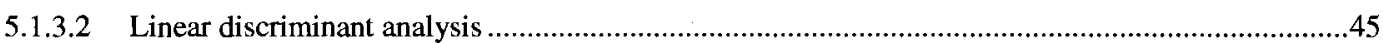

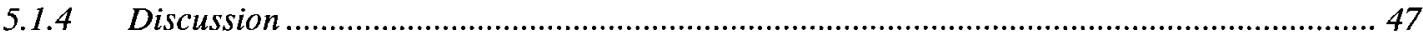

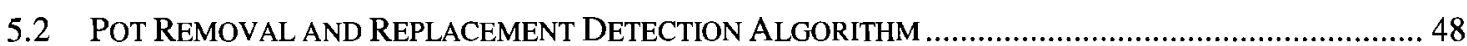

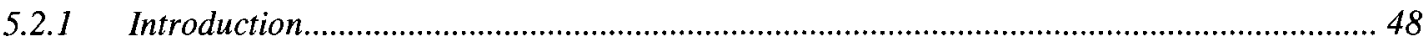

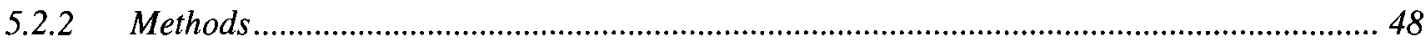

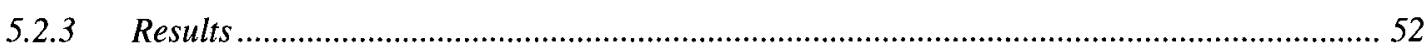




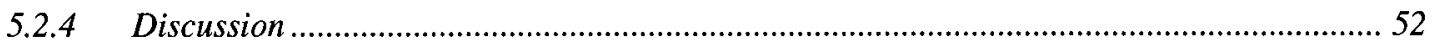

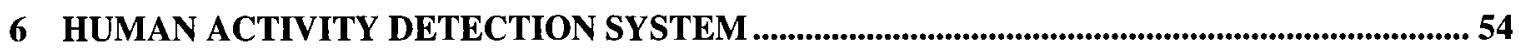

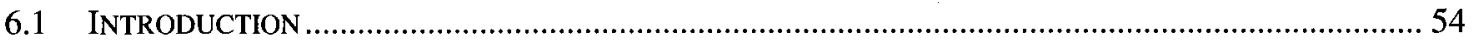

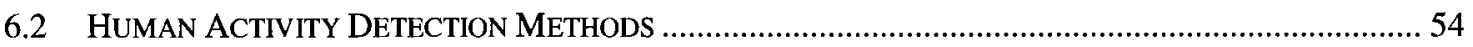

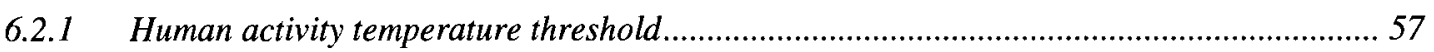

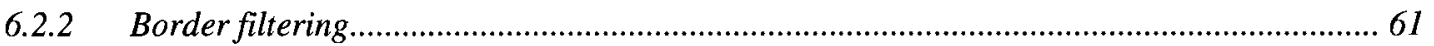

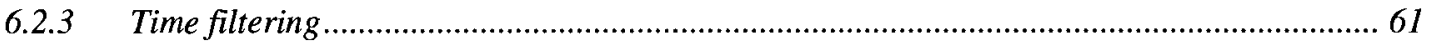

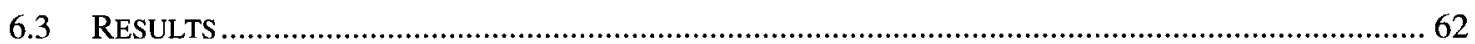

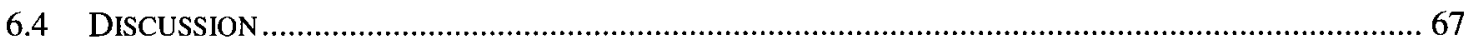

7 DATA FUSION FOR ALERT GENERATION ........................................................................................ 69

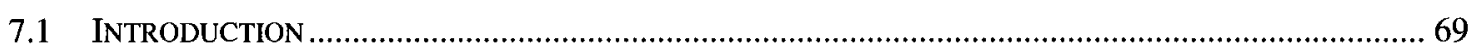

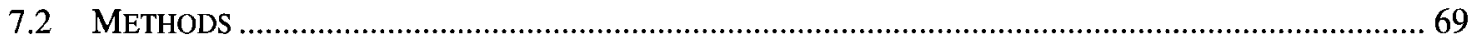

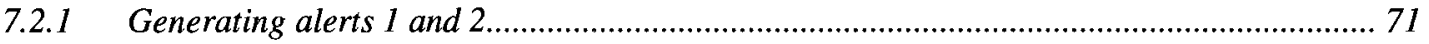

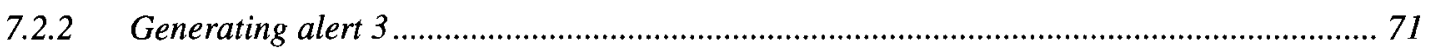

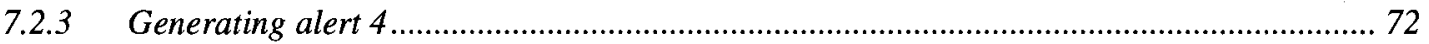

7.2.4 Test data

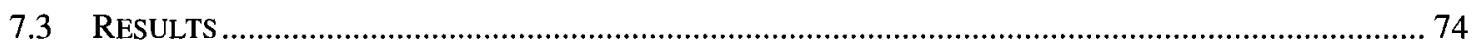

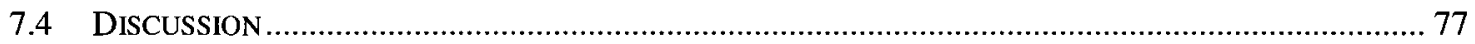

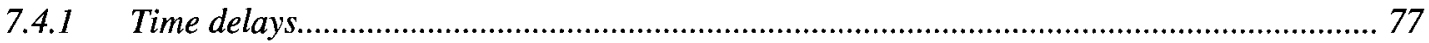

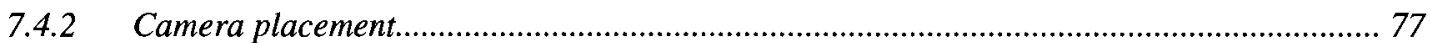

7.4.3 Data fusion to eliminate subsystems errors....................................................................... 79

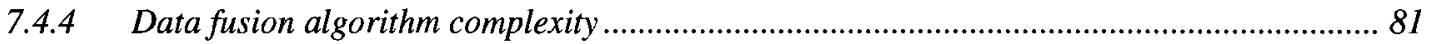

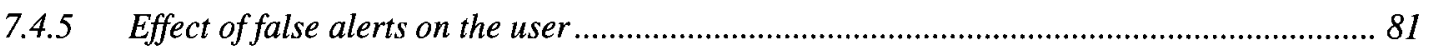

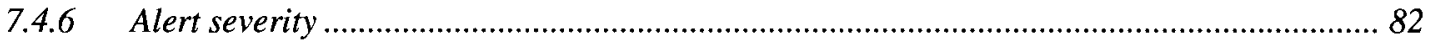

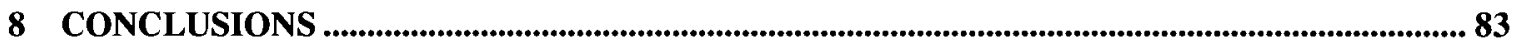

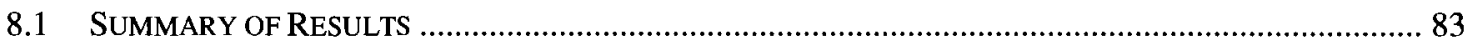

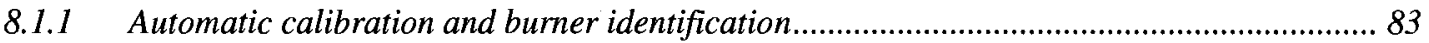




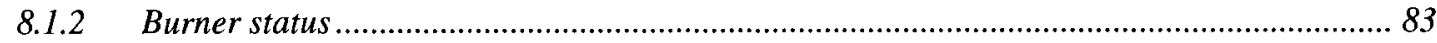

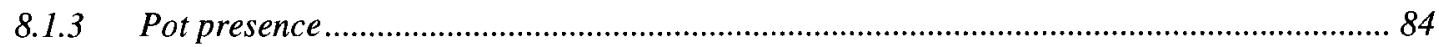

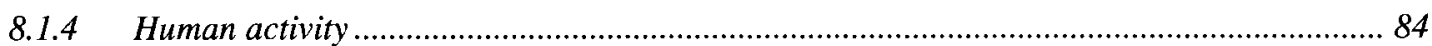

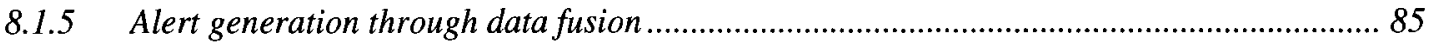

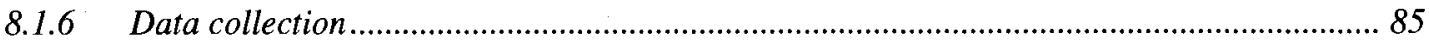

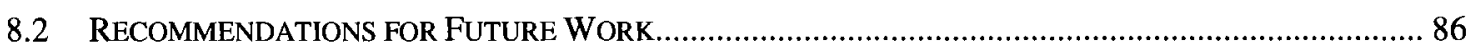

8.2.1 Processing frames in real-time

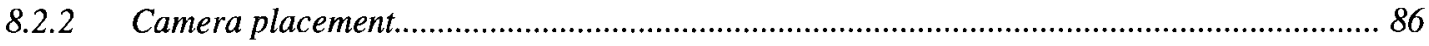

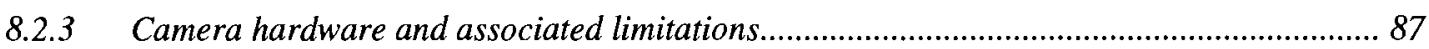

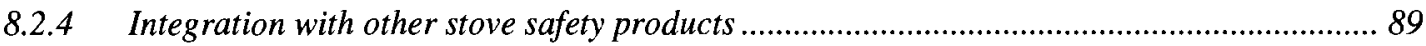

8.2.5 Other applications of thermal imaging for independent living ............................................ 90

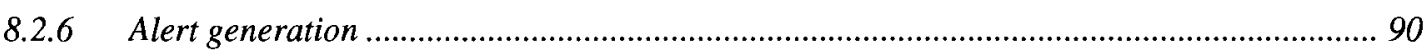

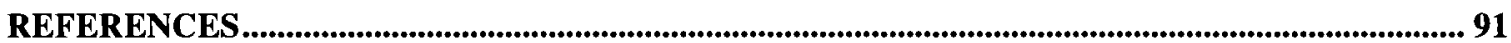

APPENDIX A - EXPERIMENTAL PROCEDURES …............................................................................. 96 


\section{List of Figures}

Figure 2.1. The electromagnetic spectrum: 1. X-ray; 2. UV; 3. Visible; 4. IR; 5. Microwaves; 6. Radiowaves (reproduced from reference [28]) ..................... 12

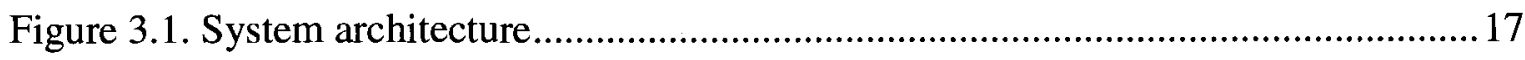

Figure 3.2. Software system block diagram ..............................................................20

Figure 3.3. Flow chart showing alert generation logic of the stove top monitoring system 22

Figure 3.4. Image processing steps for calibration mode 23

Figure 3.5. Calibration results for 4-burner electric ceramic (top), 2-burner electric coil (middle), and 5-burner natural gas (bottom) stove tops showing correct burner identification 26

Figure 4.1. The relation between time and the temperature of metal to cause injury to skin (values below 1s are extrapolated, adapted from [53])

Figure 4.2. Burner 4 average temperature for natural gas stove showing effect of flame .. 32

Figure 4.3. Smoothed profile from Figure 4.2 after computing trimmed mean at each point

Figure 4.4. Difference between trimmed means at $\mathrm{t}=\square$ and $\mathrm{t}=-1$ for experiment $\mathrm{G} 3$ with threshold of $\pm 0.1^{\circ} \mathrm{C} / \mathrm{s}$ shown in green

Figure 5.1. a) Front view of the burner (the visible part of the burner is bright while most of the burner is covered by the pot). b) Histogram for burner 4 (top-right) showing clear bimodal distribution. 40 
Figure 5.2. a) Thermal image of uncovered burners. b) Corresponding histogram for burner 4 (top-right) showing a unimodal distribution with most pixels at maximum temperature .41

Figure 5.3. A frame from Exp C3 where burner 4 is blocked by test subject's head. ....... 41

Figure 5.4. Diff_score values for two uncovered burners (electrical coil) .......................44

Figure 5.5. Diff_score values for two covered burners and two burners that were off (burner 1 and 4 were on and occupied with pots, burner 2 and 3 were off) ....44

Figure 5.6. Classification of initial pot presence/absence using diff_score measured at the 20th second after burner becoming active .46

Figure 5.7. Classification of initial pot presence/absence using minimum diff_score observed over first 20 s

Figure 5.8 Temperature profile for 4 burners in experiment $\mathrm{C} 2$ showing human activity and pot removal/replacement events. 48

Figure 5.9. Temperature profile from Figure 5.8 after human activity detection. The yellow bars indicates periods of human activity, the green bar indicates a period of pot removal and replacement. 50

Figure 5.10. The subject opens the hot pot lid which increases burner temperature above 40 Celsius degrees in Experiment $\mathrm{C} 2$ .50

Figure 5.11. Plot of temperature spike magnitudes for thermal noise, human activity, and pot removal and replacement events. .51

Figure 6.1. Thermal noise (within the red circle, from a laptop vent) is visible in the bottom right corner of the image. This noise was incorrectly labelled as human activity since i) it is connected to the image border thereby bypassing the 
border filtering, and ii) its centroid differs sufficiently over 30 seconds to bypass the temporal filtering.................................................................55

Figure 6.2. Thermal image of 4-burner stove top showing human activity (top-right) and thermal noise (within the red circle). 55

Figure 6.3. Thermal image of 5-burner gas stove top with strong thermal noise connected to the border of image (within the red circle) 56

Figure 6.4. Flow chart of detecting human activity .57

Figure 6.5. Clothing surface temperature vs. different clothing insulations assuming an ambient temperature of $20^{\circ} \mathrm{C}$ and a body temperature of $36.8^{\circ} \mathrm{C}$ .60

Figure 6.6. a) Subject's arm with thick coat. Surface temperature is $28.6^{\circ} \mathrm{C}$ and the system fails to detect human activity. b) Subject's hand connected to the border of the image. Surface temperature is $31.4^{\circ} \mathrm{C}$ and the system detects human activity successfully. .64

Figure 6.7. The top row picture shows the thermal image in experiment $\mathrm{G} 2$ with no human activity (frame 239, on left) with resulting picture after the bordering and time filtering (on right). The bottom left picture shows the next frame in which human activity is clearly visible. The bottom right image shows the frame after bordering and time filtering; the red line circles the human hand missed by the algorithm. .65

Figure 6.8. Illustration of false positive prediction of human activity. a) Frame 55 from experiment ECT3 showing three thermal noise blobs. b) Frame 56 showing blobs 2 and 3 merged into a new blob mistaken for human activity.

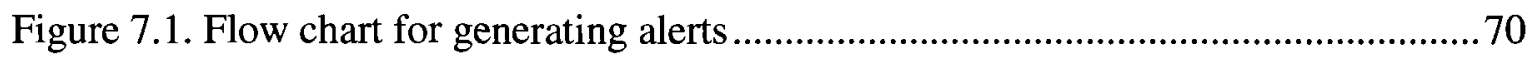

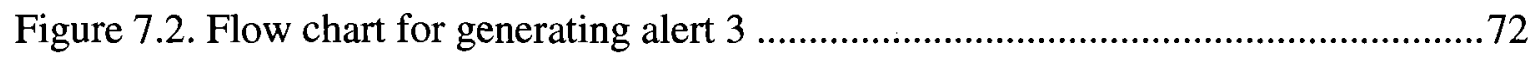


Figure 7.3. The front view of gas stove (Exp G2), pot on B4 is regarded as part of the burner 5 78

Figure 7.4. The front view of gas stove (Exp G3), the reflection, from the flame of burner 4 , is heating up the metallic pot in burner 5 (the red line circles the reflection) .79

Figure 7.5. Effect of human activity on the pot removal/replacement system .80

Figure 7.6. Examples of human activity affecting pot presence. Red circle in b) indicates human arm occluding burner resulting in falsely predicted pot replacement event. Red circle in c) shows human user completely blocking two burners. When burners become unblocked, a false pot removal event occurs 81

Figure 8.1. Temperature profile of a pot boiling dry ………............................................. 88

Figure 8.2. Safe-T-element ${ }^{\mathrm{TM}}$ cooking system (adapted from [10]) …................................ 89 


\section{List of Tables}

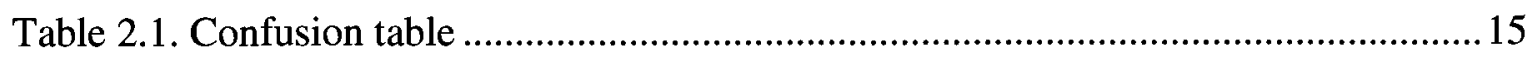

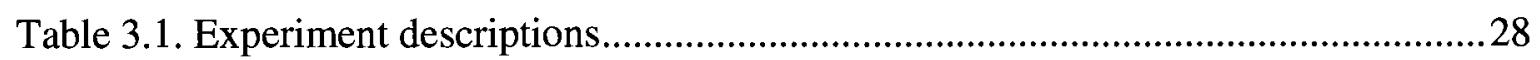

Table 3.2. Summary table showing which experiment is used to evaluate which subsystem .29

Table 4.1. Auto-ignition temperature for various fuels and chemicals [54] .......................31

Table 4.2. Experiment description for temperature trend detection system ........................35

Table 4.3. Burner temperature trend confusion table for electric coil .................................36

Table 4.4. Burner temperature trend confusion table for ceramic ......................................36

Table 4.5. Burner temperature trend confusion table for natural gas...................................36

Table 4.6. Detecting burner temperature system performance ..............................................36

Table 5.1. Descriptions of experiments used in Chapter 5 ................................................39

Figure 5.2. Number of actual positive and negative events ..............................................43

Table 5.3. Template matching algorithm performance .....................................................45

Table 5.4. Temperature profile analysis for pot presence/absence .......................................51

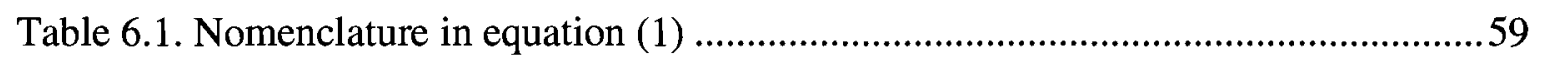

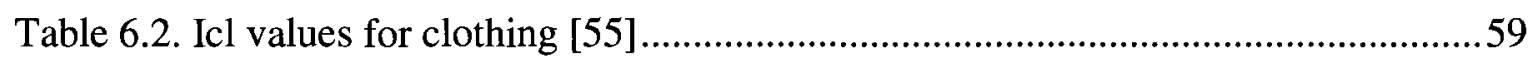

Table 6.3. Description of human activity experiments .......................................................63

Table 6.4. Human activity detection performance per frame. Sn=sensitivity and

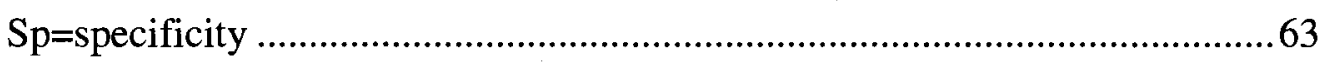

Table 6.5. Human activity monitoring performance per event ............................................66

Table 7.1. Summary table for data fusion experiments ..................................................... 74

Table 7.2. Summary table of dangerous events in 22 experiments.....................................75 
Table 7.3. Evaluation of data fusion alert generation per event.................................... 76

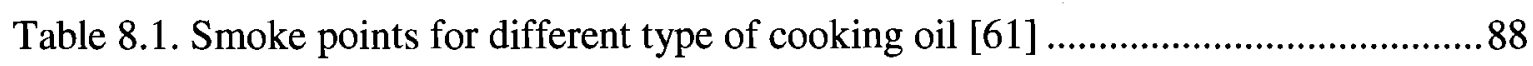




\section{Chapter 1}

\section{Introduction}

\subsection{Motivation}

The elderly segment of the population is growing worldwide. In Canada, seniors (i.e. persons over the age of 65) comprise the fastest growing segment of the population [1] and are expected to form $18 \%$ of the Canadian population by the year 2021 [2]. This trend will place an increasing strain on the health care system as people tend to require more health care as they age [3]. Significant cost savings can be achieved if elderly persons are able to continue to live independently, a situation which is often preferred by patients to the alternatives of institutionalization in hospitals or long term care facilities. Diverse technologies are being developed to facilitate this so called 'aging in place' [4-8]. However, most monitoring system initiatives have thus far focused on the bedroom, bathroom, and exit doors, and there remains a significant need for safety monitoring in the kitchen. Specifically, we are faced with the following facts: the stove is the number one cause of fire accidents in the residence [9], a kitchen fire occurs every 8 minutes in North America [10], unattended cooking is responsible for over $70 \%$ of these fires [11], cooking accounts for $42 \%$ of all apartment fires and seniors are the most vulnerable to fire and are the highest risk group [12].

Several populations are faced with decreased mental acuity or forgetfulness such as the elderly, those with intellectual disabilities, or with neurological trauma. These conditions 
can lead to potentially unsafe behaviours when using a stove top. For example, fire hazards are created when the incorrect burner is turned on, or when a pot is removed without the burner being turned off. In some cases the dangers associated with these fire hazards pose a major obstacle to independent living and may require the individual to enter a long term care facility even when they would prefer to continue to live independently. A suitable monitoring system that could identify these unsafe situations and alert the individual may greatly increase kitchen safety and lead to increased independent living. In order to be widely adopted, such a monitoring system will have to be unobtrusive, address user privacy concerns, and be amenable to retrofitting on existing stove tops.

\subsection{Problem Statement}

This thesis aims to develop a non-obtrusive automated stove top monitoring system to detect unsafe situations and human behaviours and generate alerts before fire hazards arise. Due to privacy concerns, this system will be restricted to solely using a thermal imaging camera with a fixed narrow field of view, although the addition of a natural light camera would greatly simply the problem. Furthermore, no modifications to the stove are permitted such that the system can be retrofitted to any commercial stove top.

\subsection{Objectives and Scope}

The problem statement is addressed through the development of an automated stove top monitoring system that meets the following objectives:

- Automatic calibration and identification of all burners for an arbitrary stove top configuration, and arbitrary placement of the camera. 
- Detect the status of all burners as being active or inactive. Furthermore, determine the temperature trend of all active burners as being increasing, decreasing, or remaining constant.

- Detect if an active burner is occupied with pot or not at all times.

- Continuous monitoring of human activity at the stove top when any burner is active.

- Data fusion of burner status, pot status, and human activity in order to generate alerts for the following commonly observed dangerous behaviours:

1. A user turns on the burner and forgets to place a pot on it.

2. A user turns on one burner (burner A) but puts the pot on the wrong one (burner B).

3. A user does not tend to an active stove top for a user configurable time-out period.

4. A pot is removed from a burner, but the user forgets to turn off the burner.

Two final constraints are that 1) all objectives are to be achieved without the use of a natural light camera to address privacy concerns, and 2) that the monitoring system will not require any modification of the stove top such that it can be retrofitted to any commercial stove.

\subsection{Thesis Contributions}

A preview of the major thesis contributions made during my research is listed below:

- First stove top monitoring system in the kitchen to auto-calibrate (i.e. identify all burner centroids and diameters) and then continuously monitor each burner's status 
(i.e. active or inactive) and temperature trend (i.e. temperature increasing, same, or decreasing).

- Created a novel monitoring system based on thermal imaging to track human activity associated with stove top usage. Excellent accuracy was achieved when measured per frame (sensitivity $=81.8 \%$, specificity $=95 \%$ ) or per event (sensitivity $=87 \%$, positive predictive value $=93 \%$ ) for human activity detection on ceramic, electric coil, and gas stoves. This system was published at the $31^{\text {st }}$ annual Canadian Medical and Biological Engineering Conference (CMBEC 31), in Montreal, June 10-13, 2008 [13] and was presented by myself.

- Robust detection of pot presence was achieved by first detecting whether a burner was covered when it was initially active, and then by tracking removal and replacement events over time.

- Achieved excellent sensitivity (mean=94\%), positive predictive value (mean=83\%) per event for data fusion algorithm on ceramic, electric coil and natural gas stoves.

\section{Additional deliverables:}

Twenty nine experiments were performed in four different locations with three different stove top technologies (electric coil, electric ceramic, and natural gas). Ten of these experiments include human activity within the field of view in order to test for human activity. These data are useful not only for this thesis, but also for future work in this field. 


\subsection{Thesis Outline}

Chapter 2 provides a literature review of previous work in the field, including remote monitoring for the promotion of independent living, thermal imaging, and techniques for human detection from thermal video.

Chapter 3 provides a system overview including a description of the hardware used and experiments performed. Flow charts are shown describing how all the algorithms will be combined. The targeted dangerous behaviours and corresponding alerts are defined.

Chapter 4 describes the burner status detection systems, including burner activity detection (active/inactive), and burner temperature trend (increase/decrease/constant) detection.

Chapter 5 describes the pot presence tracking algorithms. This task is broken down into detection of initial pot presence, and subsequent detection of pot removal/replacement events.

Chapter 6 focuses on the human activity detection system. This chapter defines human activity for the purpose of this thesis and describes the algorithms developed to detect human activity in stove top monitoring system. Challenges overcome, and experimental results are detailed. A number of recommendations for camera placement to get improved results are also given. 
Chapter 7, provides data fusion of stove top status, pot presence, and human activity in order to identify dangerous events and generate appropriate alerts.

In chapter 8 concluding remarks are made. Also, a brief synopsis of the results presented in the thesis and suggestions for further research are presented.

Appendix A details all twenty nine experiments on the three different stove tops: electric coil, ceramic, and natural gas. 


\section{Chapter 2}

\section{Background Review}

This section describes other attempts to improve safety in the home through automated monitoring systems, presents a literature review of techniques for human detection from thermal camera video data, and gives a definition of the metrics used in this thesis to measure system accuracy.

\subsection{Promoting Independent Living via Automated Monitoring}

Health care costs could be minimized if elderly people are able to live independently [14]. A number of initiatives are underway in numerous countries to promote independent living via automated monitoring systems. These systems combine fairly simple applications of different sensors, control systems, and data analysis to enable independent living. A number of significant projects are discussed below.

\subsubsection{TAFETA, Ottawa, Canada}

The "Technology Assisted Friendly Environment for the Third Age" (TAFETA) is a project whose goal is to help elderly people live independently. This project applies technology to benefit elderly persons with declining mental acuity, those who are developmentally delayed, or those with cognitive impairments. This research ultimately facilitates aging in place, defined as "not having to move from one's present residence in order to secure necessary support services in response to changing need" [15]. 
The TAFETA project has set up a smart apartment in the Elisabeth Bruyere Health Centre of the SCO Health Service in Ottawa, Canada. This apartment offers many unique devices and add-ons trying to create a smart environment to promote independent living for the elderly. For example, in the bedroom, an unobtrusive pressure sensor array is placed under the mattress of the bed. Should elderly people get up in the middle of the night, lights are automatically switched on in the bedroom and the bathroom, and turned off again when the person returns to bed [16]. This is aimed to reduce falls during otherwise unlit trips to the washroom during the night. A sensor on the fridge door reminds the user if the door is open for too long. In the bathroom, a smart grab bar and a smart toilet bar are installed and equipped with sensors to detect user-applied pressure. Along with the help of visual and auditory cues, data from these sensors are enabling research into decreasing the risk of falls during bathtub and toilet transfers [17]. Meanwhile, the National Research Council (NRC), TAFETA, Saint-Vincent Hospital (SCO Health Service), and IVIM Inc. are incorporating a "nose as mouse" technology called the Nouse into the smart apartment. This technology transfers a user's nose movement into cursor clicks and movement [17].

\subsubsection{MARC, University of Virginia, United States}

The "Medical Automation Research Center" (MARC) at the University of Virginia has established a SmartHouse project with various sensors installed to provide remote monitoring health checks. This project consists of a series of motion-detection sensors and binary switches. Eight motion sensors have been installed in each room of the house: bedroom, bathroom, office, living room, kitchen, and laundry room/back door area, one at the front door, and one in the shower. When there is a movement within the sensor's field 
of view, it is logged. The switches are established mainly in the kitchen and indicate actions such as the opening of a kitchen cabinet or the microwave [18]. Sensor readings are recorded continuously which consists of location of sensors and time when the sensor is triggered in order to monitor a person's in-home activity. For the purpose of detecting behavioural patterns and inferring activities, data-analysis techniques such as using plots and histograms $[19,20]$, comparing sensor readings to a daily activity log [21,22], using neural networks [23] and mixture models [18] have been investigated. When a disturbance of behavioural patterns or activities is observed, an alert will be generated and sent to care givers to promote independent living.

\subsubsection{CareNet, United Kingdom}

CareNet is a telecare integration architecture developed in the United Kingdom [24, 25]. The Modular Intelligence Domiciliary Alarm System (MIDAS) is a prototype implementation of the CareNet general architecture specifically designed for the elderly and disabled people $[26,18]$. A prominent feature of the MIDAS is its ability to detect deviations from a gold standard of daily living activity. Another feature of the MIDAS is to provide a level of assurance to the elderly by giving direct access to a call center where the appropriate support services (social, healthcare, ambulance, police, etc) can be contacted [18]. A number of smart, non-intrusive sensors are used such as lifestyle or behaviour sensors capable of monitoring daily life activities (e.g. passive infra-red for measuring client mobility, accelerometers for detecting falls and tremors, inductive badges for determining room occupancy [24]), and environment and security sensors capable of monitoring the local environment status (e.g. thermometer for room temperature, microphone for noise pollution, coil clamp for appliance usage, etc [24]). 
These sensors are combined with assistive technologies such as speech-based warning or reminders, and are connected to a local intelligence unit capable of processing data in real time. Emergency detection is performed via a rule-based system that analyzes sequences of events by considering the time spent in specific locations [18].

\subsubsection{University of N.S.W., Sydney, Australia}

Celler et al. [27] have designed a pilot project to test whether the functional health status of the elderly at home can be assessed remotely by continuous analysis of data gathered from a number of analog devices and digital devices within the home. These devices can provide health and psychosocial status of the elderly user. Changes in status such as sleep patterns, mobility, and utilisation of cooking and toilet facilities can possibly indicate a health problem, hence, proper and cost-effective intervention of both medical based services and community based services can be accessed in time to help seniors maintain a free and healthy life style.

A number of analog sensors are used, including infrared sensor (IRS) systems, light sensors (LS), temperature sensors (TS), sound sensors, a central power sensor, appliance power sensors and pressure sensors. Digital devices include simple magnetic and mechanical switches which record the transitions between rooms when the door is open or closed. Currently, 170 households are involved in this project and the study is in progress. 


\subsection{5 "Smart" care flats, Tonsberg, Norway}

The initiative most similar to this thesis is located in Tonsberg, Norway where eight care flats were built to support the home lives for people with dementia [26]. In the kitchen, sensors can monitor the temperature of the stove top. Once it gets overheated, the main power is automatically shut down and an alert is sent to the staff. While similar in goal to the present study, this initiative differs in that it does not appear to use thermal imaging and instead monitors the stove top through direct surface temperature measurement. Unfortunately, very little detail is available regarding this initiative, and attempts to contact the authors via email received no response. A thorough literature review failed to identify any existing systems that simultaneously tracked stove top status and human activity in order to detect unsafe behaviours.

\subsection{Thermal Imaging}

The electromagnetic spectrum is composed of a number of arbitrary wavelength regions, called bands, distinguished by the methods used to produce and detect the radiation. There is no fundamental difference between radiations in the different bands of the electromagnetic spectrum (See Figure 2.1 below). 


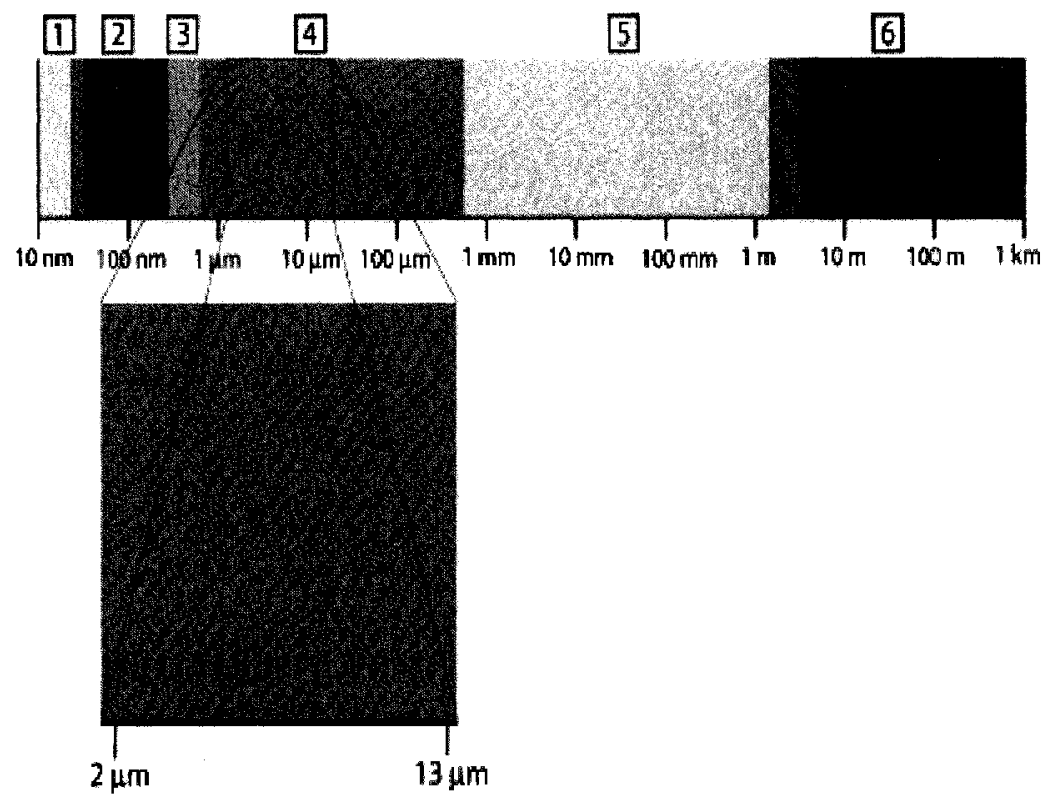

Figure 2.1. The electromagnetic spectrum: 1. X-ray; 2. UV; 3. Visible; 4. IR; 5. Microwaves; 6. Radiowaves (reproduced from reference [28])

Thermal cameras detect radiation in the infrared range of the electromagnetic spectrum and the produced images are called thermal images. The specific amount of radiation emitted by an object is a function of the object's temperature. Therefore, the higher an object's temperature, the more infrared radiation it emits. Thermal imaging makes it possible to see the environment even without visible illumination.

Thermal imaging can be applied to many fields. For example, firefighters use it to find people through the smoke or to locate the base of a fire [29], power line maintenance technicians use it to check possible failure by looking at the overheating joints and parts [29], customs agents at Japanese airports used it to prevent the potential spread of disease during the SARS outbreak period [30], and farmers can use it for early detection of infections of stored grains to reduce product loss [31]. In this thesis, thermal imaging is 
used to simultaneously track stove top status and also to detect human activity at the stove.

\subsection{Human Detection from Thermal Video}

Several methods have been used to detect humans from the normal visible light camera images including background subtraction techniques such as using a single Gaussian background model [32] or a multi-modal Gaussian formulation [33]. Other approaches include the W4 method for detecting and tracking body parts [34], the three-stage Wallflower approach [35], a two-stage color and gradient technique [36], and a Markov chain Monte Carlo approach [37]. A number of other methods use techniques which work directly on the raw input image or video without the background subtraction preprocessing step to identify people, including the direct use of wavelets [38], coarse-to-fine edge matching [39], and motion differencing [40, 41].

Human detection using thermal imagery from thermal video has also been investigated $[42,43]$. Most of these approaches depend heavily on the assumption that the person is always much hotter than the background $[44,45,46]$. Other methods use a contour analysis technique which operates on the temperature gradient [36, 47]. These papers present an algorithm to robustly detect objects at three distinct levels, i.e., pixel level, region level and frame level, and used the presence of high gradients on object boundaries to remove spurious objects. The pixel based models are updated based on the decision made from the region level. Frame level analysis is made to detect the illumination changes. This method can provide solutions to some common problems not addressed by most of other background subtraction algorithms, such as repositioning of static 
background objects, quick illumination changes, and initialization of a background model when moving objects are present in the scene [36].

Han and Bhanu [48] combine the use of an infrared camera and a standard camera for detecting humans. The infrared camera can compensate for the weakness of the standard camera in the case of human silhouette extraction when some part of the human body or clothing has similar color to those in the background, when shadows are present, and when the input images are taken under low lighting conditions. This method is not limited to the detection of human activity. In fact, it can detect any moving object with a thermal signature [49].

The techniques listed above consider the whole human body or upper body motion or appearance [50] as human activity. This differs from the present study as we define the human activity as any activity where the user reaches into the field of view, such as to stir a pot, remove a lid, turn a dial, etc (refer to Chapter 6.1 below). As mentioned above, in this thesis, we restrict ourselves to a thermal camera with a narrow fixed field of view which cannot capture the entire subject or upper body appearance. Furthermore, it is not expected that there will be a strong gradient between a user's arm and the heated stove top. Therefore, the previous human detection techniques cannot be directly applied in this thesis. 


\subsection{Measures of System Accuracy}

A confusion table [51] summarizes information about actual and predicted classifications done by a pattern classification system. Usually, a confusion table is used to evaluate the performance of such a system. Table 2.1 shows a sample confusion matrix for a two class classifier.

The entries in the confusion matrix are defined as follows:

- True positive is the number of correct predictions that an instance is positive,

- False positive is the number of incorrect predictions that an instance is positive,

- False negative is the number of incorrect of predictions that an instance negative,

- True negative is the number of correct predictions that an instance is positive.

Actual Class

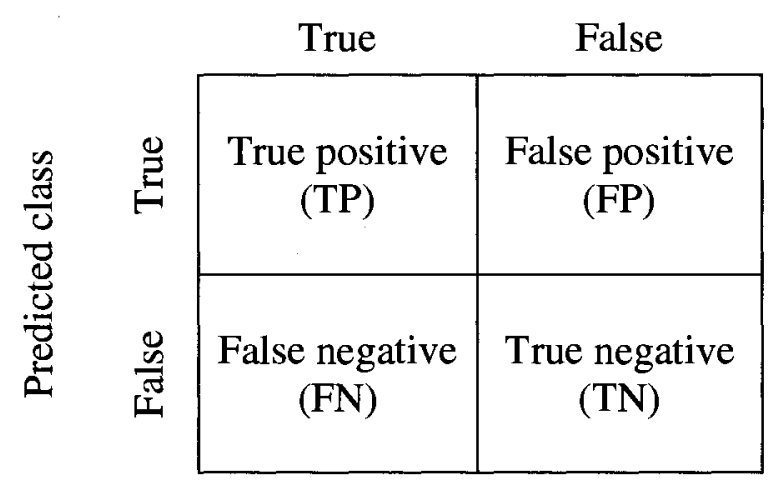

Table 2.1. Confusion table

Correct predictions are true positive and true negative. False positive predictions are defined as type I errors and false negatives are defined as type II errors [52]. We use the terms in Table 2.1 to define the following performance metrics:

$$
\text { Accuracy }=\frac{(T P+T N)}{(T P+T N+F N+F P)}
$$


Sensitivity $=\mathrm{Sn}=\frac{T P}{(T P+F N)}$

Specificity $=\mathrm{Sp}=\frac{T N}{(T N+F P)}$

False Positive Rate $=1-\mathrm{Sp}=\frac{F P}{(T N+F P)}$

False Negative Rate $=1-\mathrm{Sn}=\frac{F N}{(T P+F N)}$

Positive Predictive Value $=\frac{T P}{(T P+F P)}$

Negative Predictive Value $=\frac{F P}{(T P+F P)}$

It is not enough to evaluate the system performance by using a single metric. In order to best evaluate classifier accuracy, we should use multiple performance metrics simultaneously. In this research, many of the metrics defined above are used to assess the performance of each subsystem of the stove top monitoring system. Results are given in chapters $4,5,6$ and 7 . 


\section{Chapter 3}

\section{System Overview}

The system components include a FLIR A-40 infrared camera mounted on a tripod above a stove top, connected to a laptop computer via an IEEE 1394 FireWire connection. ThermaCAM Research Professional 2.8 SR-3 software (FLIR Systems) was used to convert the acquired thermal camera images into MATLAB images. All image processing was done offline using custom software written in MATLAB. The system architecture is shown in the Figure 3.1 below.

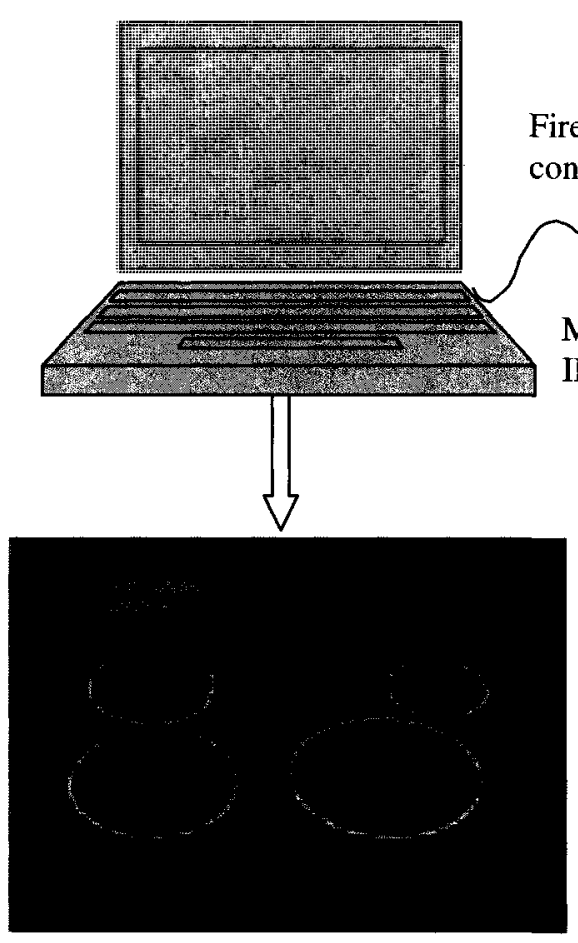

Raw IR image

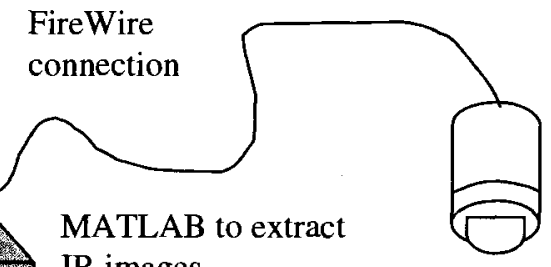

IR images
FLIR A40

thermal camera

Figure 3.1. System architecture 
This system is designed to be retrofit on an existing stove top. In this way, this system differs from other potential solutions which would monitor stove status (i.e. burner state and temperature) through direct measurement of current flow to the burners or via thermocouples on the stove surface. This is critical in order to keep the cost of the monitoring system at a minimum rather than requiring the user to purchase a new appliance with embedded sensors. This is an especially important consideration for elderly users who are often on fixed incomes. Of course, any commercial system would make use of commercial off-the-shelf components rather than a high-end infrared camera and such a setup will be evaluated in future work.

\subsection{Camera Used in This Study}

In this thesis, an un-cooled microbolometer detector type infrared thermal camera (Model: ThermaCAM ${ }^{\mathrm{TM}}$ A40 of FLIR systems, Burlington, ON, Canada) with a spectral range of $7.5-13 \mu \mathrm{m}$ and a resolution of $320 \times 240$ pixels was used to take thermal images of different types of stove tops to track their status and associated human activity. Like most thermal cameras, the A-40 is monochromatic with only a single type of sensor responding to limited wavelength range of infrared radiation $(7.5-13 \mu \mathrm{m})$. However, images are displayed in pseudo-color where change in color represents the change in temperature. In this research, the A-40 IR camera records electromagnetic radiation emitted by the stove top in a continuous sequence of images whose pixel values represent temperature in degrees Kelvin. 


\subsection{The System Target Audience}

While the initial target audience for this device are elderly persons with declining mental acuity, other populations may benefit from such a stove monitoring system. For example, persons who are developmentally delayed or who have cognitive disabilities may also benefit from such a system.

\subsection{Detecting Dangerous Situations}

A number of algorithms were developed in MATLAB to perform the following tasks: detecting whether the burner is active or inactive (refer to section 4.1), detecting burner temperature trend (refer to section 4.2), indicating burner occupancy (refer to chapter 5), detecting human activity (refer to chapter 6), and data fusion for alert generation (refer to chapter 7). The results from each of these algorithms is combined in order to create a stove top monitoring system with the block diagram shown in Figure 3.3 below. Note that both burner temperature trend and pot presence detection rely on human activity as an input. This is because when human activity is present, it often affects all subsystems and therefore reliable estimates of pot presence and burner temperature cannot be obtained during these periods. Therefore, frames containing human activity are ignored by these subsystems. 


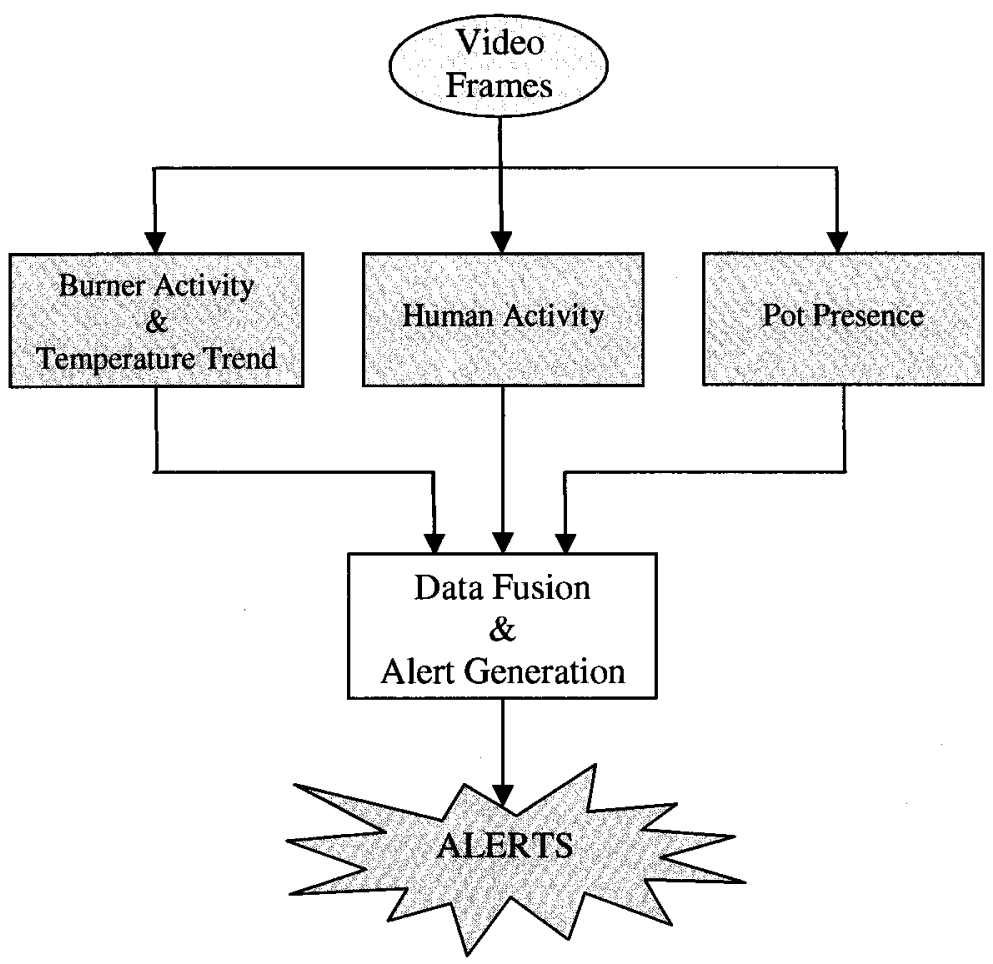

Figure 3.2. Software system block diagram

The goal of the system is to detect the following dangerous situations:

Alert 1: The user turns on the burner and forgets to put a pot on it.

Alert 2: The user turns on one burner (burner A) and puts the pot on the wrong one (burner B).

Alert 3: The user leaves the stove unattended for an extended period of time (user configurable time-out value) with one or more burners active.

Alert 4: A pot is removed from the burner but the user forgets to turn off the burner.

A rule-based system (described in chapter 7) is used to generate alerts based on the outputs for the modules shown in Figure 3.2 above. A high level illustration of the logic used to combine the various sub-systems to generate alerts is shown in Figure 3.3 below. The alert numbers in Figure 3.3 correspond to the dangerous behaviours listed above. The 
dashed arrow from the human activity subsystem to the pot presence subsystem indicates that pot presence is ignored during periods of human activity (discussed in section 7.4).

\subsection{System Calibration}

System calibration is the first step of the stove top monitoring system; each subsystem builds on its results. During calibration, the system automatically determines the number, perimeter, centroid, and size of each burner. The system does not assume that all burners are circular, which accommodates irregular burner shapes and skewed images due to offcenter camera placement. To calibrate the system, all burners are turned on at full heat for 60 seconds. The captured thermal image is converted to a binary mask by applying a temperature threshold of 80 degrees Celsius. The size of the binary image is $240 \times 320$ pixels, and at a distance where the entire stove top fits within the camera field of view, the diameter for a typical burner ranges from 45 to 90 pixels for the ceramic stove, 24 to 


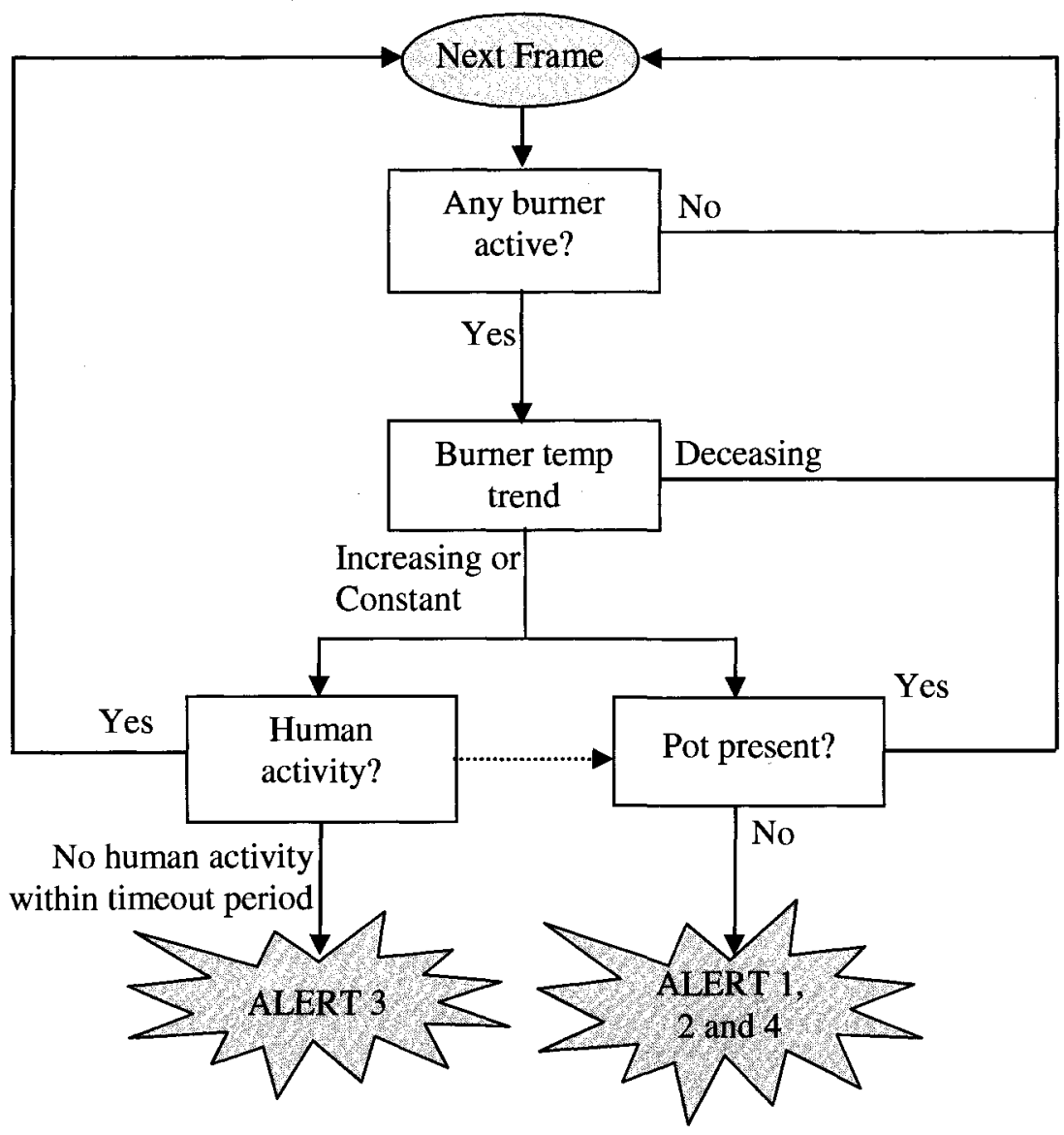

Figure 3.3. Flow chart showing alert generation logic of the stove top monitoring system

47 pixels for the gas stove, and 110 to 137 pixels for the electric coil stove. Contiguous regions of white pixels (i.e. those pixels passing the temperature threshold) are classified into 'blobs'. Resulting blobs are dilated to connect individual hot spots within a burner, and any remaining blobs of less than 7 pixels are removed, as these small isolated blobs are likely to represent thermal noise. The remaining blobs are considered to be burners. A margin of twice the nominal burner radius is added to each burner to account for possible spreading of heat or the presence of an oversized pot, and the perimeter, size and centroid are calculated for each burner. The image processing steps are also illustrated in the following Figure 3.4 


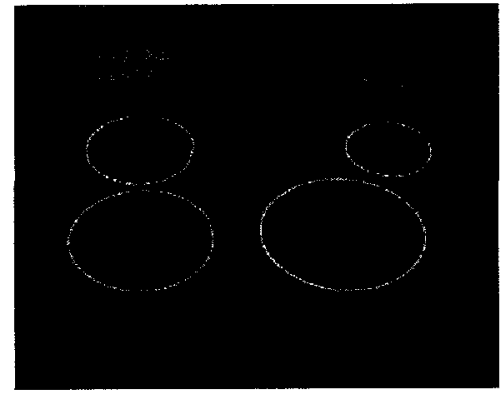

1. Raw image from the thermal camera

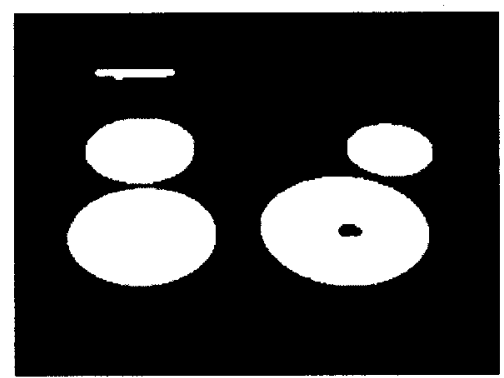

2. Apply temperature threshold $\left(80^{\circ} \mathrm{C}\right)$

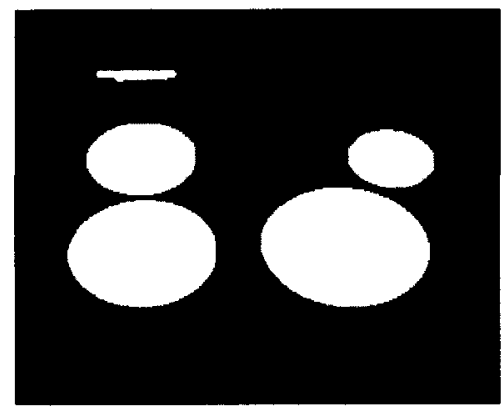

3. Dilate blobs (fill holes)

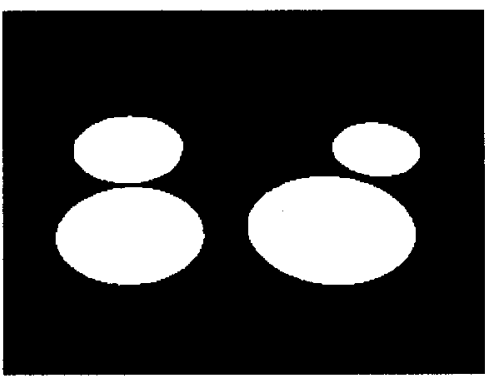

4. Erase small blobs (eliminate noise)

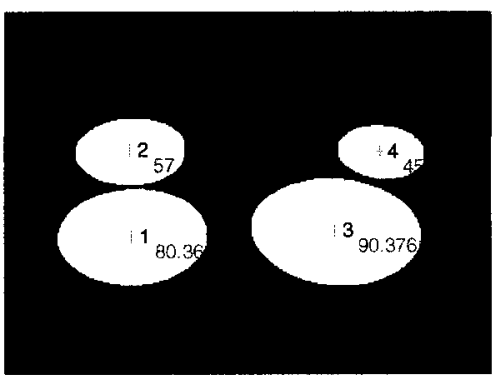

5. Identify burner centroids and diameters

6. Create mask identifying each burner

Figure 3.4. Image processing steps for calibration mode 


\subsubsection{System calibration results}

As detailed below, several experiments were conducted using three different stove tops: 2-burner electric coil, 4-burner electric ceramic, and 5-burner natural gas. Calibration was successful on all stove types, with the number of burners identified automatically in all cases. Calibration results are illustrated in Figure 3.5 below, with raw images on the left and detected burners on the right. The calibration results are generally good on all experiments. We are not expecting a perfect circle in the case of the electric coil stove top since the coil itself is not a perfect circle (shown in the middle of Figure 3.5). In fact, the natural gas stove is far worse (in the bottom of Figure 3.5) - the burners do not appear circular at all. However, for the purposes of identifying burner centroids and effective diameters, these results are sufficient.

\subsubsection{System calibration discussion}

While the calibration system performed robustly on all 4 stoves evaluated in this thesis, if burners are very close together, the calibration system may confuse them as a single burner. In order to avoid this situation, we could change the calibration plan to turn on one burner at a time, thereby identifying each burner one by one.

\subsection{Monitoring Mode}

Once system calibration is complete, the system enters monitoring mode. In this mode, the camera continuously captures and analyzes images and determines if dangerous situations have arisen. Various camera frame rates were investigated. A minimum frame rate of 1 frame per ten seconds was chosen such that typical human activity and the change of pot occupancy are likely to be captured by at least one frame. Most 
experiments used a frame rate of 1 frame per second (fps). In a final system that used online processing, the frame rate would be determined by the processing speed of the image processing system, but is expected to be $1 \mathrm{fps}$ or higher if all algorithms were implemented in hardware. This mode is used to monitor human activity, stove top status, and pot presence in each frame as per Figure 3.5 below. 

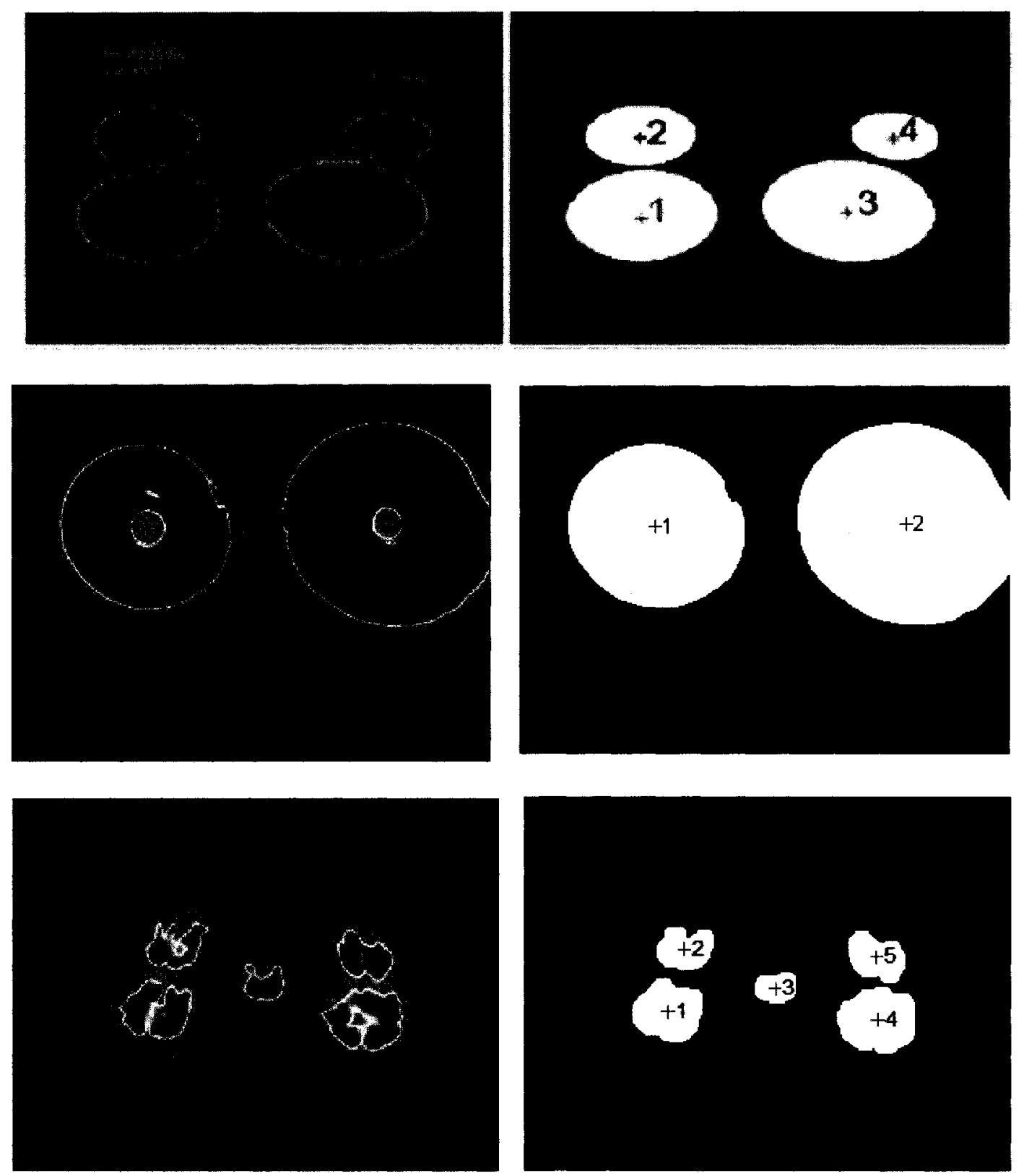

Figure 3.5. Calibration results for 4-burner electric ceramic (top), 2-burner electric coil (middle), and 5-burner natural gas (bottom) stove tops showing correct burner identification

\subsection{Experiments Performed}

In the research, there were 29 experiments done using three different stove top technologies: electrical coil, electric ceramic, and natural gas. All experiments were conducted using the following protocols: 
- Place the thermal camera on the tripod.

- Position the camera directly above the stove as much as possible.

- Attempt to position camera such that thermal images include an air gap on all sides of the stove top (details see in section 8.2.2). This is not always possible due to the fixed narrow field of view of the camera. Unfortunately, a wide angle lens was not available for the camera.

- Use auto-focus feature of FLIR software to ensure camera was in focus. Note that some experiments were out of focus which negatively impacted system performance. This is discussed in more detail in section 7.3.

The exact description of each experiment can be found in Appendix A. A synopsis of each experiment is provided below in Table 3.1. Table 3.2 lists which experiment were used to evaluate each subsystem (i.e. calibration, burner temperature detection, pot presence, and human activity). In the tables below, 'EC' refers to 'electric coil', 'ECT' refers to 'electric coil top-view', 'C' refers to 'electric ceramic', 'CT' refers to 'ceramic top-view' and 'G' refers to 'natural gas'. 


\begin{tabular}{|c|c|c|c|c|}
\hline ID & $\begin{array}{l}\text { Stove } \\
\text { Type }\end{array}$ & $\begin{array}{l}\text { Frame } \\
\text { Period }\end{array}$ & $\begin{array}{c}\text { Total } \\
\text { Frames }\end{array}$ & Brief Description \\
\hline EC1 & Coil & $2 \mathrm{~s}$ & 31 & $\begin{array}{l}\text { Calibration sequence (all burners on full } \\
\text { uncovered) }\end{array}$ \\
\hline $\mathrm{EC} 2$ & Coil & $10 \mathrm{~s}$ & 38 & Test cooling rate \\
\hline EC3 & Coil & $1 \mathrm{~s}$ & 31 & $\begin{array}{l}\text { Calibration sequence (all burners on full } \\
\text { uncovered) }\end{array}$ \\
\hline EC4 & Coil & $10 \mathrm{~s}$ & 83 & Test human activity \& pot removal \\
\hline EC5 & Coil & $5 s$ & 106 & $\begin{array}{l}\text { Test human activity, observe the temperature } \\
\text { change of the pot with water boiling dry }\end{array}$ \\
\hline EC6 & Coil & $5 \mathrm{~s}$ & 32 & Test pot replacement / removal \\
\hline EC7 & Coil & $5 s$ & 37 & Test human activity \\
\hline EC8 & Coil & $5 \mathrm{~s}$ & 16 & $\begin{array}{l}\text { Test the human activity \& pot } \\
\text { removal/replacement }\end{array}$ \\
\hline EC9 & Coil & $2 \mathrm{~s}$ & 94 & $\begin{array}{l}\text { Calibration sequence (all burners on full } \\
\text { uncovered) }\end{array}$ \\
\hline EC10 & Coil & $2 \mathrm{~s}$ & 245 & $\begin{array}{l}\text { Test the initial pot occupancy status \& pot } \\
\text { removal/ replacement, human activity }\end{array}$ \\
\hline EC11 & Coil & $2 \mathrm{~s}$ & 259 & Test the human activity \& initial pot occupancy \\
\hline EC12 & Coil & $2 \mathrm{~s}$ & 132 & $\begin{array}{l}\text { Observe the temperature change of the pot from } \\
\text { boiling to boiling dry }\end{array}$ \\
\hline ECT1 & Coil & $2 \mathrm{~s}$ & 41 & $\begin{array}{l}\text { Calibration sequence (all burners on full } \\
\text { uncovered) }\end{array}$ \\
\hline ECT2 & Coil & $2 \mathrm{~s}$ & 157 & Test the pot removal/ replacement \\
\hline ECT3 & Coil & $2 \mathrm{~s}$ & 124 & Test the human activity \\
\hline ECT4 & Coil & $2 \mathrm{~s}$ & 38 & $\begin{array}{l}\text { Calibration sequence (all burners on full } \\
\text { uncovered) }\end{array}$ \\
\hline ECT5 & Coil & $2 \mathrm{~s}$ & 410 & Test human activity \& pot rem/ replace. \\
\hline ECT6 & Coil & $2 \mathrm{~s}$ & 384 & Test human activity \& pot rem/ replace. \\
\hline $\mathrm{C} 0$ & Ceramic & $5 \mathrm{~s}$ & 21 & $\begin{array}{l}\text { Calibration sequence (all burners on full } \\
\text { uncovered) }\end{array}$ \\
\hline $\mathrm{C} 1$ & Ceramic & $1 \mathrm{~s}$ & 28 & All burners cooling from very hot \\
\hline $\mathrm{C} 2$ & Ceramic & $1 \mathrm{~s}$ & 454 & Test the human activity \\
\hline $\mathrm{C} 3$ & Ceramic & $1 \mathrm{~s}$ & 399 & Test the human activity \\
\hline $\mathrm{C} 4$ & Ceramic & $10 \mathrm{~s}$ & 143 & Plot the cooling curve \\
\hline CT1 & Ceramic & $1 \mathrm{~s}$ & 105 & $\begin{array}{l}\text { Calibration sequence (all burners on full } \\
\text { uncovered) }\end{array}$ \\
\hline CT2 & Ceramic & $1 \mathrm{~s}$ & 275 & Test the human activity \& put the pot correctly \\
\hline CT3 & Ceramic & $1 \mathrm{~s}$ & 326 & Test the pot presence algorithm \\
\hline G1 & Gas & 1s & 164 & $\begin{array}{l}\text { Calibration sequence (all burners on full } \\
\text { uncovered) }\end{array}$ \\
\hline G2 & Gas & $1 \mathrm{~s}$ & 639 & Test the human activity \& Test pot presence \\
\hline G3 & Gas & $1 \mathrm{~s}$ & 68 & $\begin{array}{l}\text { Test whether the system can detect pot placed on } \\
\text { the wrong burner }\end{array}$ \\
\hline
\end{tabular}

Table 3.1. Experiment descriptions 


\begin{tabular}{|c|c|c|c|c|c|}
\hline ID & Calibration & $\begin{array}{c}\text { Temperature } \\
\text { detection }\end{array}$ & $\begin{array}{c}\text { Pot } \\
\text { presence }\end{array}$ & $\begin{array}{l}\text { Human } \\
\text { activity }\end{array}$ & Data Fusion \\
\hline $\mathrm{EC1}$ & $\mathrm{N}$ & $\mathrm{Y}$ & $\mathrm{Y}$ & $\mathrm{N}$ & $\mathrm{Y}$ \\
\hline $\mathrm{EC} 2$ & $\mathrm{~N}$ & $\mathbf{N}$ & $\mathrm{N}$ & $\mathrm{N}$ & $\mathrm{Y}$ \\
\hline EC3 & $\mathrm{Y}$ & $\mathrm{Y}$ & $\mathrm{Y}$ & $\mathbf{N}$ & $\mathrm{Y}$ \\
\hline EC4 & $\mathrm{N}$ & $\mathrm{N}$ & $\bar{Y}$ & $\mathrm{Y}$ & $\mathrm{Y}$ \\
\hline EC5 & $\mathrm{N}$ & $\mathrm{N}$ & $\mathrm{N}$ & $\mathrm{N}$ & $\mathrm{Y}$ \\
\hline EC6 & $\mathrm{N}$ & $\mathrm{N}$ & $\mathrm{N}$ & $\mathrm{N}$ & $\mathrm{Y}$ \\
\hline EC7 & $\mathrm{N}$ & $\mathbf{N}$ & $\mathbf{N}$ & $\mathrm{Y}$ & $\mathrm{Y}$ \\
\hline EC8 & $\mathbf{N}$ & $\mathrm{N}$ & $\mathbf{N}$ & $\mathrm{N}$ & $\mathrm{Y}$ \\
\hline EC9 & $\mathrm{N}$ & $\mathrm{N}$ & $\mathrm{N}$ & $\mathrm{N}$ & $\mathrm{N}$ \\
\hline EC10 & $\mathrm{N}$ & $\mathrm{N}$ & $\mathrm{N}$ & $\mathrm{N}$ & $\mathbf{N}$ \\
\hline EC11 & $\mathrm{N}$ & $\mathrm{N}$ & $\bar{N}$ & $\mathrm{~N}$ & $\mathrm{~N}$ \\
\hline $\mathrm{EC} 12$ & $\mathrm{~N}$ & $\mathrm{~N}$ & $\mathrm{~N}$ & $\mathrm{~N}$ & $\mathrm{~N}$ \\
\hline ECT1 & $\mathrm{Y}$ & $\mathrm{Y}$ & $\mathrm{Y}$ & $\mathrm{N}$ & $\mathrm{Y}$ \\
\hline ECT2 & $\mathrm{N}$ & $\mathrm{Y}$ & $\mathrm{Y}$ & $\mathrm{Y}$ & $\mathrm{Y}$ \\
\hline ECT3 & $\mathrm{N}$ & $Y$ & $\mathrm{Y}$ & $Y$ & $\mathrm{Y}$ \\
\hline ECT4 & $\mathrm{Y}$ & $\mathbf{N}$ & $\mathrm{N}$ & $\mathrm{N}$ & $\mathrm{N}$ \\
\hline ECT5 & $\bar{N}$ & $\mathrm{~N}$ & $\mathrm{~N}$ & $\mathrm{~N}$ & $\mathrm{~N}$ \\
\hline ECT6 & $\mathrm{N}$ & $\mathrm{Y}$ & $\mathrm{N}$ & $\mathrm{N}$ & $\mathrm{N}$ \\
\hline $\mathrm{C} 0$ & $\mathrm{Y}$ & $\overline{\mathrm{N}}$ & $\bar{Y}$ & $\mathrm{~N}$ & $\mathrm{Y}$ \\
\hline $\mathrm{C} 1$ & $\mathrm{~N}$ & $\mathrm{~N}$ & $\mathrm{~N}$ & $\mathbf{N}$ & $\bar{Y}$ \\
\hline $\mathrm{C} 2$ & $\mathrm{~N}$ & $\mathrm{~N}$ & $\mathrm{Y}$ & $\mathrm{Y}$ & $\mathrm{Y}$ \\
\hline $\mathrm{C} 3$ & $\mathrm{~N}$ & $\mathrm{~N}$ & $\mathrm{Y}$ & $\mathrm{Y}$ & $\mathrm{Y}$ \\
\hline $\mathrm{C} 4$ & $\mathrm{~N}$ & $\mathbf{N}$ & $\bar{Y}$ & $\mathrm{~N}$ & $\mathrm{Y}$ \\
\hline CT1 & $\mathrm{Y}$ & $\bar{Y}$ & $\mathbf{N}$ & $\mathrm{N}$ & $\mathrm{Y}$ \\
\hline CT2 & $\mathrm{N}$ & $\mathrm{Y}$ & $\mathrm{N}$ & $\mathrm{Y}$ & $\mathrm{Y}$ \\
\hline CT3 & $\mathrm{N}$ & $\mathrm{Y}$ & $\mathrm{N}$ & $\mathrm{Y}$ & $\mathrm{Y}$ \\
\hline G1 & $\mathrm{Y}$ & $\mathrm{Y}$ & $\mathrm{Y}$ & $\mathrm{N}$ & $\mathrm{Y}$ \\
\hline $\mathrm{G} 2$ & $\mathrm{~N}$ & $\mathrm{Y}$ & $\mathrm{Y}$ & $\mathrm{Y}$ & $\mathrm{Y}$ \\
\hline G3 & $\mathbf{N}$ & $\mathrm{Y}$ & $\mathrm{Y}$ & $\mathrm{Y}$ & $\mathrm{Y}$ \\
\hline
\end{tabular}

Table 3.2. Summary table showing which experiment is used to evaluate which subsystem 


\section{Chapter 4}

\section{Stove Top Status}

During monitoring mode, the stove top status algorithms continuously check the following: detect if each burner is active or inactive; check if the temperature trend of the burner is increasing, decreasing, or remaining the same.

\subsection{Detecting Burner Activity}

We consider a burner to be inactive if it poses no danger of injuring the user and no risk of igniting a fire. Inactive burners are ignored at the data fusion level. In Figure 4.1, we can see that for conduction from heated metal at 60 degrees Celsius, pain occurs after $1 \mathrm{~s}$ and a burn after $10 \mathrm{~s}$.

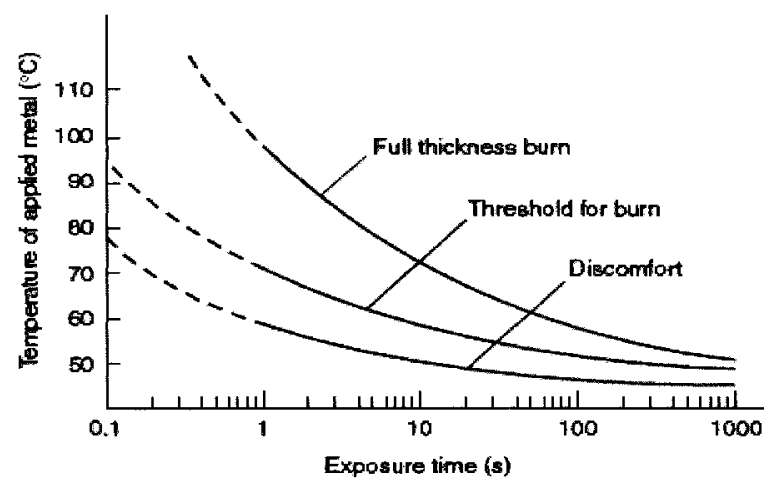

Figure 4.1. The relation between time and the temperature of metal to cause injury to skin (values below 1s are extrapolated, adapted from [53])

The auto-ignition temperature is the minimum temperature required for igniting a gas or vapour in air without a spark or flame. Common fuel auto-ignition temperatures can be 
found in Table 4.1 for various materials. Based on the data in Figure 4.1 and Table 4.1, 60 degrees Celsius was chosen to be the lowest limit at which a burner was considered to be "active". This temperature was chosen since it provides ample warning before tissue damage may occur (10s) and it falls well below the auto-ignition temperature for all materials expected to be present in the kitchen.

\begin{tabular}{|c|c|}
\hline Fuel or Chemical & Auto-ignition Temperature $\left({ }^{\circ} \mathbf{C}\right)$ \\
\hline Butane & 420 \\
\hline Carbon & 700 \\
\hline Carbon monoxide & 609 \\
\hline Coal-tar oil & 580 \\
\hline Charcoal & 349 \\
\hline Hydrogen & 500 \\
\hline Gasoline & 280 \\
\hline Oak Wood (dry) & 482 \\
\hline Propane & 480 \\
\hline Wood & 300 \\
\hline Pine Wood & 427 \\
\hline
\end{tabular}

Table 4.1. Auto-ignition temperature for various fuels and chemicals [54]

Note that we distinguish here between the tasks of detecting the ON/OFF status of a burner (i.e. is power or fuel being applied to the burner), versus the task of detecting the active/inactive status of a burner. We are not trying to detect burner ON/OFF status since this is not possible without directly instrumenting the stove top. For example, in experiment $\mathrm{C} 2$, burners 1 and 4 were initially occupied with pots full of cold water. Although the burners are ON (at maximum power), it takes greater than 7 minutes before the temperature of the pots reach a detectable level (i.e. significantly above ambient temperature). We cannot detect burner 1 and 4 as $\mathrm{ON}$ at the beginning of the experiment due to the cold water, but we can detect the time at which the burners reach the dangerous active temperature threshold temperature of 60 degrees Celsius. 


\subsection{Burner Temperature Trend Detection}

\subsubsection{Introduction}

In order to further investigate the status of burners, we need to know if the temperature of each burner is increasing, decreasing, or unchanged. This information is required for alert generation as illustrated in Figure 3.3 and discussed in chapter 8.

\subsubsection{Methods}

If we compare the temperature of a burner with the previous image one by one, this leads to poor estimate of temperature trend. This is because a time window size of one frame is too sensitive to thermal noise such as human activity, heat spread, and transient heat reflection. For example, in Figure 4.2 below, the effect of flame flickering is evident in the noisy average temperature of an uncovered burner. Due to all of these issues, a simple difference between adjacent frames will result in an overly noisy estimate of the burner trend (increasing/decreasing/constant).

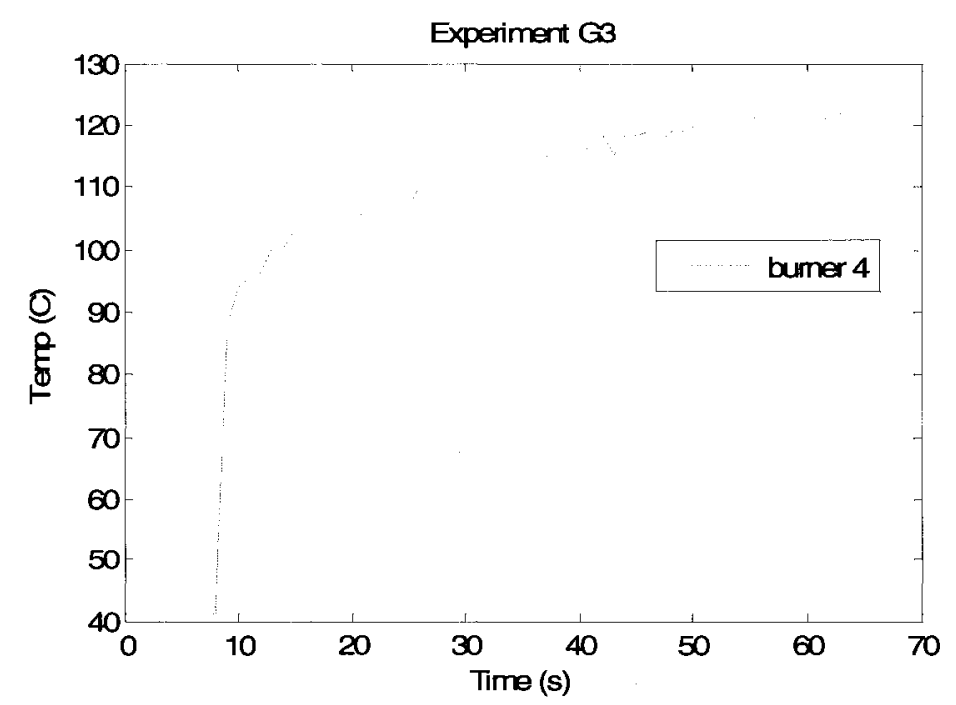

Figure 4.2. Burner 4 average temperature for natural gas stove showing effect of flame 


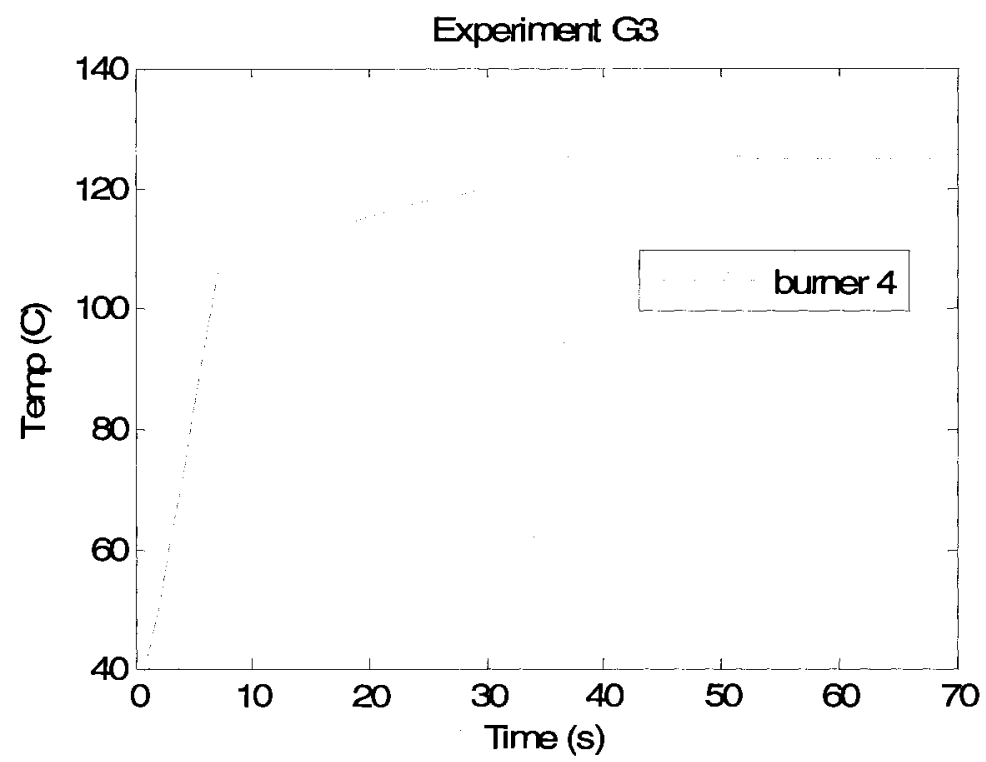

Figure 4.3. Smoothed profile from Figure 4.2 after computing trimmed mean at each point

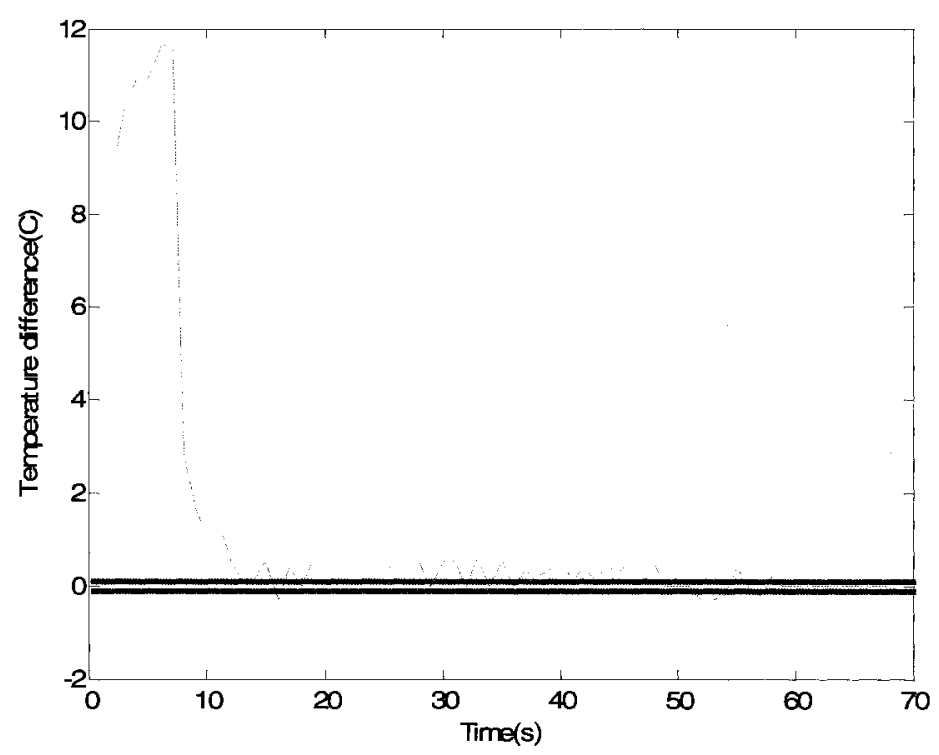

Figure 4.4. Difference between trimmed means at $t=\tau$ and $t=-1$ for experiment $G 3$ with threshold of $\pm 0.1^{\circ} \mathrm{C} / \mathrm{s}$ shown in green

A simple change of method results in significantly improved temperature trend estimates. A sliding window with a width of 10 seconds was required to smooth out local discontinuities caused by oscillations, noise, and human activity as illustrated above. In this research, the trimmed mean is defined as the mean of all points in a $10 \mathrm{~s}$ window after 
discarding the highest and lowest $20 \%$ of the data when sorted by temperature. For a frame rate of $1 \mathrm{fps}$, this results in 6 data points being used. For a frame rate of $0.5 \mathrm{fps}$, this results in 3 data points being used. Figure 4.3 above illustrates the smoothing effect when the trimmed mean is calculated for all time points for the data presented in Figure 4.2. To compute the temperature trend at time $t=\tau$, the trimmed mean, $m_{\tau}$, of a 10 s window covering $t=[\tau-9, \tau]$, is compared with the trimmed mean $m_{\tau-1}$. The two trimmed means at the two time points will normally only differ by 1 frame, leading to very small observed temp changes. The A40 thermal camera detects temperature variations as small as $0.08^{\circ} \mathrm{C}$ [28]. Therefore, we use the threshold value $0.1^{\circ} \mathrm{C} / \mathrm{s}$. If the difference is greater than $0.1^{\circ} \mathrm{C} / \mathrm{s}$, then the trend is increasing. If the difference is less than -0.1 , then the trend is decreasing. Otherwise, it is said to be constant.. The mathematical equations below show how the temperature trend algorithm works.

$m_{\tau-1},=$ trimmed mean of a 10 s window covering $\mathrm{t}=[\tau-10, \tau-1]$

$m_{\tau,},=$ trimmed mean of a 10 s window covering $\mathrm{t}=[\tau-9, \tau]$

$$
\text { TempTrend }_{\tau}=\left[\begin{array}{ll}
\text { increase, } & \text { if } m_{\tau}>m_{\tau-1}+0.1 \times s p f \\
\text { decrease, } & \text { if } m_{\tau}<m_{\tau-1}-0.1 \times s p f \\
\text { cons } \tan t, & \text { else }
\end{array}\right]
$$

\subsubsection{Results}

In order to evaluate the performance of the burner temperature detection system, 11 sample experiments were chosen from the original 29 including all types of stove tops. The experiment descriptions are listed below in Table 4.2. Here and elsewhere B1, B2, B3, B4 and B5 indicate burner one, two, three, four and five. 


\begin{tabular}{|c|c|l|}
\hline ID & $\begin{array}{c}\text { Stove } \\
\text { Type }\end{array}$ & \multicolumn{1}{|c|}{ Brief Description } \\
\hline EC1 & Coil & Calibration sequence (all burners on) \\
\hline EC3 & Coil & Calibration sequence (all burners on) \\
\hline ECT1 & Coil & Calibration sequence (all burners on) \\
\hline ECT2 & Coil & B1 initially on, turned off from frame 136 to end; B2 off \\
\hline ECT3 & Coil & $\begin{array}{l}\text { B1 was hot at the beginning, starts to cool off gradually; B2 was } \\
\text { initially on and a cold pot was placed on it and removed twice }\end{array}$ \\
\hline G1 & Gas & Calibration sequence (all burners on) \\
\hline G2 & Gas & $\begin{array}{l}\text { B1, B2, B3 and B5 were off; B4 was on with pot, turned off after } \\
\text { frame 478 }\end{array}$ \\
\hline G3 & Gas & B1, B2, B3 and B5 were off; B4 was on \\
\hline CT1 & Ceramic & Calibration sequence (all burners on ) \\
\hline CT2 & Ceramic & B1, B2 and B4 were off, B3 was on until the 218 ${ }^{\text {th }}$ frame \\
\hline CT3 & Ceramic & $\begin{array}{l}\text { B2 and B4 were off; B1 was on from frame 10 to 221; B3 was } \\
\text { initially hot, starts to cool off gradually }\end{array}$ \\
\hline
\end{tabular}

Table 4.2. Experiment description for temperature trend detection system

In order to evaluate the results, we manually annotated the heating curves of each experiment every 30 seconds as being increasing, decreasing, or constant according to the overall trend at that point. We then compared the manually determined trend to the predicted trend at each of these points. The temperature trend is manually determined by examining the graph of the average burner temperature profile for all burners and deciding whether the temperature is increasing, decreasing, or constant at each point, given the local trend around that point. We regard each point as one event. Hence, there are 25 events for the electric coil stove, 89 events for the ceramic stove and 140 events for the gas stove. The results for each stove type are shown in the following three confusion tables, symbols ' $\mathrm{C}$ ' means the temperature remains constant, ' + ' means the temperature increases and '-' represents the decreasing temperature trend. 


\begin{tabular}{|c|c|c|c|}
\hline \multirow{5}{*}{ 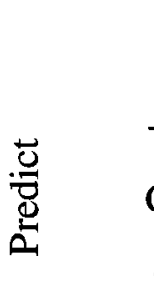 } & \multicolumn{3}{|c|}{ Actual } \\
\hline & + & $\mathrm{C}$ & - \\
\hline & 14 & 1 & 0 \\
\hline & 0 & 8 & 0 \\
\hline & 0 & 0 & 2 \\
\hline
\end{tabular}

Table 4.3. Burner temperature trend confusion table for electric coil

\begin{tabular}{|c|c|c|c|}
\hline & \multicolumn{3}{|c|}{ Actual } \\
\hline & + & $\mathrm{C}$ & - \\
\hline+ & 30 & 0 & 0 \\
\hline $\bar{\Xi}$ & 0 & 51 & 0 \\
\hline - & 2 & 0 & 6 \\
\hline
\end{tabular}

Table 4.4. Burner temperature trend confusion table for ceramic

\begin{tabular}{|c|c|c|c|c|}
\hline & & \multicolumn{3}{|c|}{ Actual } \\
\hline \multirow{4}{*}{ 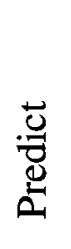 } & & + & $\mathrm{C}$ & - \\
\hline & + & 30 & 0 & 0 \\
\hline & C & 0 & 75 & 0 \\
\hline & - & 8 & 0 & 27 \\
\hline
\end{tabular}

Table 4.5. Burner temperature trend confusion table for natural gas

The burner temperature trend accuracy for all three burner types is summarized below in Table 4.6.

\begin{tabular}{|c|c|}
\cline { 2 - 2 } \multicolumn{1}{c|}{} & Accuracy \\
\hline Coil & 0.96 \\
\hline Ceramic & 0.97 \\
\hline Gas & 0.94 \\
\hline
\end{tabular}

Table 4.6. Detecting burner temperature system performance 
The accuracy is excellent on all experiments, with mean value equal to $95.6 \%$. The relatively low accuracy of $94 \%$ for the gas stove top experiments was caused by the gas stove having large flames resulting in more heat reflection from the metal stove top.

\subsubsection{Discussion}

The burner temperature trend system performs very well on all three burner types. Human activity can negatively impact the performance of the burner status detection system since a human arm may occlude a burner leading to a sudden change in the estimated burner temperature. However, since our ultimate goal is to combine all the sub-systems and analyze these generated events together, it is expected that subsequent data fusion will reduce the impact of human activity on this system. 


\section{Chapter 5}

\section{Pot Presence/Absence Detection System}

In this research, we break the pot presence/absence detection system into two phases. The first phase, discussed in Chapter 5.1, determines if the burner is initially covered by a pot when first turned on. The second stage, discussed in Chapter 5.2, detects if the there is a pot replacement or removal event afterwards. The combination of these two stages effectively monitors the pot presence/absence status during the entire experiment period. Descriptions for all the experiments used for evaluation in chapter 5.1 and 5.2 are given below in Table 5.1.

\subsection{Initial Pot Presence/Absence Detection System}

\subsubsection{Introduction}

Several algorithms were investigated for the detection of initial pot presence and absence. While ultimately, template matching against the calibration image was used, the following two sections describe methods that were not successful.

\subsubsection{Heating curve algorithm}

This algorithm was developed based on the fact that the heating rate of an uncovered burner is expected to be much greater than for a covered burner. Unfortunately, pot presence is confounded by the burner power setting (i.e. low, medium, high) which is unknown. This algorithm is only applicable if burners are used in a binary configuration 
(OFF vs. FULL_POWER) which is not a realistic assumption. Therefore this algorithm was abandoned.

\begin{tabular}{|c|c|c|c|c|}
\hline ID & $\begin{array}{l}\text { Stove } \\
\text { Type }\end{array}$ & $\begin{array}{l}\text { Frame } \\
\text { Period }\end{array}$ & $\begin{array}{c}\text { Total } \\
\text { Frames }\end{array}$ & Brief Description \\
\hline EC1 & Coil & $2 \mathrm{~s}$ & 31 & Burner 1 is on and uncovered entire time. \\
\hline $\mathrm{EC} 3$ & Coil & $1 s$ & 31 & $\begin{array}{l}\text { Calibration sequence (i.e. all burners on full } \\
\text { uncovered) }\end{array}$ \\
\hline $\mathrm{EC} 4$ & Coil & $10 \mathrm{~s}$ & 83 & $\begin{array}{l}\text { Burner } 1 \text { is covered within frames } 1-15 \text {, } \\
\text { uncovered within } 16-25 \text { and } 61-65 \text {; covered } \\
\text { within } 26-60 \text { and } 66-83 \text {; } \\
\text { Burner } 2 \text { is off the entire experiment }\end{array}$ \\
\hline EC5 & Coil & $5 s$ & 106 & Burner 1 is on and covered from beginning. \\
\hline EC6 & Coil & $5 s$ & 32 & Burner 1 is on and covered from beginning. \\
\hline EC7 & Coil & $5 s$ & 37 & Burner 1 is on and covered from beginning. \\
\hline $\mathrm{EC} 8$ & Coil & $5 s$ & 16 & Burner 1 is on and covered from beginning. \\
\hline ECT1 & Coil & $2 s$ & 41 & Calibration sequence \\
\hline ECT2 & Coil & $2 \mathrm{~s}$ & 157 & $\begin{array}{l}\text { Burner } 1 \text { is on uncovered within frames } 8-49 \text { and } \\
130-157 \text {, covered within frames } 50-129 \text {; Burner } \\
2 \text { is off the entire experiment. }\end{array}$ \\
\hline ECT3 & Coil & $2 \mathrm{~s}$ & 124 & $\begin{array}{l}\text { Burner } 1 \text { is turned off and cools from max } \\
\text { temperature; Burner } 2 \text { is on and uncovered } \\
\text { within frames 5-28 and } 109-115 \text {, covered within } \\
\text { frames } 29-108 \text { and } 116-124 \text {. }\end{array}$ \\
\hline G1 & Gas & $1 \mathrm{~s}$ & 164 & Calibration sequence \\
\hline $\mathrm{G} 2$ & Gas & $1 \mathrm{~s}$ & 639 & $\begin{array}{l}\text { Burner } 4 \text { is on and covered within frames } 14- \\
477 \text {, uncovered within frames } 478-639 \text {, the rest } \\
\text { of burners are off the entire experiment }\end{array}$ \\
\hline G3 & Gas & $1 \mathrm{~s}$ & 68 & $\begin{array}{l}\text { Burner } 4 \text { is turned on uncovered within frames } \\
9-68, \text { the rest of burners are off . }\end{array}$ \\
\hline $\mathrm{CO}$ & Ceramic & $5 s$ & 21 & $\begin{array}{l}\text { Calibration sequence (all burners on full } \\
\text { uncovered) }\end{array}$ \\
\hline $\mathrm{C} 2$ & Ceramic & 1s & 454 & $\begin{array}{l}\text { Burner } 1 \text { is on covered within frames } 1-74 \text {. } \\
\text { Uncovered within frames } 389-396 \text {, covered } \\
\text { within } 397-454 \text {. Burner } 4 \text { is on covered within } \\
\text { frames } 1-454 \text {, rest are off. }\end{array}$ \\
\hline C3 & Ceramic & 1s & 399 & $\begin{array}{l}\text { Burner } 1 \text { is on covered the entire experiment, } \\
\text { open lid within frames } 133-136,179-183 \text {. } \\
\text { Burner } 4 \text { is on covered within frames } 1-98 \text { and } \\
105-391 \text {, uncovered within } 99-104 \text { and } 392-399 \text {. } \\
\text { The rest of burners are off the entire experiment. }\end{array}$ \\
\hline $\mathrm{C} 4$ & Ceramic & $10 \mathrm{~s}$ & 143 & $\begin{array}{l}\text { Burner } 1 \text { and } 4 \text { are initially hot and uncovered. } \\
\text { They cool throughout the experiment; Burners } 2 \\
\text { and } 3 \text { are inactive throughout. }\end{array}$ \\
\hline
\end{tabular}

Table 5.1. Descriptions of experiments used in Chapter 5 


\subsubsection{Percentage of max temperature pixels algorithm}

Following system calibration (see section 3.4), the location of each burner is known. In order to determine whether a given burner is covered by a pot, the percentage of pixels in the burner region that is greater than $80 \%$ of the max temperature is calculated. If the 'hot' pixel count is greater than half of the total pixels, we regard the burner is uncovered, otherwise, the burner is covered. This algorithm relies on the camera being positioned in front of the stove. In this way, when a burner is covered, some portion of the burner is directly visible to the camera while most of the burner is covered by the pot. See an example image in Figure part a). The resulting histogram of pixel temperatures shown in Figure part b) is highly bi-modal reflecting the difference in pixel temperatures of the burner and pot pixels. Whereas an uncovered burner (Figure 5.2) results in a unimodal histogram with most pixels at the maximum temperature.

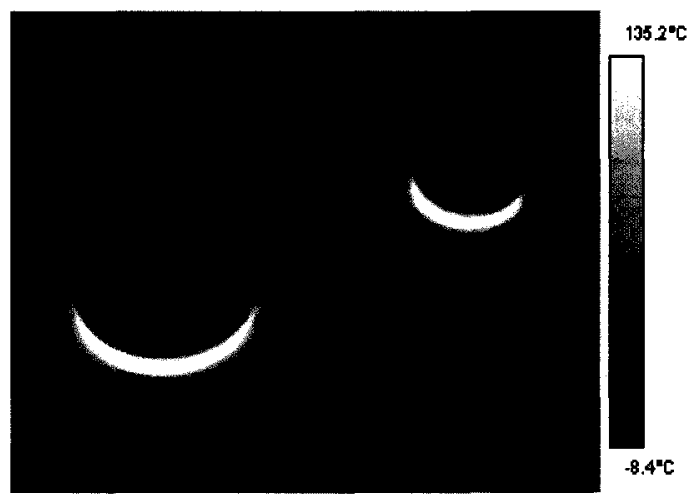

a)

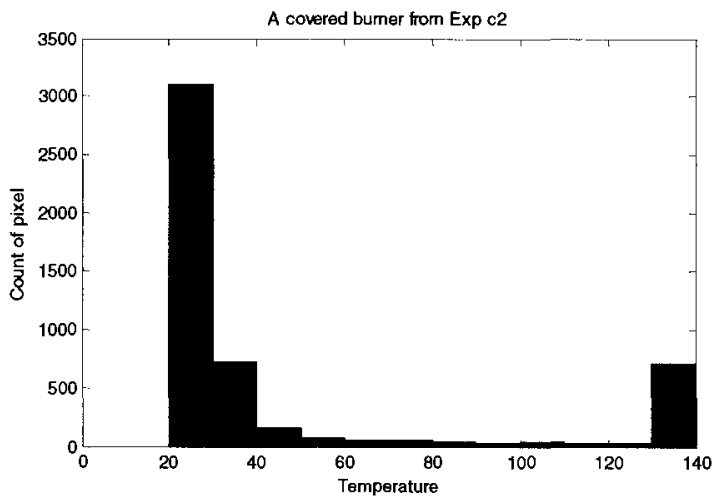

b)

Figure 5.1. a) Front view of the burner (the visible part of the burner is bright while most of the burner is covered by the pot). b) Histogram for burner 4 (top-right) showing clear bimodal distribution. 


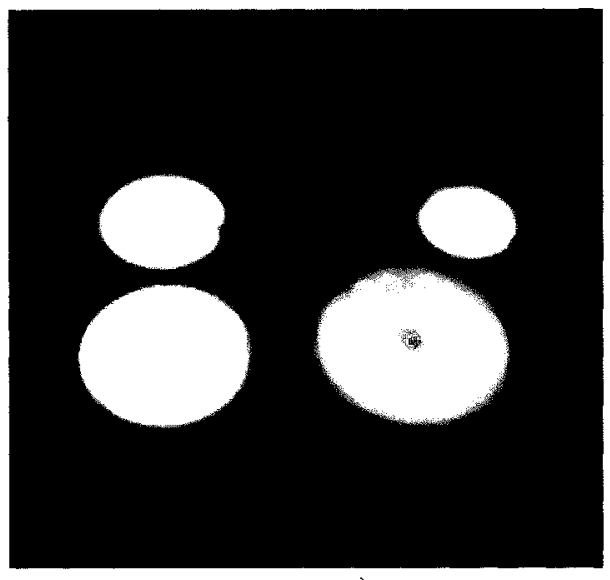

a)

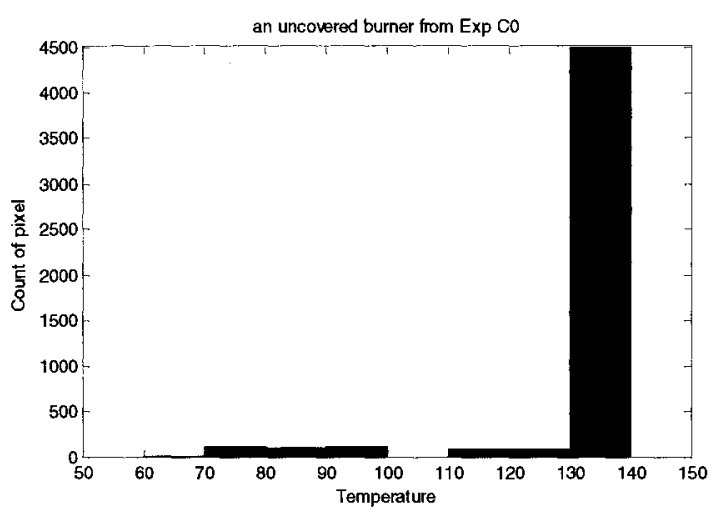

b)

Figure 5.2. a) Thermal image of uncovered burners. b) Corresponding histogram for burner 4 (top-right) showing a unimodal distribution with most pixels at maximum temperature

To evaluate the performance of this algorithm, 4 experiments when the camera was put in front of the stove were conducted on different types of stoves including electrical coil and electric ceramic. The algorithm was applied to each experiment and frames were noted where pot absence was detected. The sensitivity and specificity calculated on per-frame basis were both $100 \%$ except the specificity for Exp C3 which was equal to $98.18 \%$. These errors were caused by the camera being completely blocked by the test subject's head (see Figure 5.3).

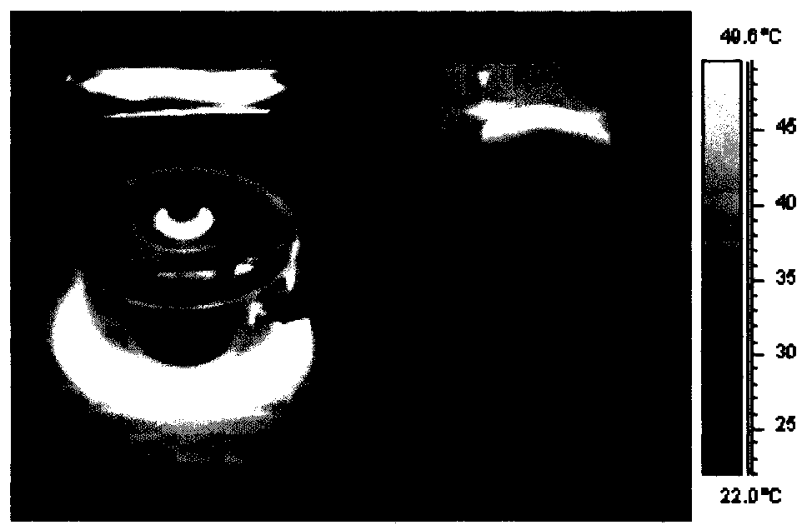

Figure 5.3. A frame from Exp C3 where burner 4 is blocked by test subject's head. 
Ultimately, this algorithm was not used in the final system for two reasons. First, when the camera is positioned directly overhead of the stove (important for privacy concerns), then no burner pixels are visible. Secondly, if an oversize pot is placed on a burner, no burner pixels are visible and the system reported this situation as a false positive event. Ultimately, an algorithm based on template matching against the calibration image was used as described below.

\subsubsection{Pot detection via template matching}

During system calibration, thermal images are captured when all burners are uncovered. During monitoring mode, when a burner is detected as being 'active' (i.e. its temperature rises above $60^{\circ} \mathrm{C}$ ) we use the calibration image as a template and compare it one by one with the first 20 seconds to measure the similarity between them. An uncovered burner should be nearly identical to the template, while a covered burner will be dissimilar to the template image. To quantify this, the mean pixel difference between a frame and the template image is computed. This difference is called the diff_score. If the diff_score drops below a preset threshold on any frame within the first 20 seconds following a burner becoming active, then the burner is considered to be initially uncovered. The choice of threshold was optimized both manually and automatically via linear discriminant analysis, as described below.

\subsubsection{Results}

In order to evaluate the performance of this algorithm, 10 experiments with frame rates of 0.5 or 1 fps were used, including five for an electrical coil stove, three for a gas and three for a ceramic stove top. The frames within first 20 seconds were analysed from each 
experiment. A true event is defined as a burner that is active but uncovered (i.e. not covered by a pot). Conversely, a false event is defined as a burner that is active and is covered with a pot. The table below lists the number of actual positive and negative events for each stove type for all experiments used to evaluate the pot presence detection subsystem.

\begin{tabular}{r|c|c|}
\multicolumn{1}{c}{} & \multicolumn{2}{c}{ Actual } \\
\cline { 2 - 3 } Coil & True & False \\
\cline { 2 - 3 } Ceramic & 8 & 5 \\
\cline { 2 - 3 } Gas & 4 & 4 \\
\cline { 2 - 3 } & 6 & 1 \\
\cline { 2 - 3 } & &
\end{tabular}

Figure 5.2. Number of actual positive and negative events

\subsubsection{Optimal diff_score threshold}

The optimal threshold value of $37^{\circ} \mathrm{C}$ was manually picked by looking at all the diff_score values for all 13 experiments. Using this optimal threshold, prediction accuracy reaches 100\%. Figure 5.4 shows two uncovered burners (both active) and Figure Figure 5.5 shows two covered active burners, and two inactive burners. The green line in both graphs is the optimal threshold value (straight line: $y=37$ ) separating the pot presence and absence situations.

From the diagrams below, we can see that all diff_score values for covered burners fall above the threshold of 37 while the uncovered ones fall below the threshold within the first 20 seconds. 


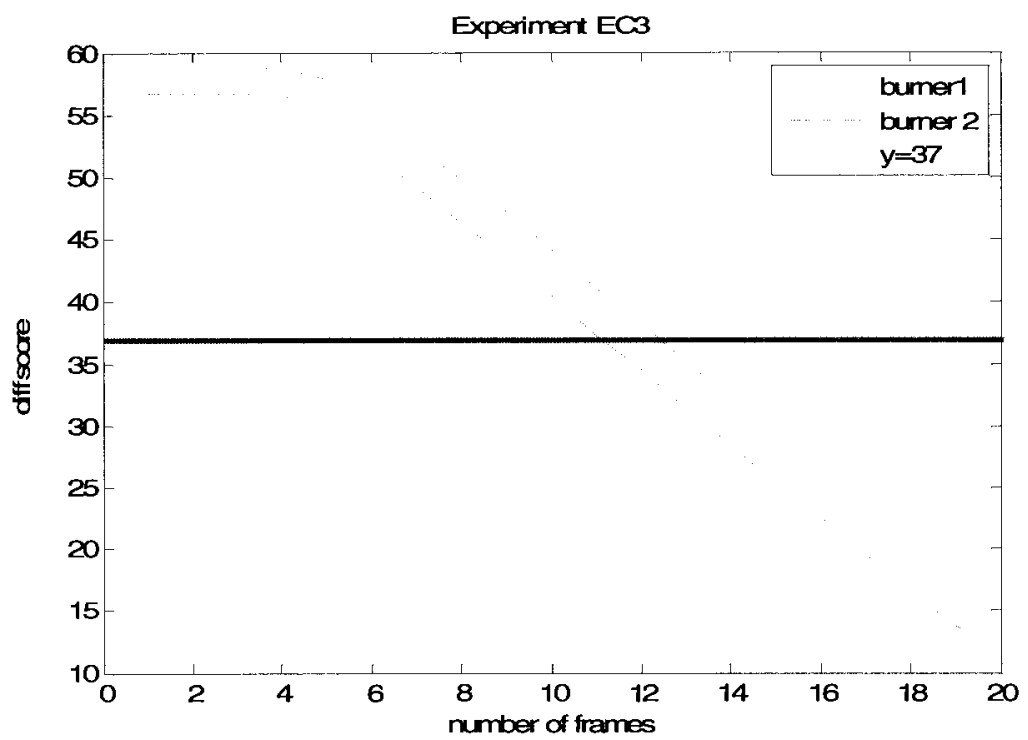

Figure 5.4. Diff_score values for two uncovered burners (electrical coil)

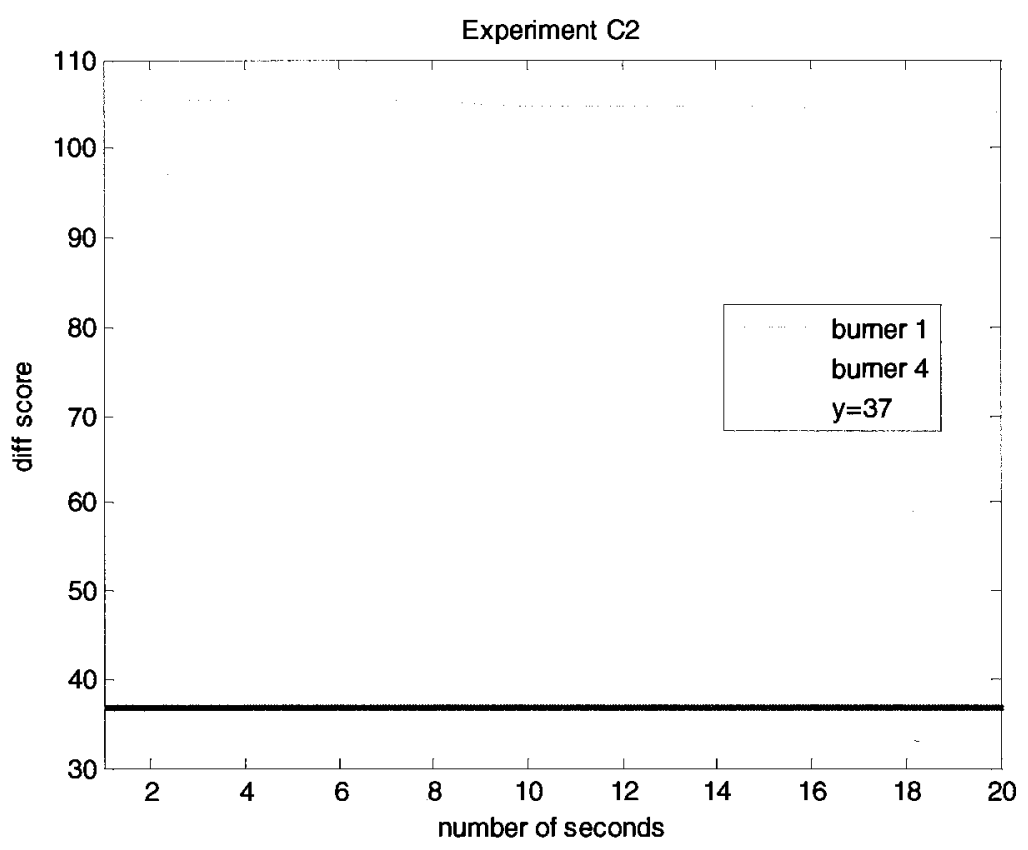

Figure 5.5. Diff_score values for two covered burners and two burners that were off (burner 1 and 4 were on and occupied with pots, burner 2 and 3 were off) 


\subsubsection{Linear discriminant analysis}

There is a danger when manually selecting the optimal threshold value by examining all available training data that the specific threshold value will be overfit to the particular training data and will not generalize well to new data. Therefore, linear discriminant analysis (LDA) was used to automatically select a threshold on a subset of available training data and its accuracy was measured on the remaining data as follows. The 13 experiments provide 28 events including true and false events in total: 13 events for an electrical coil, 7 for a gas and 8 for a ceramic stove top. As input to LDA, we tried both the diff_score at the $20^{\text {th }}$ second and the minimum diff_score observed over the first 20 seconds. The classifier is trained and evaluated by a method called leave-one-out testing. In this test protocol, we find the threshold value of the diff_score using all samples excluding one sample. The threshold is then evaluated using the single withheld test sample. This process is repeated until all 28 samples have been withheld. Therefore, we obtain 28 different threshold values and we report the mean threshold value. The results are summarized below (Table 5.3).

\begin{tabular}{|c|c|c|c|c|}
\hline Training data & $\begin{array}{c}\text { Boundary } \\
\text { value }\end{array}$ & Accuracy & Sensitivity & Specificity \\
\hline $\begin{array}{c}\text { diff_score @ } \\
\text { 20 second }\end{array}$ & 43.1 & 0.96 & 1 & 0.90 \\
\hline $\begin{array}{c}\text { Min diff_score } \\
\text { over first 20s }\end{array}$ & 42.3 & 0.96 & 1 & 0.90 \\
\hline
\end{tabular}

Table 5.3. Template matching algorithm performance

Based on the values picked from the frame at the $20^{\text {th }}$ second, the resulting boundary value is 43.1 which differ substantially from the optimal diff_score value 37 . This leads to an accuracy of $96 \%$. The threshold and diff_score for all 28 events are shown below in Figure 5.6. 


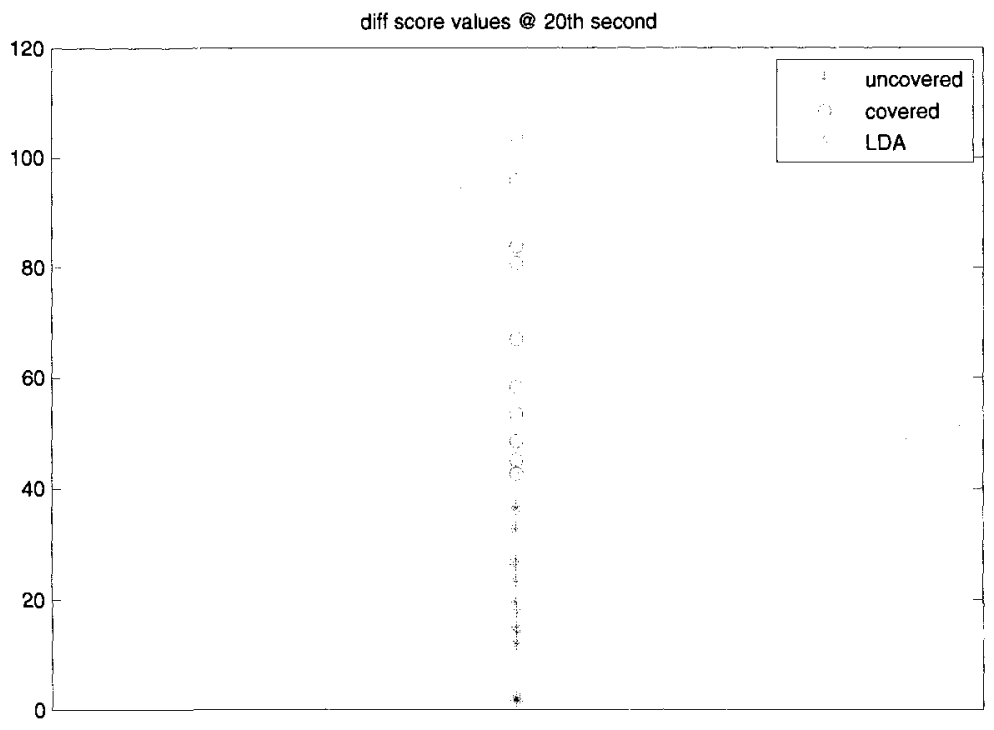

Figure 5.6. Classification of initial pot presence/absence using diff_score measured at the $20^{\text {th }}$ second after burner becoming active

Instead of using the diff_score at the 20 s mark, a boundary value of 42.3 is obtained when the minimum diff_score observed over the first 20 seconds is used. This boundary results in identical performance to using the diff_score at the 20 s mark. The minimum diff_score and LDA-selected threshold is shown in

Figure 5.7 below. 


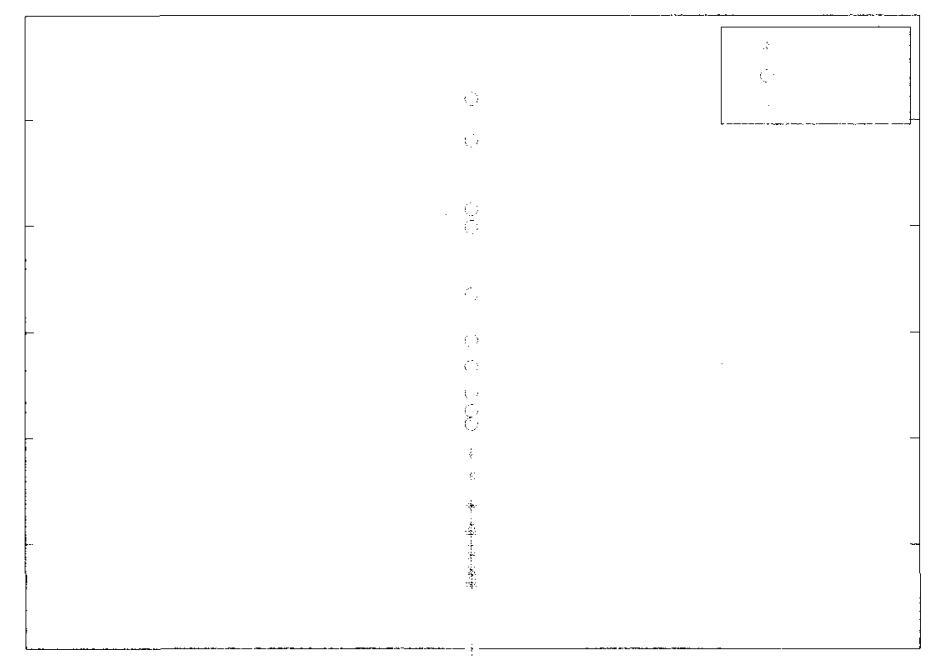

Figure 5.7. Classification of initial pot presence/absence using minimum diff_score observed over first 20 s

\subsubsection{Discussion}

Thirteen experiments were performed to evaluate the performance of the pot detection via template matching algorithm. It is easy to look at all diff_score values and pick the optimal threshold value. To arrive at a more robust estimate of expected error rate on new data, a leave-one-out test was performed on the 28 different training samples where the class (covered/uncovered) is known. When the minimum diff_score over the first 20 seconds of burner activity is used, excellent classification of covered vs. uncovered is achieved. It should be noted that all burners were used at maximum temperature when on. An additional experiment was conducted to verify that the initial pot presence algorithm continues to function when burners are run at low power settings. This experiment was a success resulting in a minimum diff_score of 33 which is below the threshold after 20 seconds. As future work, pot presence could be detected by monitoring the apparent size of a burner. For example, when an oversized pot is placed on a burner, we expect the region of constant heat to become larger than the template image. 


\subsection{Pot Removal and Replacement Detection Algorithm}

\subsubsection{Introduction}

Once initial pot presence or absence is determined through the algorithm described above, ongoing monitoring of pot presence is achieved by looking for rapid changes in observed burner temperature.

\subsubsection{Methods}

When a pot is removed from a burner, a sudden increase in burner temperature is observed. The same is true when a pot, which is almost certainly hotter than a burner, is replaced on a burner. Therefore, a simple thresholding of the frame-by-frame difference is used to detect pot removal and replacement events.

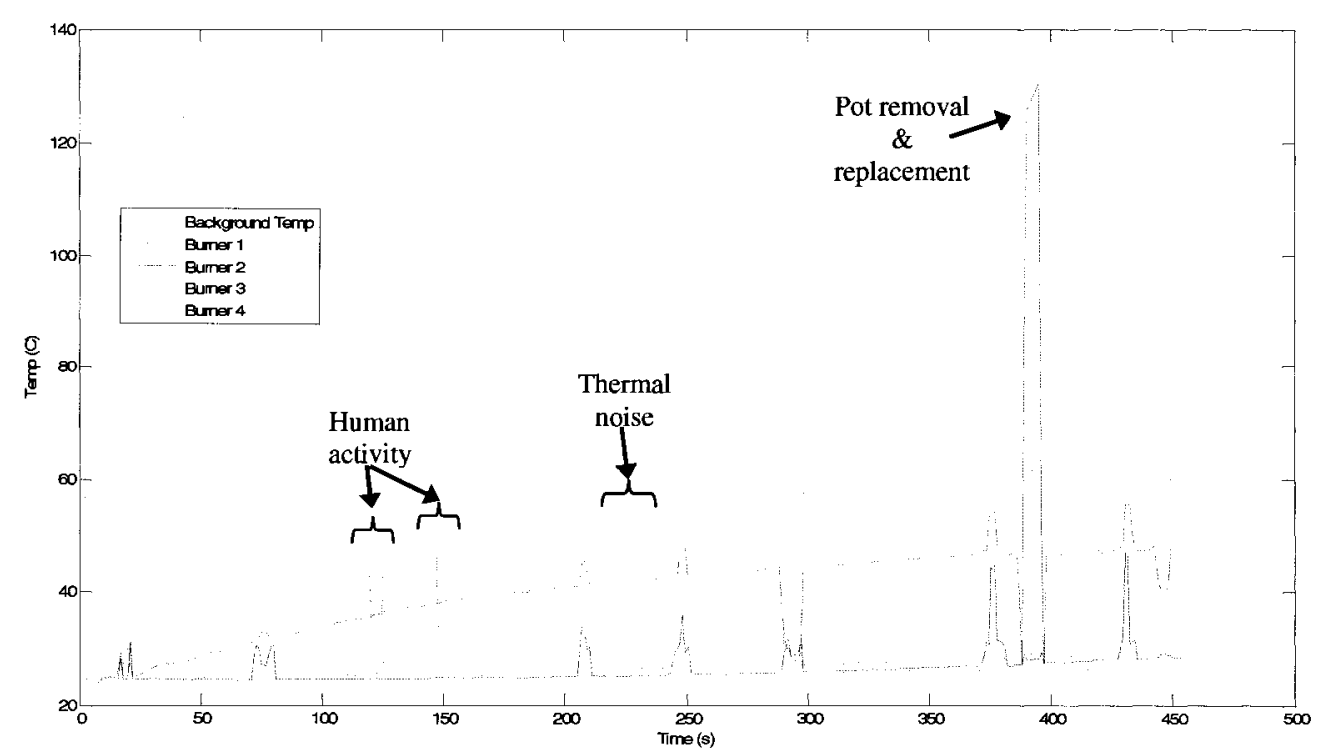

Figure 5.8 Temperature profile for 4 burners in experiment $\mathrm{C} 2$ showing human activity and pot removal/replacement events 
Figure 5.8 above shows a temperature profile for a 4-burner ceramic stove from experiment $\mathrm{C} 2$. Each coloured line shows a different burner and background temperature during the experiment. There are some spikes existing on each line, these are caused by either thermal noise, human activity, or pot removal or replacement events. Thermal noise spikes are usually very small $\left(<1^{\circ} \mathrm{C}\right)$ and can be ignored when we take the difference between frames in this method. Human activity can be detected through other algorithms as described in Chapter 6. This leaves pot removal and replacement events. Even though there are some undetected human activity frames; we can still differentiate between a pot removal/replacement and human activity by applying a threshold to find significant temperature spikes, since the spike resulting from pot removal and replacement is typically much higher than the human activity one as illustrated in Figure 5.9 and Figure 5.11below.

Figure 5.8 above shows the temperature profile for four burners from experiment $\mathrm{C} 2$. Figure 5.9 below is the same figure annotated with the results from human activity detection and pot removal/replacement analysis. Here, the frames marked with yellow bars represent the ones where human activity happened. The green bar indicates those frames where a pot was removed and replaced. Note that the spike within the green bar shows an increase in temperature of over 100 Celsius degrees within short amount of time. Human activity is characterized by much smaller temperature spikes. Therefore, we can set up a spike threshold to detect a pot removal and replacement event. 


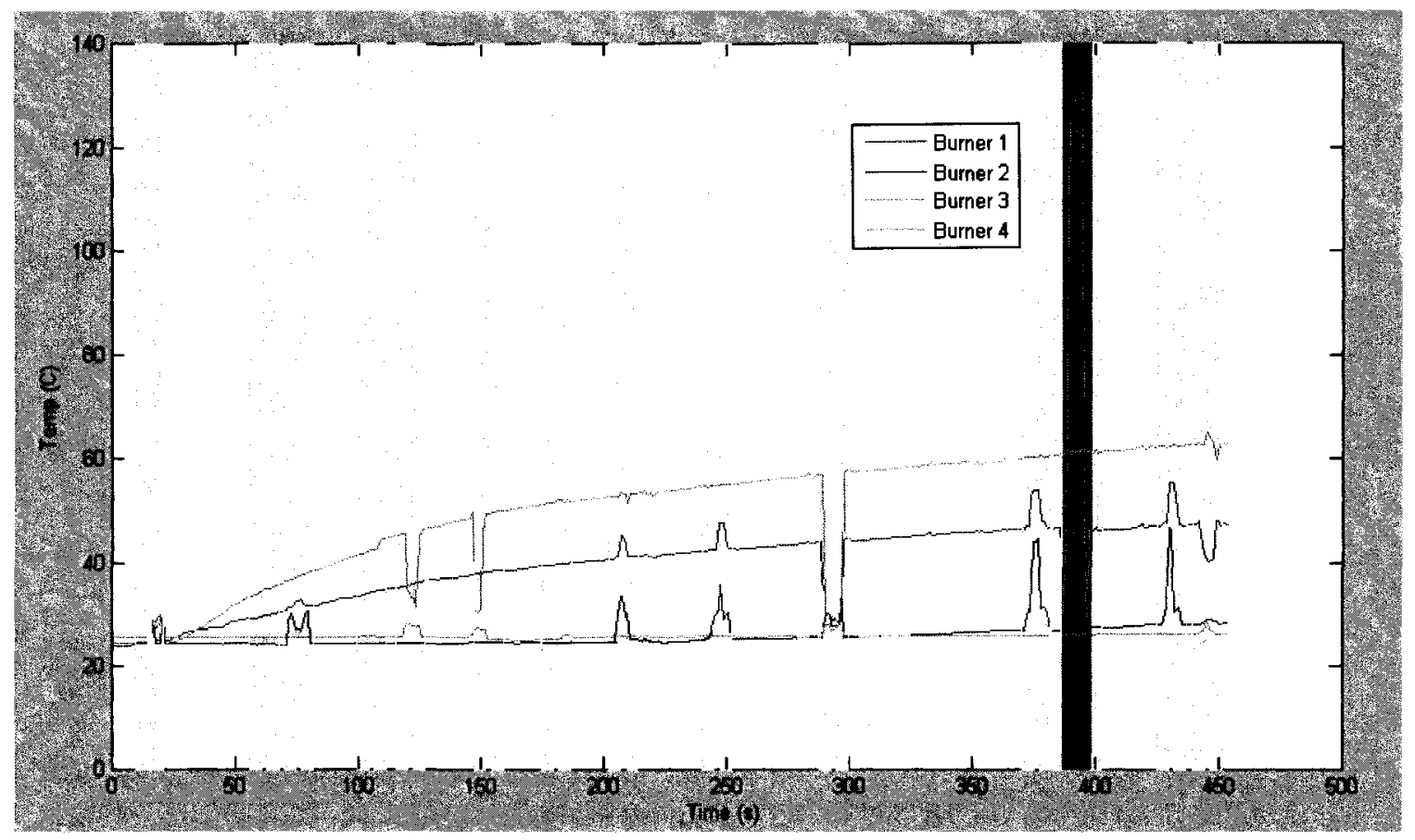

Figure 5.9. Temperature profile from Figure 5.8 after human activity detection. The yellow bars indicates periods of human activity, the green bar indicates a period of pot removal and replacement.

It is interesting to note that for the B1 temperature profile line in Figure 5.9, some human activity increases the temperature above 40 Celsius degrees. This jump in temperature is caused by the subject opening the lid on the hot pot (see Figure 5.10 below).
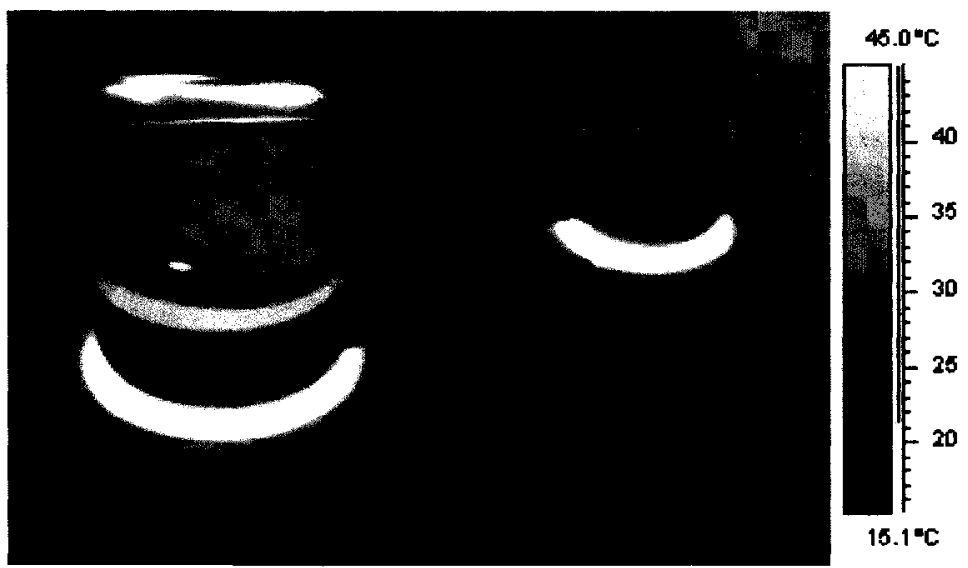

Figure 5.10. The subject opens the hot pot lid which increases burner temperature above 40 Celsius degrees in Experiment C2 
When the temperature spike magnitudes are plotted for thermal noise, human activity, and pot removal and replacement, it is clear that the three classes are almost disjoint. This is shown below in Figure 5.11. However, in this work human activity is detected using the methods described in chapter 6 and removed at the data fusion level described in chapter 7. Therefore, only a binary classification is made between thermal noise and pot removal and replacement.

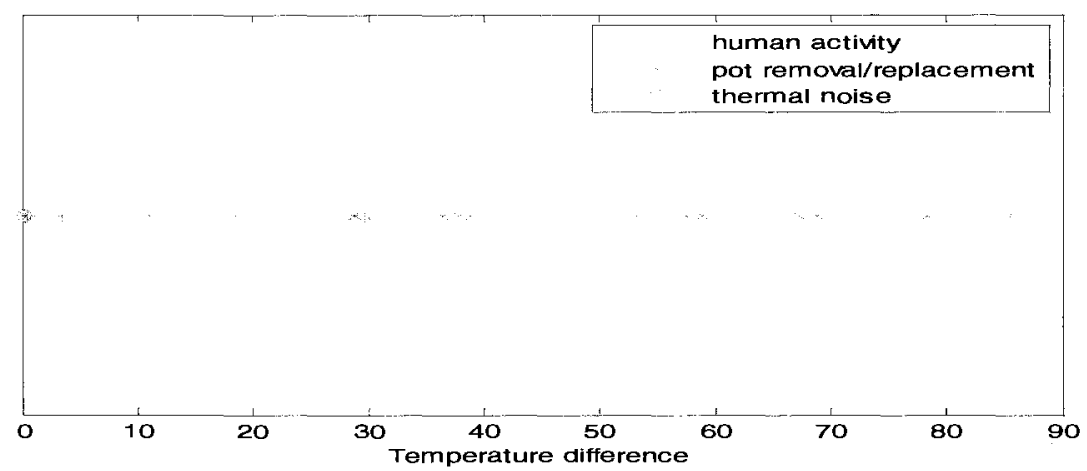

Figure 5.11. Plot of temperature spike magnitudes for thermal noise, human activity, and pot removal and replacement events

\begin{tabular}{|c|c|c|}
\hline Removal/Replacement & Diff $\mid\left({ }^{\circ} \mathbf{C}\right)$ & Experiment \\
\hline removal & 58.88 & EC4 \\
\hline removal & 28.80 & EC4 \\
\hline replacement & 68.91 & EC4 \\
\hline replacement & 37.78 & EC4 \\
\hline removal & 38.76 & ECT3 \\
\hline replacement & 67.25 & ECT3 \\
\hline replacement & 28.89 & ECT3 \\
\hline removal & 85.28 & ECT5 \\
\hline removal & 78.34 & ECT5 \\
\hline replacement & 53.21 & ECT5 \\
\hline removal & 36.55 & ECT6 \\
\hline removal & 57.66 & ECT6 \\
\hline replacement & 31.27 & ECT6 \\
\hline removal & 112 & C2 \\
\hline replacement & 108.5 & C2 \\
\hline
\end{tabular}

Table 5.4. Temperature profile analysis for pot presence/absence 
In order to set the spike threshold, 16 pot removal and replacement events from five experiments were analysed and the results are summarized in Table 5.4 above. From the table, we can see the temperature difference due to a pot removal/replacement event is at least $28.8^{\circ} \mathrm{C}$ and therefore the spike threshold of $28^{\circ} \mathrm{C}$ is applied to all experiments.

\subsubsection{Results}

By using the spike threshold $28^{\circ} \mathrm{C}$ in all data fusion experiments (see list in Table 7.1), all 35 true positive pot removal and replacement events are correctly detected. However, five false positive events were observed ( 2 for EC6, 2 for EC7, and one for ECT3). These false positives were caused by a pot lid being removed and replaced. For example, in experiment ECT3, there is one temperature spike caused by a lid replacement event whose magnitude is $33.78^{\circ} \mathrm{C}$ which is higher than the spike threshold of $28^{\circ} \mathrm{C}$. This exceptionally large spike was caused by the subject putting a cold lid on a hot pot causing the sudden reduction of temperature. In this particular case, the system regards this as a pot replacement when the pot is already in place, so there is no overall negative effect on system performance. False positive events were also observed in experiments EC6 and EC7 due to lid removal and replacement events. These false positives caused errors at the data fusion level as discussed in chapter 7 .

\subsubsection{Discussion}

Ongoing pot presence is computed by monitoring for pot removal and replacement events. These events manifest themselves as sharp temperature spikes when examining the burner temperature over time. A spike magnitude threshold is applied to differentiate between thermal noise and pot removal and replacement events. Spikes caused by human 
activity are removed at the data fusion level as discussed in section 7.4. However, it is difficult to find an optimal spike threshold value to distinguish between lid removal/replacement and pot removal/replacement events since their temperature differences are in the same range: $28^{\circ} \mathrm{C}-110^{\circ} \mathrm{C}$. Future work combining the template matching and temperature difference algorithms may solve this problem.

When the pot is on the active burner and at the steady state, the pot could reach the same temperature as the burner, therefore, the sudden increase in temperature may not be present. The consideration of change in apparent burner diameter could be possible to solve this problem and it remains as the future work. 


\section{Chapter 6}

\section{Human Activity Detection System}

\subsection{Introduction}

When a stove is left unattended, fire hazards are more likely to develop. The purpose of human activity detection system is to detect whether the user is actively monitoring the stove top. By knowing this information, the system can generate reminders and alerts if no human activity is detected for a period of time. We define human activity as any activity where the user reaches into the field of view such as stir a pot, remove a lid, turn a dial, etc.

\subsection{Human Activity Detection Methods}

To detect human activity, a threshold of $30^{\circ} \mathrm{C}$ is applied to each frame. Burner regions are excluded, as defined by the masks generated during calibration. A number of regions representing thermal noise are often included in the resulting image, representing potential false positives since they do not represent true human activity. In this thesis, we define thermal noise as pixels whose temperature is higher than $30^{\circ} \mathrm{C}$ and which do not represent true human activity. Example causes of thermal noise include steam generated from boiling water, the placement of other heat sources beside the stove (e.g. see Figure 6.1 below), or heat reflection from the surface of stove top (e.g. see Figure 6.2 and Figure 6.3 below). 


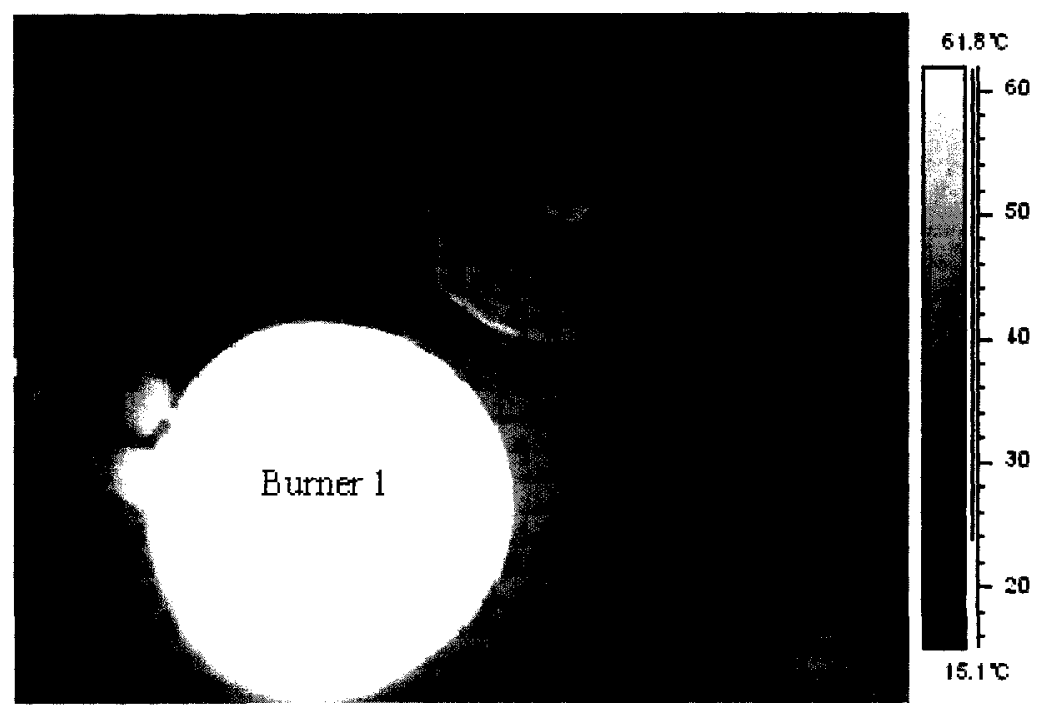

Figure 6.1. Thermal noise (within the red circle, from a laptop vent) is visible in the bottom right corner of the image. This noise was incorrectly labelled as human activity since i) it is connected to the image border thereby bypassing the border filtering, and ii)

its centroid differs sufficiently over 30 seconds to bypass the temporal filtering.

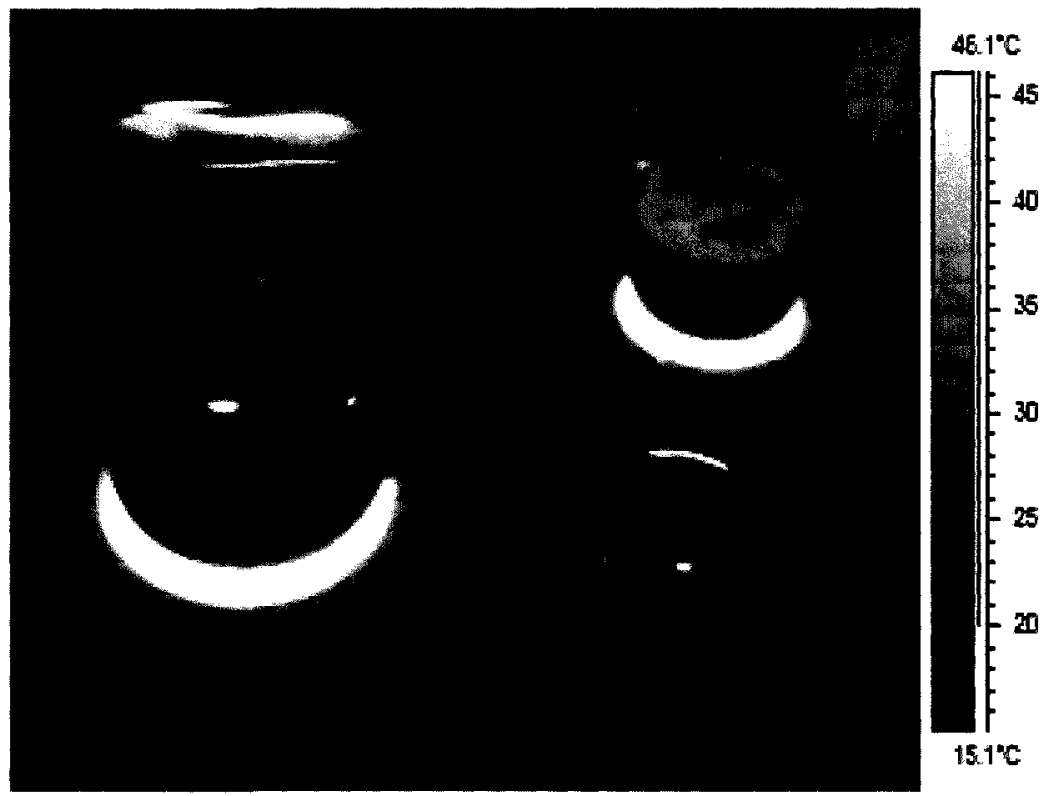

Figure 6.2. Thermal image of 4-burner stove top showing human activity (top-right) and thermal noise (within the red circle). 


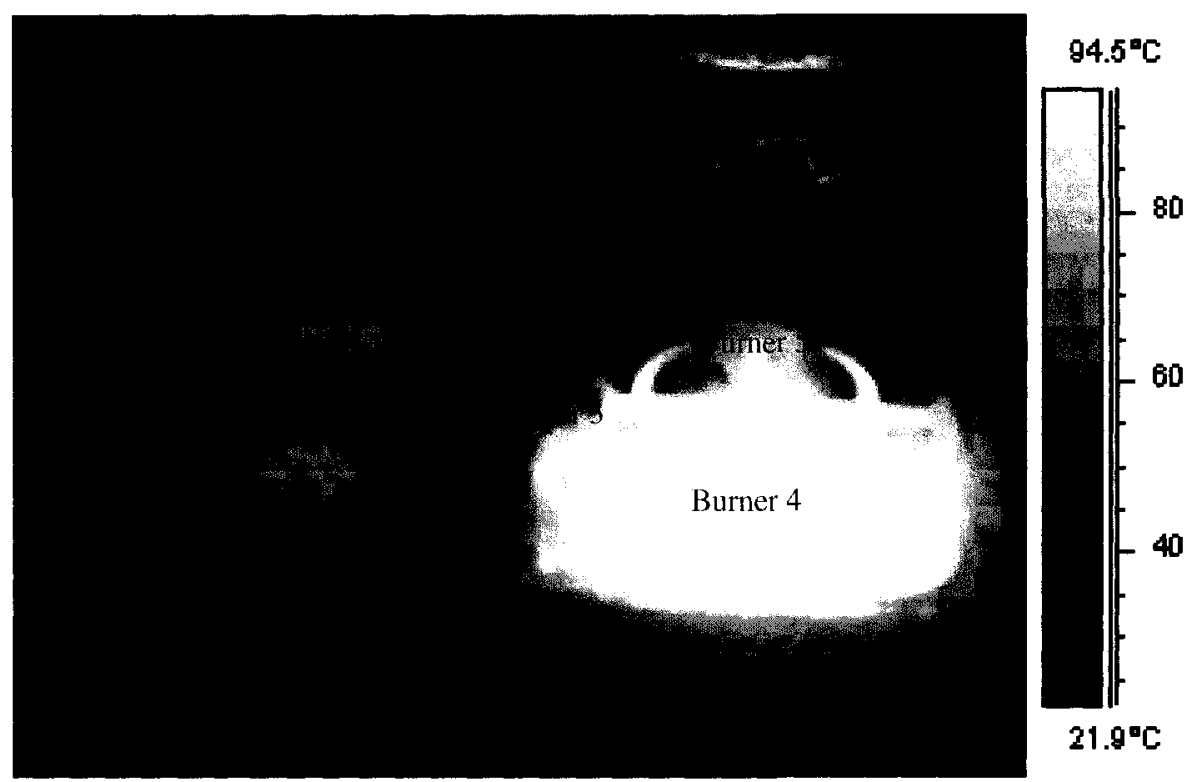

Figure 6.3. Thermal image of 5-burner gas stove top with strong thermal noise connected to the border of image (within the red circle)

Two strategies are employed to differentiate between human activity and thermal noise. These are spatial filtering, in the form of border filtering, and temporal filtering. The details of the human activity detection algorithm are shown in Figure 6.4 below. The flow chart on the right shows the various algorithms used to detect human activity step by step; the images produced from each step are shown on the left, culminating with a successful detection of a human activity event in experiment $\mathrm{C} 2$. The red line circles a subject's hand in the first picture on the left. The second picture is the result after applying a temperature threshold of $30^{\circ} \mathrm{C}$. Burner regions are excluded as defined by the masks generated during calibration (as explained in section 3.4), including a margin of twice the burner radius to account for possible spreading of heat or the presence of an oversized pot. A number of regions representing thermal noise are often included in the resulting binary image. The two strategies of bordering filtering (see section 6.2.2) and time filtering (see section 6.2.3) are employed to remove this noise. The third picture on the 
left shows the results after border filtering is applied. The next sequence of pictures shows the process of time filtering. Since the blob representing the human hand is absent after 30 seconds (shown in last image), then the system detects a human activity event happened in this frame.

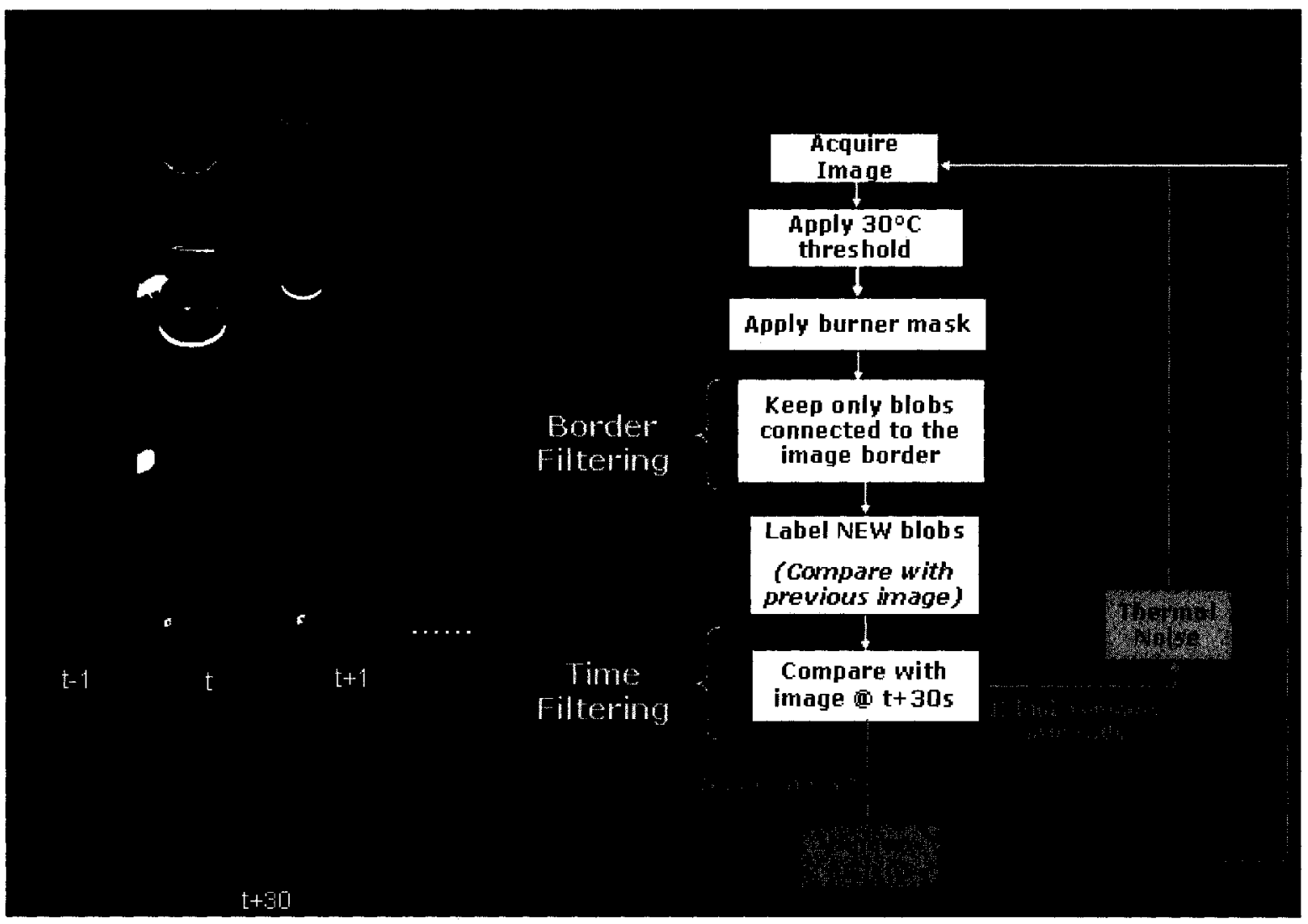

Figure 6.4. Flow chart of detecting human activity

\subsubsection{Human activity temperature threshold}

In this research, it is assumed that human activity within the field of view of the camera will lead to a connected region (i.e. blob) of greater than $30^{\circ} \mathrm{C}$. It is tempting to increase this temperature threshold given than normal body temperature is $36.8^{\circ} \mathrm{C}$, however, when a user's arm is covered in thick clothing the observed surface temperature may be 
significantly reduced. Following reference [55], the expected surface temperature may be calculated using Fanger's equation [56] where the clothing surface temperature, $t_{c l}$, is given by:

$$
t_{c l}=t_{s k}-I_{c l} \times k_{1} \times f_{c l} \times\left[\left(t_{c l}+273\right)^{4}-\left(t_{e q}+273\right)^{4}\right]-I_{c l} \times f_{c l} \times h_{c, e q} \times\left(t_{c l}-t_{e q}\right)
$$

This equation contains terms which relate to:

$$
\begin{gathered}
I_{c l}=\text { clothing }- \text { specific insulation value } \\
k_{1}=\varepsilon \cdot \sigma \cdot \frac{A_{r}}{A_{D u}}=39.6 \cdot 10^{-9} \\
h_{c, e q}=2.38 \cdot\left(t_{c l}-t_{e q}\right)^{0.25} \\
f_{c l}=1.00+1.29 \cdot I_{c l} \quad \text { for } I_{c l}<0.078^{\circ} \mathrm{C} \cdot \mathrm{m} / \mathrm{W} \\
f_{c l}=1.05+0.645 \cdot I_{c l} \quad \text { for } I_{c l} \geq 0.078^{\circ} \mathrm{C} \cdot \mathrm{m} / \mathrm{W} \\
t_{e q}=t_{a}+\frac{L_{v}}{C_{p d}} \times r \quad[57] \\
t_{s k}=\text { skintemperature }
\end{gathered}
$$

All the terms in this equation is clearly defined in below:

\begin{tabular}{|c|c|l|c|}
\hline Equation & Term & \multicolumn{1}{|c|}{ Description } & Unit \\
\hline 1 & $t_{c l}$ & Clothing surface temperature & ${ }^{\circ} \mathrm{C}$ \\
\hline 1 & $t_{s k}$ & Skin temperature & ${ }^{\circ} \mathrm{C}$ \\
\hline 1 & $t_{e q}$ & $\begin{array}{l}\text { Equivalent temperature, it is the temperature of an } \\
\text { air parcel from which all the water vapour has } \\
\text { been extracted by an adiabatic process. }\end{array}$ & ${ }^{\circ} \mathrm{C}$ \\
\hline 3 & $I_{c l}$ & $\begin{array}{l}\text { Clothing insulation. It is an average including } \\
\text { uncovered parts of the body. Values for different } \\
\text { clothing are given in Table } 6.2 .\end{array}$ & $\left({ }^{\circ} \mathrm{C} \cdot \mathrm{m}^{2} / \mathrm{W}\right)$ \\
\hline 3 & $k_{1}$ & $\begin{array}{l}\text { Heat constant } \\
\text { Nentive radiant area of a body. Surface that }\end{array}$ & $\mathrm{N}^{2}$ \\
\hline
\end{tabular}




\begin{tabular}{|c|c|l|c|}
\hline & & because the body is not a convex surface. & \\
\hline 3 & $A_{D U}$ & $\begin{array}{l}\text { Dubois body surface area. The total surface area } \\
\text { of a person as estimated by the Dubois formula. }\end{array}$ & $\mathrm{m}^{2}$ \\
\hline 4 & $h_{c, e q}$ & $\begin{array}{l}\text { Convective heat transfer coefficient when air } \\
\text { velocity in enclosure is zero. }\end{array}$ & $\mathrm{W} / \mathrm{m}^{2} /{ }^{\circ} \mathrm{C}$ \\
\hline 4 & $t_{a}$ & $\begin{array}{l}\text { Air temperature } \\
\text { Clothing area factor. The ration of the surface } \\
\text { area of the clothed body to the surface area of the } \\
\text { naked body. }\end{array}$ & $\mathrm{N}$ N/A \\
\hline 6 & $f_{c l}$ & $\begin{array}{l}\text { Latent heat of evaporation, it is equal to } 2271 \\
\mathrm{~kJ} / \mathrm{kg} @ 20^{\circ} \mathrm{C} \text { [58] }\end{array}$ & $\mathrm{kJ} / \mathrm{kg}$ \\
\hline 6 & $L_{v}$ & $\begin{array}{l}\text { Specific heat at constant pressure of air } \\
(\approx 1004 \mathrm{~J} / \mathrm{kg} \cdot \mathrm{K}) \text { [57] }\end{array}$ & $\mathrm{J} / \mathrm{kg} \cdot \mathrm{K})$ \\
\hline 6 & $C_{p d}$ & $\begin{array}{l}\text { Mixing ratio (equal to } 0.009 \text { when air temperature } \\
\left.\text { is } 20^{\circ} \mathrm{C}\right) \text { [59] }\end{array}$ & $\mathrm{N} / \mathrm{A}$ \\
\hline
\end{tabular}

Table 6.1. Nomenclature in equation (1)

From equation 1 above, it is clear that there are many factors that affect the observed surface temperature of a stove top user. From equation 6 and the corresponding references [57], [58] and [59], we can calculate the equivalent temperature is approximately equal to $20.02^{\circ} \mathrm{C}$ when the air temperature is chosen to be $20^{\circ} \mathrm{C}$, skin temperature is chosen to be $36.8^{\circ} \mathrm{C}$. The observed clothing surface temperature varies with $I_{c l}$ as given by Table 6.2 below.

\begin{tabular}{|c|c|}
\hline Type of Clothing & $I_{c l}\left({ }^{\circ} \mathbf{C} \cdot \mathbf{m}^{\mathbf{2}} / \mathbf{W}\right)$ \\
\hline Naked & 0 \\
\hline Short sleeve & 0.029 \\
\hline Normal, long sleeves & 0.039 \\
\hline Daily wear, belted work & 0.076 \\
\hline Thin sweater & 0.031 \\
\hline jacket & 0.054 \\
\hline coat & 0.093 \\
\hline
\end{tabular}

Table 6.2. $I_{c l}$ values for clothing [55]

Figure 6.5 illustrates different clothing surface temperatures for a number of different values of clothing insulation (under the same assumptions of skin and ambient 
temperature as above). We can see that the temperature ranges from $29.3^{\circ} \mathrm{C}$ to $35.7^{\circ} \mathrm{C}$ depending on different thicknesses of clothing insulation. This effect was observed in experiments ECT4, ECT5 and ECT6 where the subject wore a thick coat. In these experiments, the clothing surface temperature was actually below $30^{\circ} \mathrm{C}$. We therefore considered a threshold of $29^{\circ} \mathrm{C}$ to detect human activity. However, the results were poor since the temperature of thermal noise caused by heat reflection in the gas stove top experiments is slightly above $29^{\circ} \mathrm{C}$, and the resulting thermal noise blob is very large and is connected to the border of the image. Although the time filtering stage eliminates this noise, it masks all human activities in the area of the noise resulting in missed human activity events (see Figure 6.7). Therefore, a final threshold value of $30^{\circ} \mathrm{C}$ was chosen and applied to all other experiments except those three experiments where the user wore a thick sweater as mentioned above.

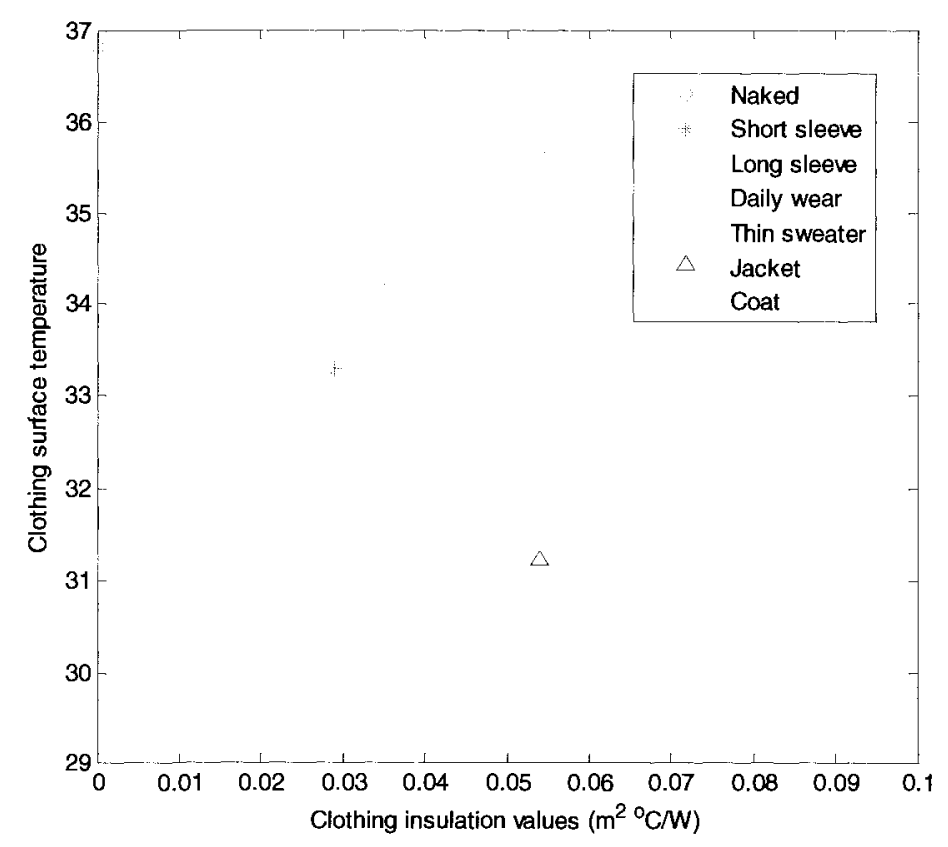

Figure 6.5. Clothing surface temperature vs. different clothing insulations assuming an ambient temperature of $20^{\circ} \mathrm{C}$ and a body temperature of $36.8^{\circ} \mathrm{C}$ 


\subsubsection{Border filtering}

The first strategy to eliminate thermal noise is called border filtering which leverages the fact that human activity originates from outside of the field of view of the camera (i.e. the stove top). When possible, the field of view is set such that a small margin surrounding all four sides of the stove top is included. This ensures that thermal noise on the cooking surface does not extend to the edge of the image, since the air gap surrounding most cooking surfaces prevents significant heat conducting beyond the cooking surface itself. Even in the absence of an air gap, such as a surface-mounted cooking surface embedded in a counter, heat conduction to the surrounding surface is expected to be minimal due to the change in material between the cooking surface and the surrounding counter. Therefore, all potential regions of human activity are filtered such that only blobs connected to the image borders are kept. This immediately reduces the rate of false positives, however occasionally thermal noise reaches the image border (e.g. through dense steam escaping an uncovered pot). Note also that due to the fixed field of view of the camera used in this study, it was not always possible to include an air gap on all sides of the stove top leading to degraded performance. This is discussed in more detail below.

\subsubsection{Time filtering}

The second strategy to reduce false positives takes advantage of the fact that human activity tends to be transient while thermal noise is often not. For example, a person may briefly reach into the field of view to stir a pot, but thermal noise from a steaming pot will tend to last longer than 30 seconds. In this algorithm, we assume all human activity lasts between 5 and 30 seconds. It is acknowledged that some human activity may last longer than 30 seconds. This situation leads to minimal negative consequences as discussed 
below. Therefore when a new candidate blob appears in the threshold-ed image, it is tracked for 30 seconds. If the blob remains within the field of view for more than 30 seconds, it is rejected as thermal noise. These two strategies (border filtering and time filtering) result in excellent sensitivity and specificity as detailed below.

\subsection{Results}

To evaluate the performance of the human activity detection system, ten experiments were conducted: EC4, EC7, ECT2 and ECT3 were conducted on the 2-burner electric coil stove top (see Figure 6.1), C2, C3, CT2 and CT3 used the 4-burner ceramic stove top (see Figure 6.2), and G2 and G3 were conducted on the 5-burner gas stove top (see Figure 6.3). In all experiments, the calibration protocol described in section 3.4 was first executed to determine the burner locations. In experiments EC4 and EC7, only one burner was active and was covered with a pot of water. In experiments ECT2, one burner was active but initially uncovered; after a while, a pot filled with minimum amount of water was placed on top of the burner. One the water in the pot started to boil the pot was removed from the burner and was placed on another inactive burner. Experiment ECT3 was conducted in a similar manner with the experiment ECT2 except with a smaller pot. In experiments $\mathrm{C} 2$ and $\mathrm{C} 3$, two burners were active, both covered by pots of water. In experiments CT2 and CT3, one burner was active at the beginning, and covered with a pot of water later on. In experiment G2, only one burner was on and was occupied with a pot of water. While in G3, one burner was on and was not covered with anything. The ten experiments are described in Table 6.3. For the purpose of evaluating the human activity detection algorithms, a frame was considered to truly contain human activity if either a portion of a human (e.g. hand) was visible within the frame, or if an object was 
manipulated by an unseen hand (e.g. a pot was moved in the experiment EC4). An 'event' is a contiguous series of frames displaying human activity.

\begin{tabular}{|c|c|c|c|c|c|}
\hline \multicolumn{3}{|c|}{ Experiment Description } & \multicolumn{2}{c|}{ Human Activity } \\
\hline ID & $\begin{array}{c}\text { Stove } \\
\text { Type }\end{array}$ & $\begin{array}{c}\text { Frame } \\
\text { Period }\end{array}$ & $\begin{array}{c}\text { Total } \\
\text { Frames }\end{array}$ & Events & Frames \\
\hline EC4 & Coil & $10 \mathrm{~s}$ & 83 & 3 & 19 \\
\hline EC7 & Coil & $5 \mathrm{~s}$ & 37 & 12 & 8 \\
\hline ECT2 & Coil & $2 \mathrm{~s}$ & 157 & 6 & 11 \\
\hline ECT3 & Coil & $2 \mathrm{~s}$ & 124 & 8 & 15 \\
\hline C2 & Ceramic & $1 \mathrm{~s}$ & 454 & 15 & 136 \\
\hline C3 & Ceramic & $1 \mathrm{~s}$ & 399 & 13 & 79 \\
\hline CT2 & Ceramic & $1 \mathrm{~s}$ & 275 & 7 & 35 \\
\hline CT3 & Ceramic & $1 \mathrm{~s}$ & 326 & 6 & 16 \\
\hline G2 & Gas & $1 \mathrm{~s}$ & 639 & 12 & 57 \\
\hline G3 & Gas & $1 \mathrm{~s}$ & 68 & 2 & 9 \\
\hline
\end{tabular}

Table 6.3. Description of human activity experiments

\begin{tabular}{|c|c|c|}
\cline { 2 - 3 } \multicolumn{1}{c|}{} & \multicolumn{2}{c|}{ Per Frame } \\
\cline { 2 - 3 } \multicolumn{1}{c|}{ Sn } & Sp \\
\hline EC4 & 0.89 & 0.98 \\
\hline EC7 & 1.00 & 1.00 \\
\hline ECT2 & 0.60 & 0.99 \\
\hline ECT3 & 0.60 & 0.85 \\
\hline C2 & 0.75 & 0.98 \\
\hline C3 & 0.94 & 0.93 \\
\hline CT2 & 0.92 & 0.87 \\
\hline CT3 & 0.88 & 0.93 \\
\hline G2 & 0.60 & 0.97 \\
\hline G3 & 1.00 & 1.00 \\
\hline
\end{tabular}

Table 6.4. Human activity detection performance per frame. $\mathrm{Sn}=$ sensitivity and $\mathrm{Sp}=$ specificity

The human activity monitoring algorithm was applied to the data from each experiment and frames were noted where human activity was detected. The sensitivity and specificity for each experiment are provided in Table 6.4 above on a per-frame basis. As can be seen, the specificity was excellent (mean $=95 \%$ ) indicating a very low false positive rate, while the sensitivity of the algorithm is very good on all experiments (mean=81.8\%). As 
discussed below, the low false positive rate is critical if we are to identify unattended stove tops.

The three experiments that saw a significant number of missed positive frames were ECT2, ECT3 and G2. In terms of ECT2 and ECT3, the subjects wore a thick long sleeve coat to conduct the experiments. The clothing surface temperature in the thermal images is below the temperature threshold of $30^{\circ} \mathrm{C}$ and therefore the system missed some positive frames when the subject's arm was on the border of the image. However, the system was able to detect the human activity when the subject's hand was on the border of the image because it is higher than $30^{\circ} \mathrm{C}$. (See Figure 6.6 below)

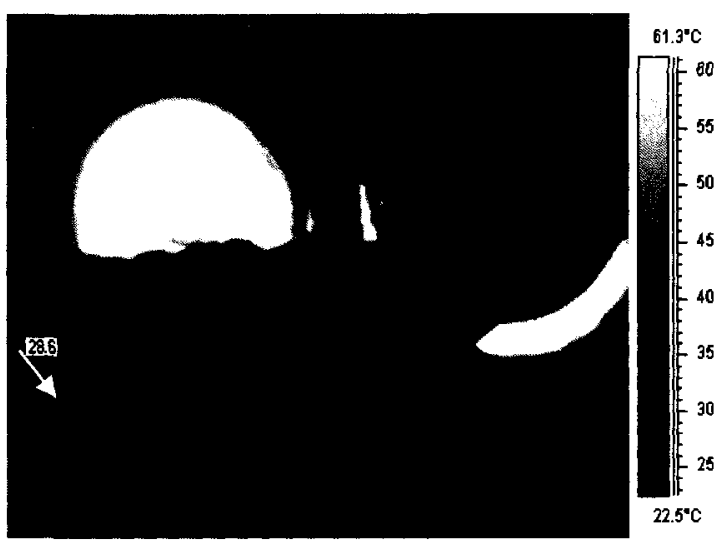

a)

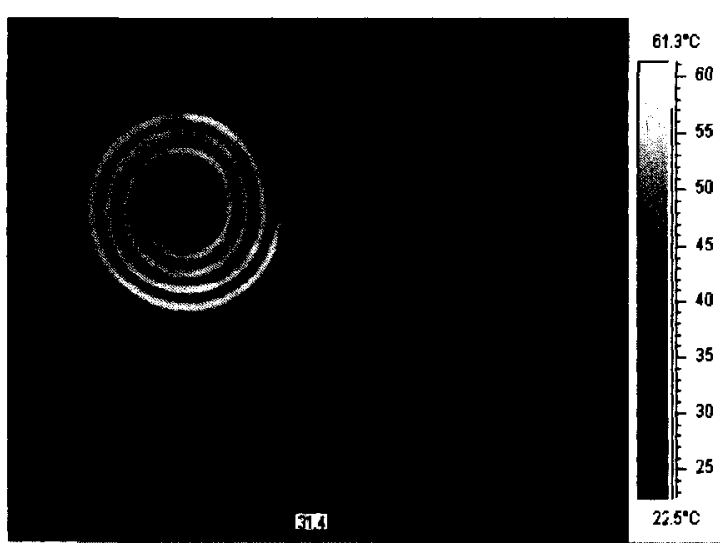

b)

Figure 6.6. a) Subject's arm with thick coat. Surface temperature is $28.6^{\circ} \mathrm{C}$ and the system fails to detect human activity. b) Subject's hand connected to the border of the image. Surface temperature is $31.4^{\circ} \mathrm{C}$ and the system detects human activity successfully.

For experiment $\mathrm{G} 2$, the main reason for missing positive frames is because the gas stove has large flames resulting in more heat reflection from the metal stove top. Although the border filter and time filter can eliminate most heat reflection, there is still some transient heat noise connected to the border of the image and that is not eliminated. In Figure 6.7 
below, the top left image is the raw thermal image of experiment G2 at the $239^{\text {th }}$ frame, the one beside it is the same picture after the bordering and time filtering. The heat reflection from burning flame produces a large thermal noise blob covering much of the stove top. When the human activity happened in the next frame, as shown in the bottom left picture, although the subject's hand is clearly visible, the system fails to recognize it as a new blob because it was connected to the thermal noise blob. As shown in the bottom right image, the system regarded the human activity and the heat reflection as a single large blob. Therefore, since there is no new blob, the time filtering stage causes the missing positive frames in experiment $\mathrm{G} 2$.
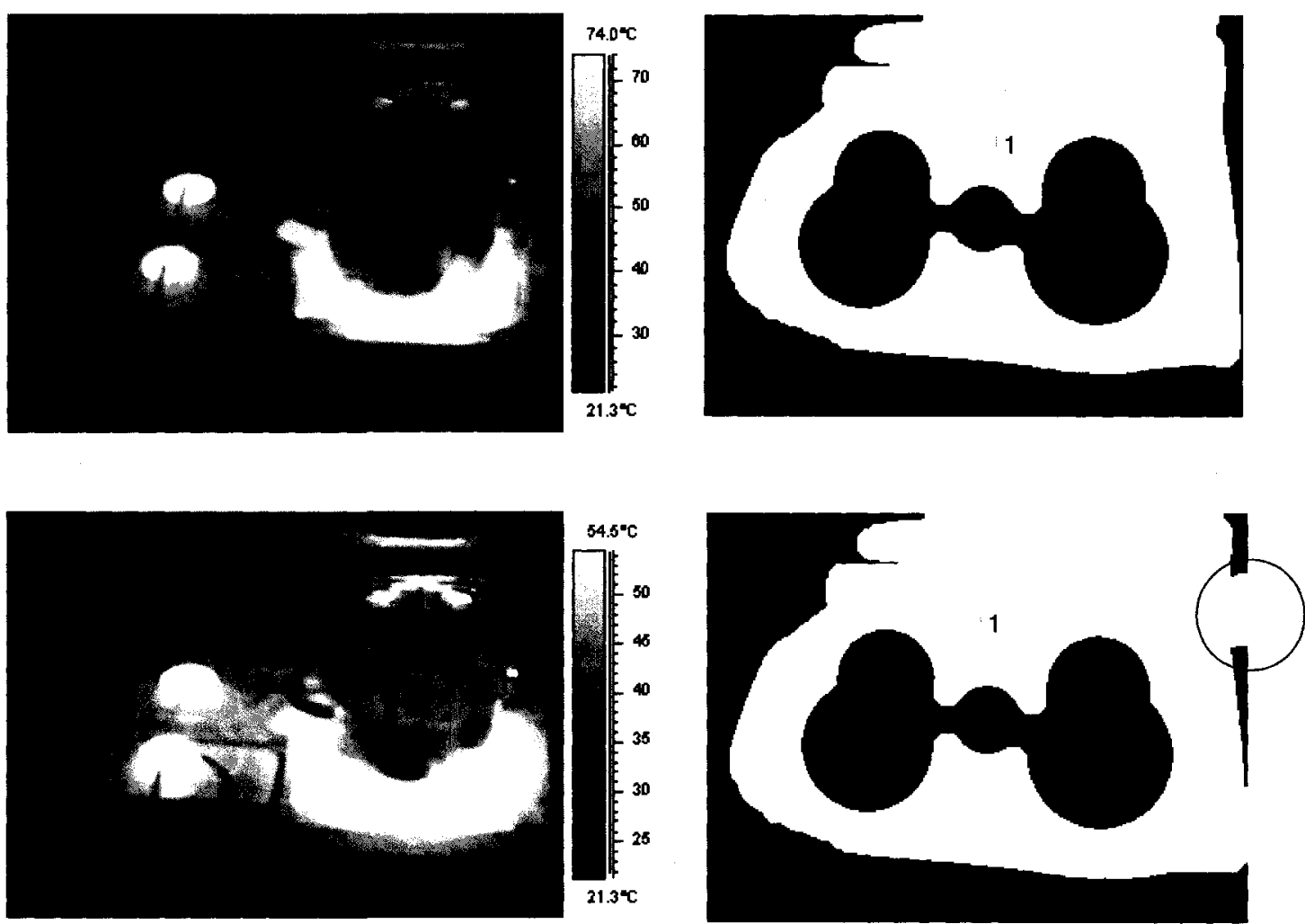

Figure 6.7. The top row picture shows the thermal image in experiment G2 with no human activity (frame 239, on left) with resulting picture after the bordering and time filtering (on right). The bottom left picture shows the next frame in which human activity is clearly visible. The bottom right image shows the frame after bordering and time filtering; the red line circles the human hand missed by the algorithm. 
Since this system is meant to detect human activity events, it makes more sense to evaluate the performance of the system in terms of events rather than individual frames. A single event may span several frames. For example, when a user reaches into the field of view of the camera, removes a pot lid, stirs the contents, replaces the lid, and leaves the scene, this single event may span 20 seconds. It is hard to define true negatives in the context of discrete events. We therefore use positive predictive value (PPV) and sensitivity here to evaluate the human activity monitoring performance per event (see definitions in section 2.4). There are 85 real human activity events in the 10 experiments used to evaluate this subsystem. If we define a series of predicted events that fall within a single real event to be one correctly predicted event, then 74 real human activity events were correctly detected while generating 6 false positives and 11 false negatives. The perevent system performance is given in Table 6.5 below.

\begin{tabular}{|c|c|c|c|c|c|}
\cline { 2 - 6 } \multicolumn{1}{c|}{} & \multicolumn{5}{|c|}{ Per Event } \\
\cline { 2 - 6 } & TP & FP & FN & Sn & PPV \\
\hline EC4 & 4 & 0 & 1 & 0.80 & 1.00 \\
\hline EC7 & 2 & 0 & 0 & 1.00 & 1.00 \\
\hline ECT2 & 5 & 1 & 1 & 0.83 & 0.83 \\
\hline ECT3 & 4 & 1 & 4 & 0.50 & 0.80 \\
\hline C2 & 22 & 0 & 0 & 1.00 & 1.00 \\
\hline C3 & 12 & 3 & 1 & 0.92 & 0.80 \\
\hline CT2 & 7 & 0 & 0 & 1.00 & 1.00 \\
\hline CT3 & 5 & 1 & 1 & 0.83 & 0.83 \\
\hline G2 & 11 & 0 & 3 & 0.79 & 1.00 \\
\hline G3 & 2 & 0 & 3 & 1.00 & 1.00 \\
\hline Total/mean & $\mathbf{7 4}$ & $\mathbf{6}$ & $\mathbf{1 1}$ & $\mathbf{0 . 8 7}$ & $\mathbf{0 . 9 3}$ \\
\hline
\end{tabular}

Table 6.5. Human activity monitoring performance per event

In the case of sensitivity, the experiments that had the most missed positives were experiments G2 and ECT3 for the same reasons as discussed above (i.e. thermal noise masking real human activity). When considering the PPV of the system, the worst 
experiments are ECT2, ECT3, C3, and CT3. These false positive events were due to timevarying thermal noise reaching the image border and being mistaken for human activity. For example in experiment ECT3, frames 56-58 are incorrectly identified as human activity. In this case, thermal noise crept in from the image border in the first frame causing it to pass the edge filter. Thirty seconds later, this noise-induced blob merged with an existing large thermal noise blob which caused algorithm to believe that the original blob had disappeared - hence it also passed the temporal filter. Therefore this thermal noise was incorrectly classified as human activity.

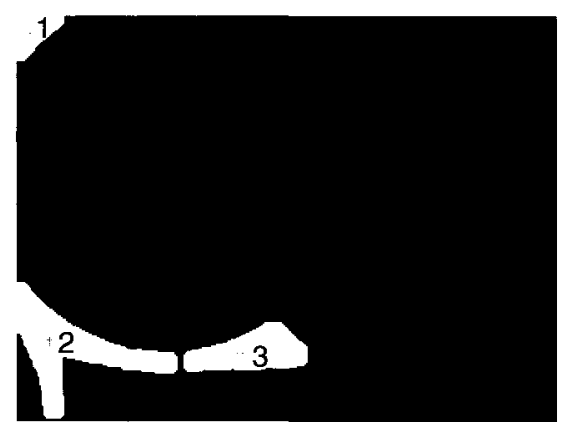

a)

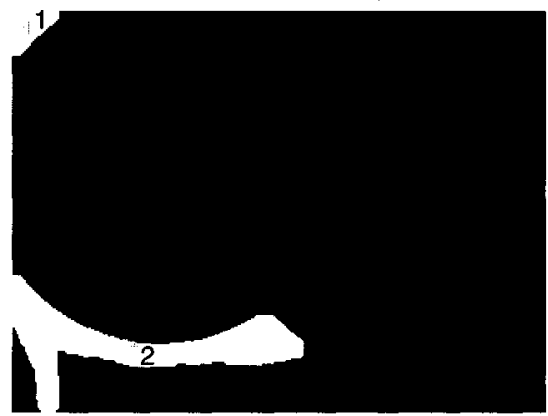

b)

Figure 6.8. Illustration of false positive prediction of human activity. a) Frame 55 from experiment ECT3 showing three thermal noise blobs. b) Frame 56 showing blobs 2 and 3 merged into a new blob mistaken for human activity.

\subsection{Discussion}

The human activity detection system is working well for most cases. A noted limitation of the system is due to the initial application of a $30^{\circ} \mathrm{C}$ temperature threshold. This requires that the subject not to wear thick clothing in order to correctly detect the human activity.

Of two fundamental types of error (I vs. II), over-prediction is the most dangerous since an unattended stove may fail to generate alerts if human activity is falsely detected. The under-prediction error has much lesser consequences where a user may simply receive 
unnecessary reminders to attend to their stove. The effect of unnecessary reminders on human users is discussed in section 7.4. In total, six false positive events (i.e. over prediction) occurred while 85 of 96 true human activity events were correctly identified leading to acceptable rates of each error type.

In this algorithm, we assume all human activity lasts between 5 and 30 seconds. As noted above, this is an acknowledged system limitation as true human activity may last longer than 30 seconds. Such prolonged human activity will not be correctly detected by the system, leading to false negative (missed positive) frames resulting in a superfluous reminder.

As can be seen in Table 6.4 above, the per-frame specificity was excellent (mean=95\%) indicating a very low false positive rate. The low false positive rate is critical if we are to identify unattended stove tops, one of the four dangerous situations described in section 3.3. If the false positive rate is high, the system detects human activity where none exists and therefore misses the right time to generate alerts. This could cause serious results and even end up with fire accidents.

In the future, we could also check the behaviour of blob. The performance could be improved by tracking blobs over time and checking to see if their movement is more like human (slow moving) or thermal noise (fixed). 


\section{Chapter 7}

\section{Data Fusion for Alert Generation}

\subsection{Introduction}

This chapter proposes a method of data fusion and applies it to alert generation. Herein, a method is developed that detects dangerous situations by combining results from each sub-system: detecting burner activity (section 4.1 ), detecting burner temperature trend (section 4.2), determining pot presence/absence (chapter 5), and detecting human activity (chapter 6). As originally defined in section 3.3 , the following dangerous situations are detected by the data fusion and alert generation system:

Alert 1: The user turns on the burner and forgets to put a pot on it.

Alert 2: $\quad$ The user turns on one burner (burner A) and puts the pot on the wrong one (burner B).

Alert 3: $\quad$ The user leaves the stove unattended for an extended period of time (user configurable time-out value) with one or more burners active.

Alert 4: $\quad$ A pot is removed from the burner but the user forgets to turn off the burner.

\subsection{Methods}

The output from the burner activity system is a matrix with $\mathrm{N}$ columns and B rows, where $\mathrm{N}$ is the number of frames in an experiment, and $\mathrm{B}$ is the number of detected burners. $\mathrm{A}$ one in element $(i, j)$ of the matrix indicates that burner $j$ is active in frame $i$. A similar 
output format is used for the burner temperature trend detection system with 0,1 , and -1 indicating constant temperature, increasing temperature, and decreasing temperature respectively. Likewise, binary matrices are used to represent the output from the pot presence/absence detecting system (a 1 represents a covered burner) and the human activity detecting system ( 1 indicates human activity in the frame $i$ ). We combine all the information together using the logic shown in Figure 7.1 (reproduced from chapter 3). We applied this data fusion logic to twenty-two experiments including 2-burner electric coil, 4-burner ceramic, and 5-burner gas stove tops. The system performance is evaluated in section 7.3.

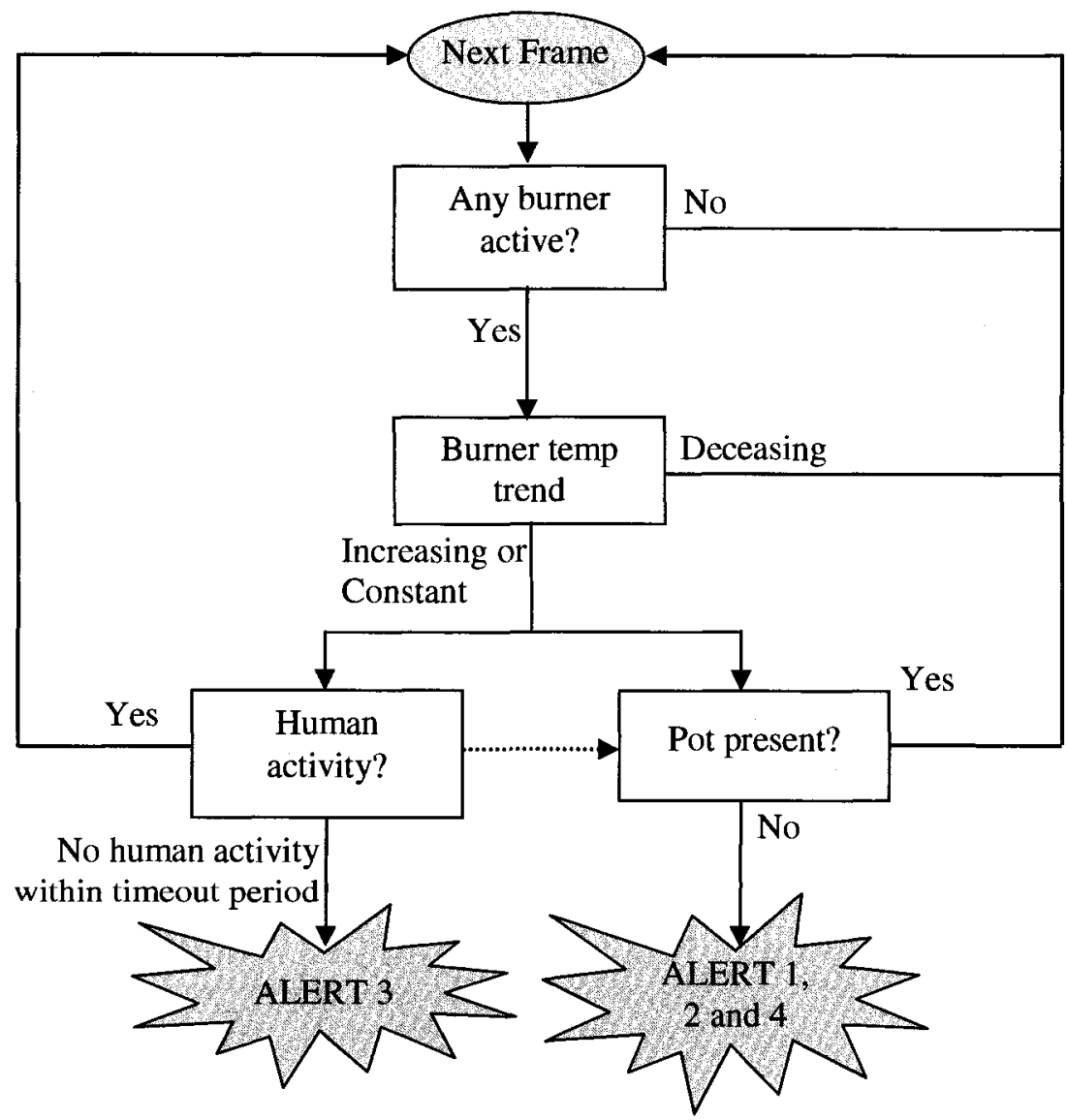

Figure 7.1. Flow chart for generating alerts 


\subsubsection{Generating alerts 1 and 2}

Alert 1 is generated when a user turns on a burner and forgets to cover it with a pot. Likewise, alert 2 is generated when a user turns on a burner, but covers the wrong burner with a pot. Both of these alerts are generated when the burner is detected to become active and the initial pot detection method (see section 5.1) reports the active burner to be uncovered. This alert is typically triggered within 20 seconds of a burner being turned on since an uncovered burner heats rapidly and is therefore detected to be active almost immediately. The initial pot presence algorithm takes 20 s to determine pot presence once the burner is detected to be active.

\subsubsection{Generating alert 3}

Alert 3 is generated when a user leaves an active stove unattended for a prolonged period of time. In a real system, the timeout period for alert 3 would be set to a reasonable value such as 15 minutes. That is, 15 minutes would be permitted to elapse between detected human activity before the system generates an alert for an unattended stove. However, for testing purposes a much smaller timeout value is used since our experiments are relatively short (10 minutes max). The alert generation logic is the same for either timeout value, so this is a valid test of our system. The timeout value was set to range between 10-50s, depending on the frame rate and total frame count in each experiment. Longer experiments used longer timeout periods, as did experiments with higher frame rates. The timeout period used in each experiment is given in Table 7.2 below.

A detailed flow chart illustrating the specific logic used to generate alert 3 is given below in Figure 7.2. 


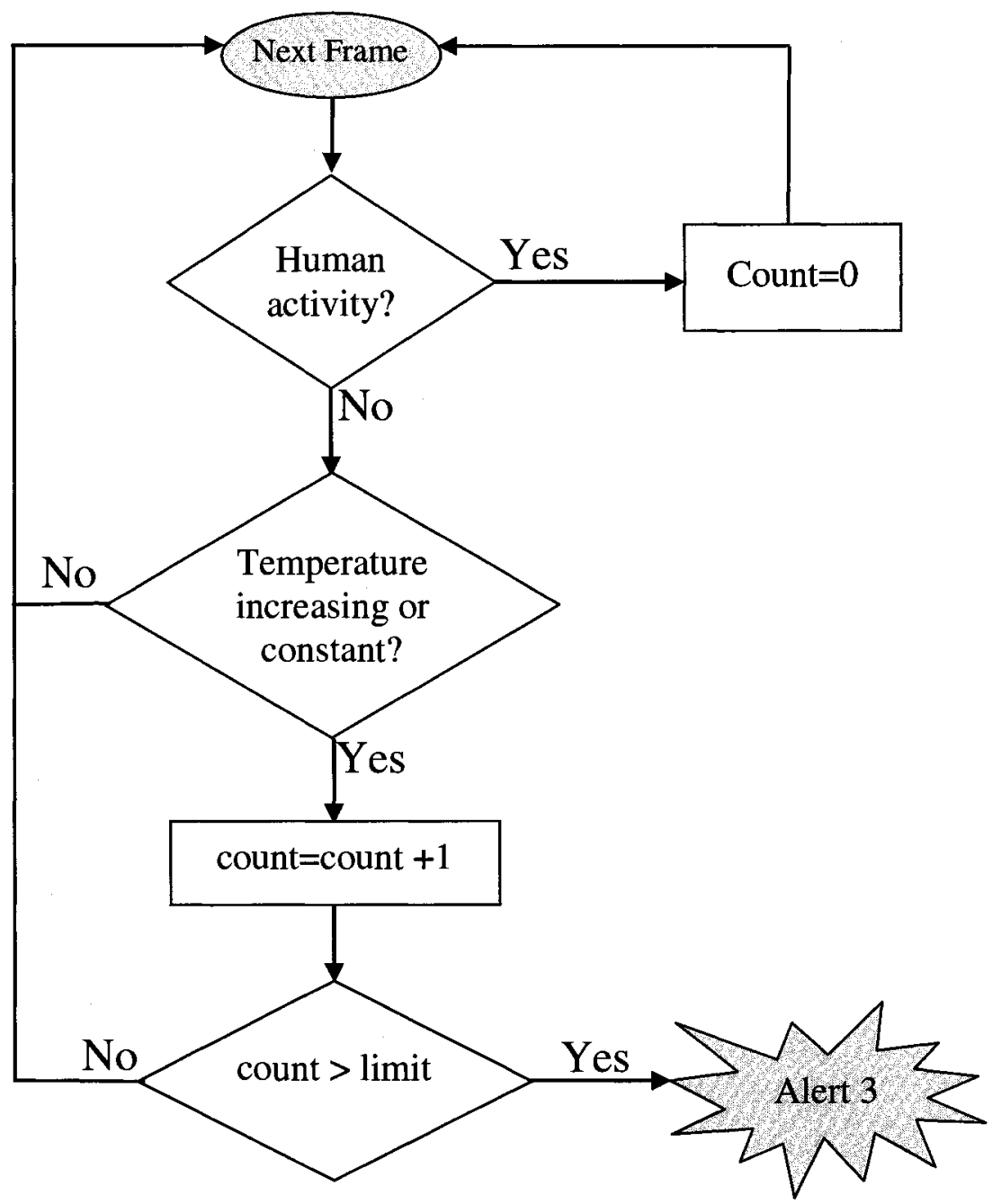

Figure 7.2. Flow chart for generating alert 3

\subsubsection{Generating alert 4}

Alert 4 is generated when a pot is removed from an active burner but the user forgets to turn off the burner. If an active burner's temperature continues to increase or remain constant after a pot removal event is detected, then an alert is immediately generated. The dashed line in Figure 7.1 indicates that human activity is taken into account during data fusion. This eliminates false positive alert 4 events where human activity may corrupt the 
outputs of the pot presence subsystem. This is discussed in more detail below in section

7.4. There is no significant time delay involved in the generation of this alert.

\subsubsection{Test data}

Twenty-two out of twenty-nine experiments were used to evaluate the data fusion performance. Experiments EC9-EC12 were not used here since the subject wore the thick sweater in the experiments caused the clothing surface temperature below $30^{\circ} \mathrm{C}$ causing the human activity detection subsystem to fail. This is an acknowledged limitation of the current system. Experiments ECT4-ECT6 were not used since the camera was out of focus leading to overly blurry thermal images which affected all subsystems. The summary of dangerous events which happened in each experiment are listed in Table 7.1 below. There are some experiments where there are no dangerous behaviours. These experiments are useful to ensure the system is not predicting too many false positives as discussed below in section 7.4.

\begin{tabular}{|c|c|}
\hline ID & Dangerous Events \\
\hline EC1 & - A user turned on burner 1 and forgot to put the pot on it. \\
\hline EC2 & $\begin{array}{l}\text { - Burner one begins very hot, and cools throughout the experiment } \\
\text { - No alerts available for this experiment }\end{array}$ \\
\hline EC3 & $\begin{array}{l}\text { - } \text { Calibration experiment } \\
\text { - Turned on both burners without putting any pot on } \\
\text { - } \quad \text { Unattended burner alert and uncovered burner alert }\end{array}$ \\
\hline EC4 & $\begin{array}{l}\text { - A pot was removed from the burner; the user forgot to turn off the burner } \\
\text { - Unattended burner alert }\end{array}$ \\
\hline EC5 & - Unattended burner alert \\
\hline EC6 & $\begin{array}{l}\text { - Put the pot on the correct burner with constant human activity } \\
\text { - No alerts for this experiment }\end{array}$ \\
\hline EC7 & $\begin{array}{l}\text { - Put the pot on the correct burner with constant human activity } \\
\text { - No alerts for this experiment }\end{array}$ \\
\hline EC8 & $\begin{array}{l}\text { - Turn off burner two and put the pot on burner one } \\
\text { - No alerts for this experiment }\end{array}$ \\
\hline $\mathbf{C O}$ & $\begin{array}{l}\text { - Calibration experiment } \\
\text { - Turned on four burners without covering with pots }\end{array}$ \\
\hline
\end{tabular}




\begin{tabular}{|c|c|}
\hline & Unattended burner alert \\
\hline $\mathbf{C 1}$ & $\begin{array}{l}\text { - Four burners were all inactive and ice cubes were used to cool them down. } \\
\text { - No alerts for this experiment. }\end{array}$ \\
\hline C2 & - Unattended burner alert \\
\hline $\mathbf{C 3}$ & Unattended burner alert \\
\hline C4 & $\begin{array}{l}\text { - Two hot burners cooling down } \\
\text { - No alerts for this experiment }\end{array}$ \\
\hline ECT1 & $\begin{array}{l}\text { - Calibration experiment } \\
\text { - Turned on both burners without covering with pots } \\
\text { - Unattended burner alert }\end{array}$ \\
\hline ECT2 & $\begin{array}{l}\text { - Turned on burner one and forgot to put the pot on it } \\
\text { - Unattended stove for burner one }\end{array}$ \\
\hline ECT3 & $\begin{array}{l}\text { - Turned on the burner two and forgot to put the pot on it } \\
\text { - Unattended stove for burner two }\end{array}$ \\
\hline CT1 & $\begin{array}{l}\text { - Calibration experiment } \\
\text { - Turned on both burners without covering with pots } \\
\text { - Unattended burner alert }\end{array}$ \\
\hline CT2 & $\begin{array}{l}\text { - A user turned on one burner (burner A) and put the pot on the wrong burner } \\
\text { (burner B) } \\
\text { - Turned on a burner without putting pot on it. } \\
\text { - Removed the pot from the active burner and forgot to turn it off } \\
\text { - Unattended burner alert }\end{array}$ \\
\hline CT3 & $\begin{array}{l}\text { - Turned on a burner and forgot to put the pot on it. } \\
\text { - Unattended burner alert. } \\
\text { - Removed the pot for the active burner and forgot to turn it off. }\end{array}$ \\
\hline G1 & $\begin{array}{l}\text { - Calibration experiment } \\
\text { - Turned on five burners without putting any pot on } \\
\text { - Unattended burner alert }\end{array}$ \\
\hline G2 & $\begin{array}{l}\text { - Unattended burner alert } \\
\text { - The pot is removed from the burner, the user forgot to turn off the burner }\end{array}$ \\
\hline G3 & - A pot is removed from the burner; the user forgot to turn off the burner. \\
\hline
\end{tabular}

Table 7.1. Summary table for data fusion experiments

The number for each dangerous situation and total times each of the four dangerous events happened in 22 experiments are described in Table 7.2 below.

\subsection{Results}

The data fusion algorithm was applied to the data from each experiment and predictions were compared to the hand-annotated ground truth of each actual dangerous event. The 
sensitivity and positive predictive value for each experiment are provided in Table 7.3 below on a per-event basis. As can be seen, the sensitivity is excellent on all experiments $($ mean $=94 \%)$.

\begin{tabular}{|c|c|c|c|c|c|c|c|c|}
\hline & \multicolumn{4}{|c|}{ Alert Type } & \multirow[b]{2}{*}{$\begin{array}{l}\text { Total } \\
\text { Alerts }\end{array}$} & \multirow[b]{2}{*}{$\begin{array}{c}\text { Frame } \\
\text { Rate } \\
\text { (s/frame) }\end{array}$} & \multirow[b]{2}{*}{$\begin{array}{c}\text { Timeout } \\
\text { Value }\end{array}$} & \multirow[b]{2}{*}{$\begin{array}{c}\text { Total } \\
\text { Frames }\end{array}$} \\
\hline ID & 1 & 2 & 3 & 4 & & & & \\
\hline EC1 & 1 & 0 & 1 & 0 & 2 & 2 & 10 & 31 \\
\hline$\overline{\mathrm{EC} 2}$ & 0 & 0 & 0 & 1 & 1 & 10 & 20 & 38 \\
\hline $\mathrm{EC} 3$ & 1 & 0 & 1 & 0 & 2 & 1 & 10 & 31 \\
\hline EC4 & 0 & 0 & 4 & 2 & 6 & 10 & 30 & 83 \\
\hline EC5 & 0 & 0 & 1 & 0 & 1 & 5 & 50 & 106 \\
\hline EC6 & 0 & 0 & 2 & 0 & 2 & 5 & 20 & 32 \\
\hline EC7 & 0 & 0 & 3 & 0 & 3 & 5 & 20 & 37 \\
\hline EC8 & 0 & 0 & 1 & 1 & 2 & 5 & 10 & 16 \\
\hline ECT1 & 1 & 0 & 1 & 0 & 2 & 2 & 20 & 41 \\
\hline ECT2 & 0 & 2 & 2 & 1 & 5 & 2 & 20 & 157 \\
\hline ECT3 & 1 & 0 & 3 & 1 & 5 & 2 & 20 & 124 \\
\hline $\mathrm{C} 0$ & 1 & 0 & 1 & 0 & 2 & 5 & 10 & 21 \\
\hline $\mathrm{C} 1$ & 0 & 0 & 0 & 0 & 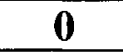 & 1 & $\mathrm{n} / \mathrm{a}$ & 28 \\
\hline $\mathrm{C} 2$ & 0 & 0 & 1 & 1 & 2 & 1 & 10 & 454 \\
\hline C3 & 0 & 0 & 8 & 2 & 10 & 1 & 10 & 399 \\
\hline $\mathrm{C} 4$ & 0 & 0 & 0 & 0 & 0 & 10 & 50 & 143 \\
\hline CT1 & 1 & 0 & 1 & 0 & 2 & 1 & 10 & 105 \\
\hline CT2 & 0 & 1 & 4 & 3 & 8 & 1 & 10 & 275 \\
\hline CT3 & 1 & 0 & 4 & 2 & 7 & 1 & 10 & 326 \\
\hline G1 & 1 & 0 & 1 & 0 & 2 & 1 & 10 & 164 \\
\hline G2 & 0 & 0 & 2 & 1 & 3 & 1 & 10 & 639 \\
\hline G3 & 0 & 1 & 1 & 0 & 2 & 1 & 10 & 68 \\
\hline Total & 8 & 4 & 42 & 15 & 69 & & & \\
\hline
\end{tabular}

Table 7.2. Summary table of dangerous events in 22 experiments

The experiments that had missed positive events were experiment EC6 and EC7 for electrical coil stove. In both experiments, the lids were removed and replaced on the pot causing the pot presence/absence system to incorrectly register pot removal and replacement events. These incorrect results led to the poor sensitivity in both experiments and also poor a positive predictive value for EC6. 
Likewise, the positive predictive value was excellent (mean=87\%) indicating a very low false positive rate. The largest sources of false positive alerts were experiments G2 (8/20) and ECT3 (7/20). The false alerts in G2 were of type 1 and 2 and were caused by the parallax effect due to the camera placement during experiments with the gas stove as discussed below in section 7.4.2.

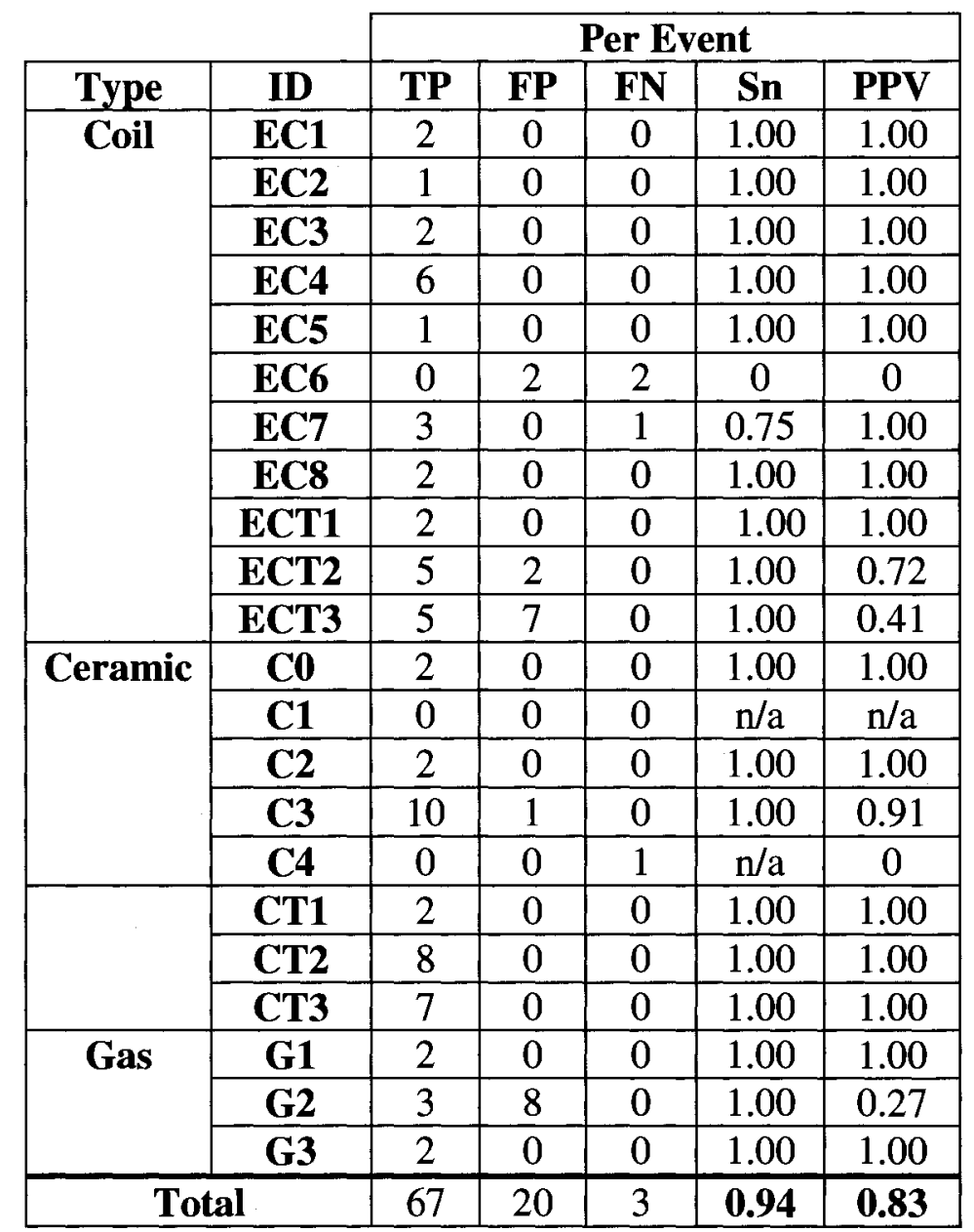

Table 7.3. Evaluation of data fusion alert generation per event

In experiment ECT3, seven false positive alerts of type 1. Here, burner 1 is initially hot, but cools throughout the experiment. Due to intermittent temperature spikes caused by human activity, the burner temperature is repeatedly mistaken to be increasing, falsely 
leading to uncovered burner alerts. These errors could be eliminated with improved data fusion as discussed in section 7.4.3 below. The single false positive alert of type 3 occurs in experiment $\mathrm{C} 3$ and this is due to a missed human activity event by the human activity detection subsystem.

\subsection{Discussion}

\subsubsection{Time delays}

There is no significant delay time for computing the data fusion logic. However, the data fusion is based on the results of four sub-systems. The average time for detecting burner activity, temperature trend, and pot presence are about 1 second per frame each. Currently, it takes approximately 3 seconds per frame to check for human activity. Therefore, the current computation time per frame considering all subsystems is equal to 6 seconds. It should be noted that no effort was made to accelerate the algorithms nor optimize their implementation. It is fully expected that real-time processing could be achieved with proper algorithm optimization and possible porting to a compiled programming language (e.g. C). Note that the camera can also be controlled in real-time via the FLIR SDK product or through OLE automation. This is discussed further in section 8.2.1.

\subsubsection{Camera placement}

A large number of false positives were observed during the experiments involving the gas stove (G2 and G3). In these experiments, the thermal camera was placed in front of the burner and the natural gas flame caused more heat reflection than other types of stoves. In experiment G2, burner 4 was active and burner 5 was off the entire experiment. However, 
the data fusion system incorrectly detects the burner 5 as being on and uncovered, leading to a false alert generation. This is because the front view camera angle makes the system regard the pot on burner 4 as being part of the burner 5 area (see Figure 7.3 below).

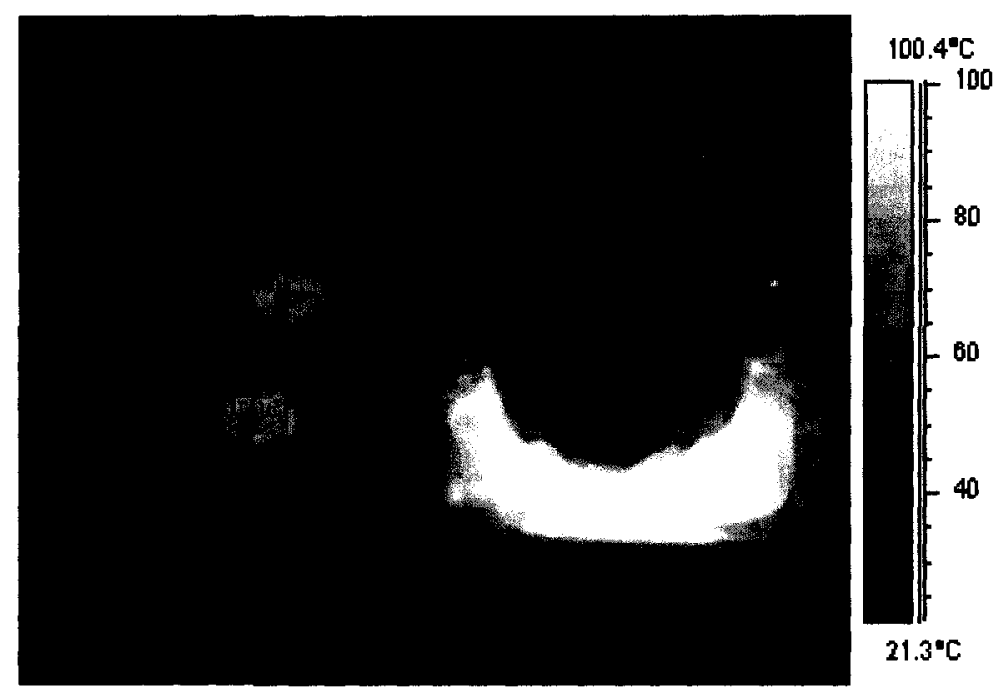

Figure 7.3. The front view of gas stove (Exp G2), pot on B4 is regarded as part of the burner 5

In experiment G3, burner 4 (front-right burner) was active with a flames coming out of it, while burner 5 (back-left burner) was inactive and was covered with metallic pot. The heat from the flames of burner 4 is reflected by the metallic pot in burner 5 causing a number of false alerts. These alerts are false because burner 5 was not actually active (see Figure 7.4). All of these false positive errors could be avoided if the camera were placed immediate above the stove top as is specified for future prototypes. 


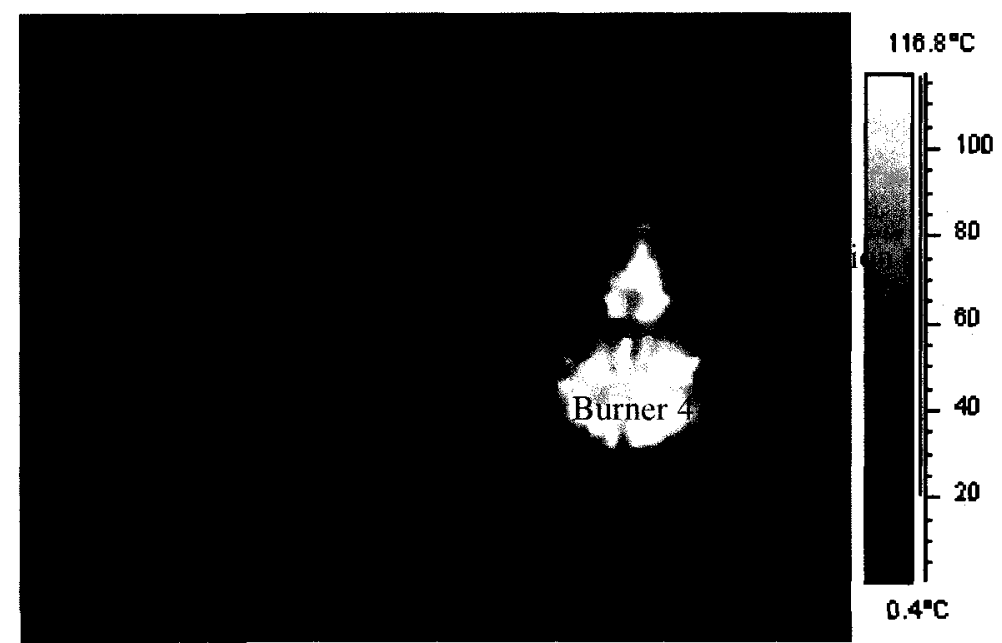

Figure 7.4. The front view of gas stove (Exp G3), the reflection, from the flame of burner 4 , is heating up the metallic pot in burner 5 (the red line circles the reflection)

\subsubsection{Data fusion to eliminate subsystems errors}

Data fusion results are based on the outputs from the underlying four sub-systems. If there are incorrect predictions generated from any of the four sub-systems, it is possible to cause an error in alert generation. In addition, the pot presence subsystem is temporarily affected by human activity, so these inputs are ignored during periods of human activity. For example, in Figure 7.5 below (reproduced from Figure 5.9), yellow bars highlight the human activity sessions and the green bar highlights the pot removal activity. As can be seen, human activity causes temperature spikes which may be mistaken for pot removal and replacement events. It was clear from Figure 5.11 above that temperature spikes caused by human activity events may have similar magnitude to those caused by pot removal and replacement events. Therefore it is important to identify human activity and to ignore outputs from the pot presence algorithm during these periods. A true pot removal or replacement event will be detected as soon as the human activity ceases. 


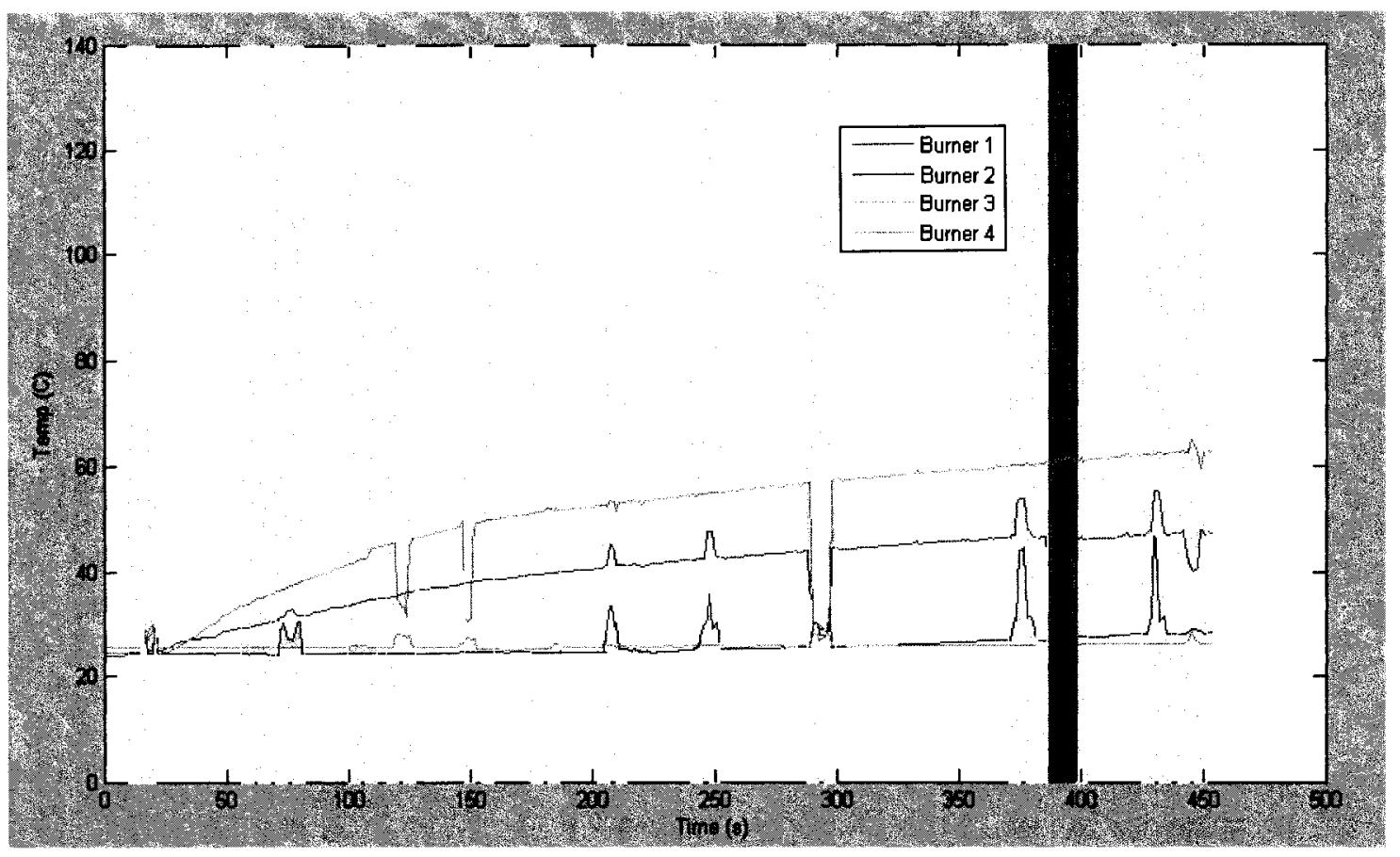

Figure 7.5. Effect of human activity on the pot removal/replacement system

Two examples of human activity affecting the pot presence system are shown in Figure 7.5 below. These images are from experiment C3, when the subject's back blocks the view totally (images $\mathrm{c}$ and $\mathrm{d}$ ) and when subject's hand block the view of burner (image a and $b$ ). This caused the temperature difference between continuous frames to be larger than the threshold value $28^{\circ} \mathrm{C}$ causing false pot removal and replacement events. Therefore, pot presence status outputs are ignored during the human activity sessions.

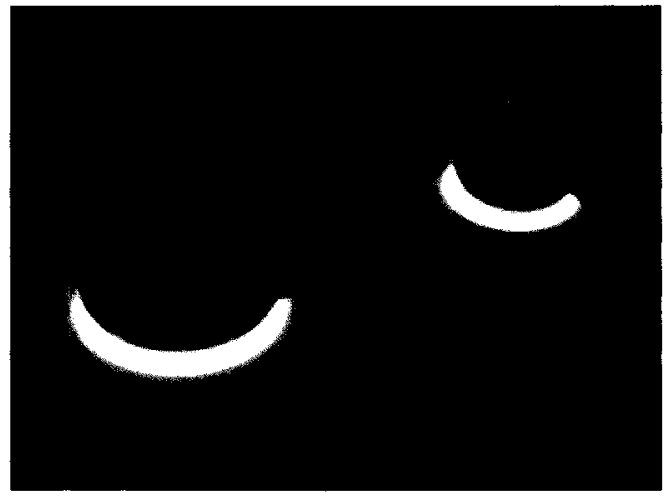

a)

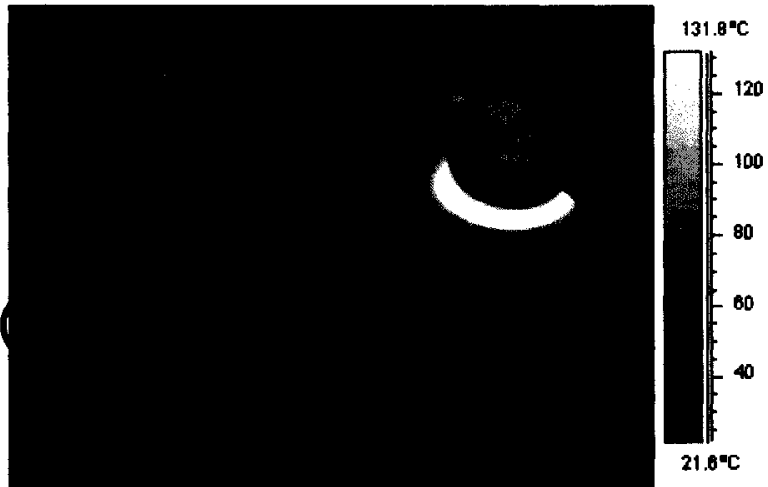

b) 


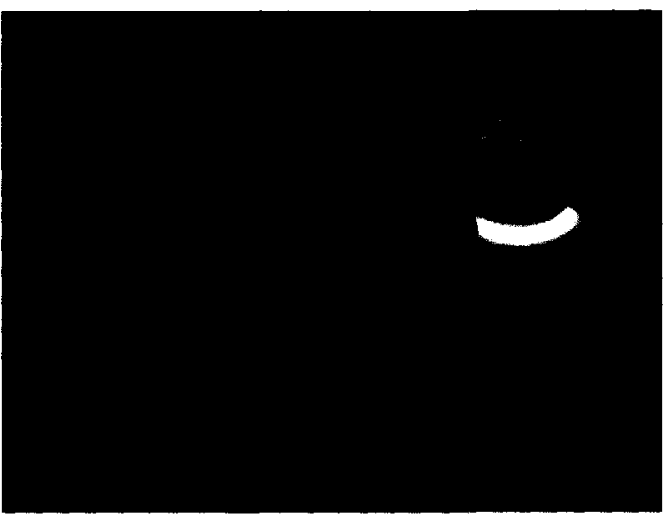

c)

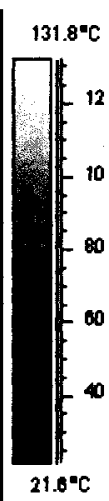

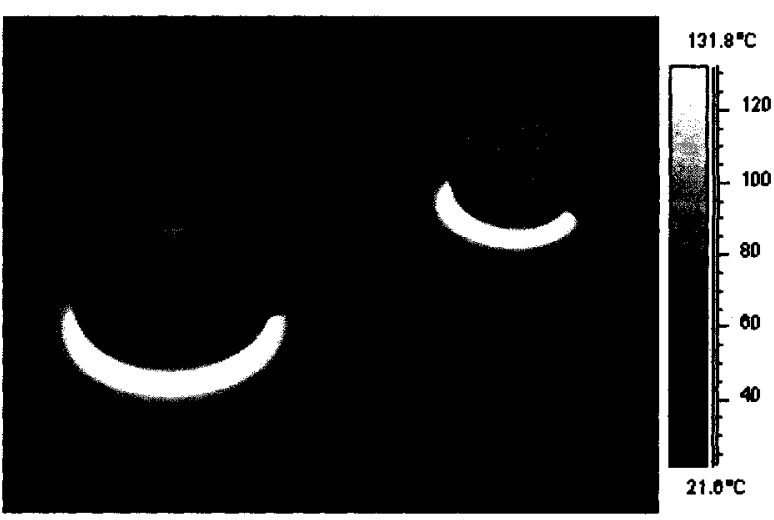

d)

Figure 7.6. Examples of human activity affecting pot presence. Red circle in b) indicates human arm occluding burner resulting in falsely predicted pot replacement event. Red circle in c) shows human user completely blocking two burners. When burners become unblocked, a false pot removal event occurs.

\subsubsection{Data fusion algorithm complexity}

The data fusion system employs a simple-rule based system to generate alerts. The data fusion system reaches good sensitive and PPV values for twenty-two experiments both with the mean value equal to $88 \%$. There may be other more complex data fusion systems which could lead to more accurate results, as suggested in ref [24]. However, if the simplest approach performs well, then there is no reason to move to a more complex approach at this time. Exploring other data fusion algorithms is left to future work.

\subsubsection{Effect of false alerts on the user}

The high PPV value of $88 \%$ means that only $12 \%$ of alerts will be false alerts. This low rate is important for several reasons. The generation of false alerts could cause several undesirable outcomes including the user starting to ignore alerts if there are too many false alerts, or the users may begin to reject the system and lose trust in our system if there are excessive alerts. False alerts also increase the overall frequency of alerts which could make the elderly user feel anxious by hearing it too times a day. This system is 
meant to promote independent living, not create an environment where the user becomes afraid to use their own appliance.

\subsubsection{Alert severity}

Thus far, alerts have been categorized based on the type of dangerous situations. Alerts can also be classified based on how serious the situations are, for example, generate the audible reminders should first be generated, emergency action should follow if more than 10 minutes pass without corrective action from the user. Ultimately, the system could be augmented to enable remote notification of a care giver or family member, or emergency cessation of power from the stove. 


\section{Chapter 8}

\section{Conclusions}

A summary of results and major contributions is listed below, along with recommendations for future work.

\subsection{Summary of Results}

As stated in chapter 1, the goal of this thesis is to meet the following requirements:

\subsubsection{Automatic calibration and burner identification}

Requirement: Automatic calibration and identification of all burners for arbitrary stove top configuration, and arbitrary placement of the camera.

Results: Requirement met.

\subsubsection{Burner status}

Requirement: Detect the status of all burners as being active or inactive. Furthermore, determine the temperature trend of all active burners as being increasing, decreasing, or remaining constant.

Results: We created a monitoring system to detect if the burner is active or inactive. For burner temperature detection system, we selected a moving filter with window size 10 seconds for eleven experiments including electrical coil, ceramic and natural gas stoves. The mean reaches the average equal to $95.6 \%$. 


\subsubsection{Pot presence}

Requirement: Detect if an active burner is occupied with pot or not at all times.

Results: A pot presence/absence detection system as developed consisting of an initial pot status detection and pot removal and removal detection systems. Excellent classification accuracy (96.4\%) of initial pot presence was achieved when LDA was applied to the minimum diff_score computed over the first 20 s of burner activity. Ongoing pot presence was determined through monitoring for pot removal and replacement events. Five experiments including fifteen pot removal/replacement events were conducted to evaluate pot removal and replacement detection system. All 35 pot removal and replacement events are correctly detected while 5 false positive events were detected, largely due to lid removal and replacement events.

\subsubsection{Human activity}

Requirement: Continuous monitoring of human activity at the stove top when any burner is active.

Results: A system was developed to identify human activity at the stove top in order to confirm that the stove is being attended to. The system performance was evaluated over 10 experiments both on a per-frame and per-event basis. Mean specificity is equal to $95 \%$ and the mean sensitivity is $81.8 \%$ on per-frame basis. In terms of per-event evaluation, the average sensitivity is $86.7 \%$ and positive predictive value is $92.6 \%$. The results were proposed and published at the CMBEC $31^{\text {st }}$, Montreal, June 10-13, 2008 [13] and were presented by myself. 


\subsubsection{Alert generation through data fusion}

Requirement: Data fusion of burner status, pot status, and human activity in order to generate alerts for the following commonly observed dangerous behaviours:

1. A user turns on the burner and forgets to put the pot on it.

2. A user turns on one burner (burner A) and puts the pot on the wrong one (burner B).

3. A user does not tend to an active stove top for a user configurable time-out period.

4. A pot is removed from a burner, but the user forgets to turn off the burner.

Results: Data fusion was used to combine results from all of the above systems; we generate four different types of alerts to remind people of dangerous situations. The data fusion and alert generation subsystem demonstrates excellent results with mean sensitivity $94 \%$ and $\%$ for positive predictive value.

\subsubsection{Data collection}

Twenty-nine experiments were completed at four different locations using three different stove types: electric coil, electric ceramic, and natural gas stoves. Ten of these experiments were undertaken with participants under observation in order to test human activity detection. These data are useful not only for this thesis, but also for future work in this field. 


\subsection{Recommendations for Future Work}

\subsubsection{Processing frames in real-time}

In the present study, all thermal images were processed offline. Thermal image sequences were exported from the ThermaCAM Research Professional software to MATLAB data files and all analysis was completed within MATLAB. Ultimately, the system should work in real-time. The ThermoVision Software Development Kit (SDK, FLIR part number: 1195710) allows users to control the camera in real-time from within MATLAB. The SDK captures full dynamic range, 16 bit image raw data and facilitates communications between MATLAB and the FLIR camera [60]. However, the SDK is a separate product and was not available in this research. In the future, the use of the SDK could make the stove top monitoring system working efficiently and in real time. It is also possible to automate the camera control from within MATLAB via OLE (Object Linking and Embedding) scripting; however this option was also not pursued in this study.

\subsubsection{Camera placement}

It is important when considering which technologies may be deployed in a home monitoring scenario to consider the perceived privacy of the user as this has a large impact on the acceptance of the technology by the user. For example, many users will feel uneasy with the installation of a pan-tilt-zoom camera in their home, even if they have assurances that the data is only processed locally and never leaves their home. With this in mind, we have limited the field of view of the camera to cover only the stove top with a small margin around it. Furthermore, the camera orientation is also fixed, thereby increasing the user's comfort that their privacy is not being unduly invaded. Lastly, 
although the use of a thermal camera was critical to the success of this study, the addition of a natural light camera to the system would greatly simplify several aspects of the thesis, particularly the detection of human activity. However, we have restricted ourselves to solely using a thermal camera as it is expected that users will be more accepting of an IR camera as opposed to a natural light camera.

Positioning the camera immediately over the cooking surface, by attaching it to the hood vent for example, has advantages for image processing in that the burner will not be skewed by camera angle. However, such a position may lead to an accumulation of cooking grease on the camera lens, thereby occluding the view over time. Instead, the camera will ultimately be positioned slightly off-center and the image processing algorithms have been designed to handle ellipsoid burners rather than assuming a specific geometry such as perfect circles. In addition, by having a stove top with air gap between the elements and the temperature dials could lead to improved results from the human activity detection system and therefore the overall system performance could be improved

\subsubsection{Camera hardware and associated limitations}

The FLIR model A40 thermal image pixel values are equal to the temperature in Kelvin at that point, and its temperature ranges is from $233 \mathrm{~K}$ to $408 \mathrm{~K}\left(-40^{\circ} \mathrm{C}\right.$ to $\left.+135 \cdot 2^{0} \mathrm{C}\right)$. This limitation could reduce the usable range of the system. For example, the present system cannot detect an abnormal event such as spilt oil catching fire due to the temperature range of the camera. In addition, we could not detect the situation when the pot is boiling dry with cooking oil, since the smoke point for cooking oil is much higher than $135.2^{\circ} \mathrm{C}$ as given in Table 8.1 below [61]. Smoke point is defined as the point at which a cooking 
fat or oil begins to break down [62] and is lower than the point at which it catches fire (see Table 4.1 for auto-ignition temperatures).

\begin{tabular}{|c|c|}
\hline \multicolumn{2}{|c|}{ Smoke point (degrees C) } \\
\hline Safflower & 265 \\
\hline Sunflower & 246 \\
\hline Soybean & 241 \\
\hline Canola & 238 \\
\hline Corn & 236 \\
\hline Peanut & 231 \\
\hline Sesame & 215 \\
\hline Olive & 190 \\
\hline Lards & 183 to 205 \\
\hline
\end{tabular}

Table 8.1. Smoke points for different type of cooking oil [61]

If the temperature range were greater, then it would be possible to detect a pot boiling dry, even for oils with high smoke points. With the current camera, it is only possible to detect such an event for water, which boils at $100^{\circ} \mathrm{C}$. As can be seen below in Figure 8.1, there is a rapid temperature increase when a pot boils dry. This can be easily detected using the same approach as detecting pot removal events. In the future, we could require a different camera to detect abnormal situations.

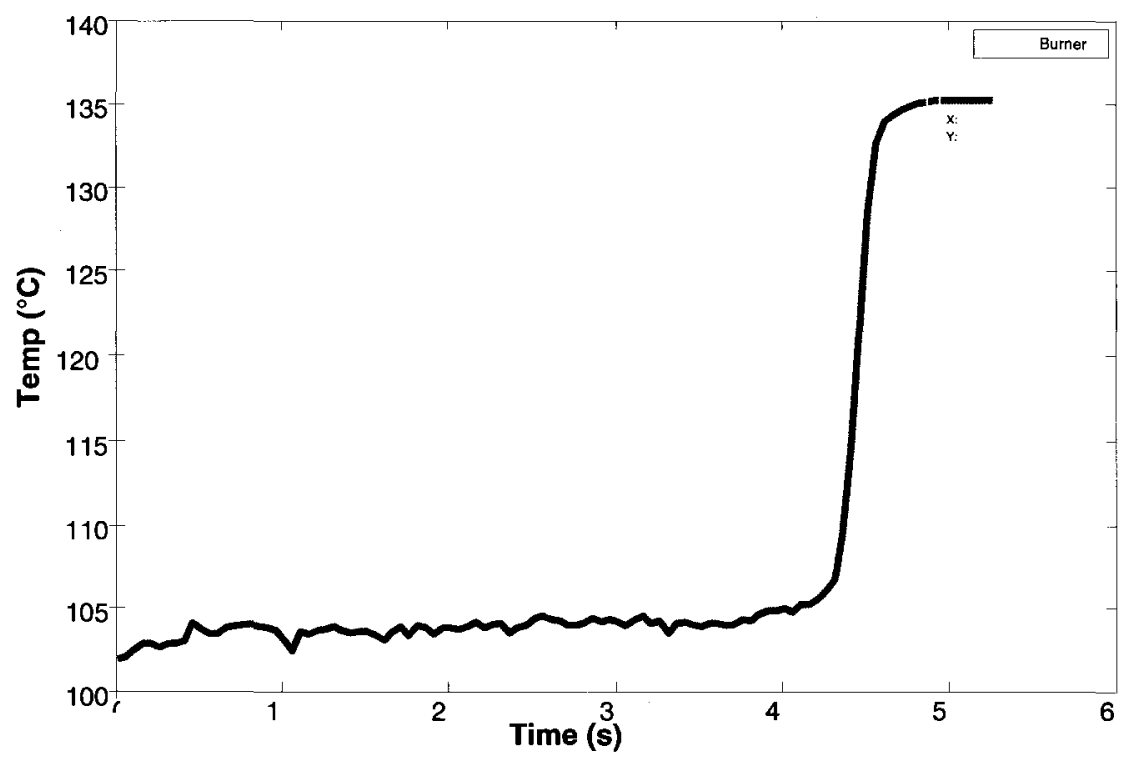

Figure 8.1. Temperature profile of a pot boiling dry 


\subsubsection{Integration with other stove safety products}

Lately, a patented product called the Safe-T-element ${ }^{\mathrm{TM}}$ cooking system was created to help prevent cooking fire accident before it starts. It is an electronically controlled solid cover plate installed on a burner as shown in Figure 8.2 below. A control unit inside the cover controls the burner power such that the temperature of the plate cover reaches no more than $350^{\circ} \mathrm{C} / 662^{\circ} \mathrm{F}$. This greatly reduces the chance of a fire because the ignition temperature for cooking oil is $370^{\circ} \mathrm{C} / 698^{\circ} \mathrm{F}$ and for household materials such as cotton and paper is between $400^{\circ} \mathrm{C} / 752^{\circ} \mathrm{F}$ and $570^{\circ} \mathrm{C} / 1058^{\circ} \mathrm{F}[10]$.

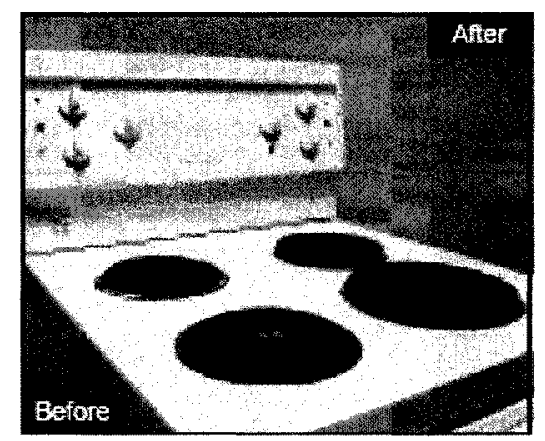

Figure 8.2. Safe-T-element ${ }^{\mathrm{TM}}$ cooking system (adapted from [10])

In the future, if we are going to combine the Safe-T-element ${ }^{\mathrm{m}}$ cooking system with the stove top monitoring system, it may be possible to get a precise burner temperature from the Safe-T-element ${ }^{\mathrm{m}}$ cooking system, while the thermal camera is used solely for detection of human activity. The combination of these two systems can further improve safety in the kitchen and keep the cooking efficient and effective. 


\subsubsection{Other applications of thermal imaging for independent living}

This thesis has demonstrated that thermal imaging may be used to detect unsafe behaviours in the kitchen. The solution developed here may be more widely applicable to promoting independent living among the elderly. For example, devices such as heaters and electric blankets may be disabled when no longer in use by tracking device usage and human activity. This system may also find use in controlling heating and air conditioning systems as thermal imaging may provide better tracking of human occupancy than motion detectors alone.

\subsubsection{Alert generation}

This study indicates when alerts should be generated when dangerous behaviours are observed. In an actual implementation, alerts will range from gentle audible reminders to emergency action. When a dangerous situation is detected, the system should generate gentle audible alert to remind the user. If the danger still exists after ten minutes, the system should increase the severity of alert gradually until the danger is addressed. If the danger remains for more than 20 minutes, the system should take the emergency action such as disable the stove and/or alert a remote caregiver. It is hoped that the prototype system developed herein serves as the basis for an actual implementation in the future that will lead to increased kitchen safety thereby promoting independent living among the elderly and disabled populations. 


\section{References}

[1] M. W. Rosenberg and E. G. Moore, "The health of Canada's elderly population: current status and future implications," Journal of the Canadian Medical Association, vol. 157, pp.1025-32. 1997.

[2] Statistics Canada. 2007. Census trends for Canada (table). Census Trends. 2006 Census. Statistics Canada Catalogue no. 92-597-XWE. Ottawa. Released December 4, 2007.

[3] Public Health Agency of Canada, web accessed February 2008, http://www.phacaspc.gc.ca/seniors-aines/pubs/fed papper/fedreport1 01 e.htm.

[4] "E-health services in home and community settings," Workshop of Health Canada, Office of Health and the Information Highway, Aylmer, QC, Canada, March 17-18, 2002.

[5] S. Hussain, S. Dar, "Architecture for smart sensors system for tele-health," IEEE International Workshop on Health Pervasive Systems, Lyon, France, June 29, 2006.

[6] N. Noury, "AILISA: experimental platforms to evaluate remote care and assistive technologies in gerontology," IEEE Proceedings of the $7^{\text {th }}$ International Workshop on Enterprise Networking and Computing in Healthcare Industry, Busan, South Korea, June 23-25, 2005. pp. 67-72.

[7] P. Harmo, T. Taipalus, J. Knuuttila, J. Vallet, A. Halme, "Needs and solutions-home automation and service robots for the elderly and disabled," IEEE International Conference on Intelligent Robots and Systems, AB, Canada, August 2-6, 2005, pp. 32013206.

[8] A. Arcelus, M. Jones, R. Goubran, and F. Knoefel, "Integration of smart Home Technologies in a Health Monitoring System for the Elderly," First International Workshop on Smart Homes for Tele-Health, 21-23 May 2007, Niagara Falls, Ontario.

[9] V. M. S. Lee, W. Wong, and C. Lau, "Home accidents in elderly patients presenting to an emergency department," Accident and Emergency Nursing, vol. 7, p. 7, 1999.

[10] Jim Crawford, "Beyond Baking Soda”, FireRescue Magazine, December 2005.

[11] NFPA, "How to prevent cooking fires and Related Injuries", web accessed September 2008, $\quad$ http://www.usfa.dhs.gov/downloads/ppt/cooking/fa-312powerpoint.ppt\#2.

[12] NFPA, "FA-312 Behavioural Mitigation of Cooking Fires", web accessed September 2008, http://www.nfpa.org/assets/files/PDF/Research/USFACookingReport.pdf. 
[13] Yuan, M.Y., Green, J.R., Goubran, R., "Stove Top Thermal Monitoring For Assisted Living At Home", The Canadian Medical and Biological Engineering Society, Montreal, June 10-13, 2008.

[14] A. Arcelus, M. Howell Jones, R.A. Goubran, F. Knoefel, "Integration of Smart Home Technologies in a Health Monitoring System for Seniors", First International Workshop on Smart Homes for Tele-Health, Niagra Falls, ON, Canada, May 2007.

[15] Seniorresource.com, "Aging in place." Web accessed September 2008, http://www.seniorresource.com/ageinpl.htm.

[16] Megan Howell Jones, "Autonomous Patient Monitoring with a Pressure Sensor Array”, M.S. thesis, University of Carleton, Ottawa, ON, Canada, 2006.

[17] Technology Assisted Friendly Environment for the Third Age (TAFETA), web assessed September 2008, http://www.tafeta.ca/englishProjects.html.

[18] Dave Gussow, Times, Published September 2005, web assessed July 2006, http://www.sptimes.com/2005/09/12/Technology/Home smart home.html.

[19] M. Ogawa, R. Suzuki, T. Izutsu, T. Iwaya, and T.Togawa, "Long term remote behavioural monitoring of elderly by using sensors installed in ordinary houses," Proceedings $2^{\text {nd }}$ Annual International IEEE-EMBS Special Topic Conference on Micro technologies in Medicine and Biology, Madison, WI, May 2-4, 2002, pp. 322-325.

[20] A. Yamaguchi, M. Ogawa, T. Tamura, and T. Togawa, "Monitoring behaviour in the home using positioning sensors," Proceedings $20^{\text {th }}$ Annual International Conference of the IEEE Engineering in Medicine and Biology Society, vol. 20, 1998, pp. 1997-1979.

[21] M. Ogawa, S. Ochiai, K. Shoji, M. Nishihara, and T. Togawa, "An attempt of monitoring daily activities at home," Proceedings $22^{\text {nd }}$ Annual EMBS conference, Chicago, IL, Jul. 23-28, 2000, pp. 786-788.

[22] M. Ogawa and T. Togawa, "Monitoring daily activities and behaviours at home by using brief sensors," Proceedings $1^{\text {st }}$ Annual International IEEE-EMBS Special Topic Conference on Micro technologies in Medicine and Biology, Lyon, France, Oct. 12-14, 2000, pp. 611-614.

[23] M. Chan, C. Hariton, P. Ringeard, and E. Campo, Smart House Automation Syst. Elderly Disabled, pp. 1586-1589.

[24] Williams G, Doughty K, Bradley DA. "A system approach to achieving CarerNet an integrated and intelligent telecare system," IEEE Transaction on Information Technology in Biomedicine, vol. 2, 1998, pp. 1-9. 
[25] Williams G, Doughty K, Bradley DA. Distributed intelligent nodes as information filters in advanced telecare systems. Proceedings $21^{\text {st }}$ Annual International Conference IEEE Engineering in Medicine \& Biology Society. Atlanta, October 13-16, 1999.

[26] National Kenniscentrum Domotica \& Slim Wonen, "Stichting Smart Homes", Web assessed August 2006, http://www.smart-homes.nl/engels/infonet/projects.html.

[27] B. G. Celler, T. Hesketh, W. Earnshaw and E. Ilsar, "An instrumentation system for the remote monitoring of changes in functional health status of the elderly at home", Proceedings $16^{\text {th }}$ Annual International Conference IEEE Engineering in Medicine and Biology Society. Baltimore, 1994.

[28] FLIR system, ThermaCAM Researcher professional edition. Version 2.8, SR-3, FLIR Company, 2006.

[29] Wikipedia contributors, "Thermography", web accessed August 2008, http://en.wikipedia.org/wiki/Thermography\#cite note-3.

[30] Monqiue Frize ( private communication), 2006.

[31] Annamalai, Manichavasagan, "Thermal imaging for potential use in cereals and oilseeds handling”, Ph.D's thesis, University of Manitoba, MB, Canada, 2007.

[32] C. Wren, A. Azarbayejani, T. Darrell, and A. Pentland. "Pfinder: real-time tracking of the human body." IEEE Transactions on Pattern Analysis and Machine Intelligence, vol.19, pp.780-785, 1997.

[33] C. Stauffer and W.E.L. "Grimson. Adaptive background mixture models for realtime tracking." Proceedings of IEEE Computer Vision and Pattern Recognition, 1999, pp. 246-252.

[34] I. Haritaoglu, D. Harwood, and L. Davis. "W4: Who? When? Where? What? A real time system for detecting and tracking people." In Proceedings of International on Automatic Face and Gesture Recognition Conference, 1998, pp.222-227.

[35] K. Toyama, B. Brumitt, J. Krumm, and B. Meyers. "Wallflower: principals and practice of background maintenance." In Proceedings of International Computer Vision Conference, 1999, pp.49-54.

[36] O. Javed, K. Shafique, and M. Shah. "A hierarchical approach to robust background subtraction using color and gradient information." Workshop on Motion and Video Computing, pp.22-27. IEEE, 2002.

[37] T. Zhao and R. Nevatia. "Stochastic human segmentation from a static camera." Workshop on Motion and Video Computing, pp.9-14. IEEE, 2002. 
[38] M. Oren, C. Papageorgious, P. Sinha, E. Osuma, and T. Poggio. "Pedestrain detection using wavelet templates." Proceedings of IEEE Computer Vision and Pattern Recognition, 1997, pp.193-199.

[39] D. Gavrila. "Pedestrain detection from a moving vehicle." Proceedings of the European Conference on Computer Vision, 2000, pp.37-49.

[40] P. Viola, M. Jones, and D. Snow. "Detectng pedestrains using patterns of motion and appearance." Proceedings of the International Conference on Computer Vision, 2003, pp.734-741.

[41] A. Lipton, H. Fujiyoshi, and R. Patil. "Moving target classificatin and tracking from real-time video." Proceedings of Workshop on Applications of Computer Vision, 1998.

[42] S. Iwasawa, K. Ebihara, J. Ohya, and S. Morishima. "Real-time estimation of human body posture from monocular thermal images." In Proceedings of IEEE Computer Vision and Pattern Recognition, 1997, pp.15-20.

[43] B. Bhanu and J. Han. "Kinematic-based human motion analysis in infrared sequences." Proceedings of Workshop on Applications of Computer Vision, pp.208-212, 2002.

[44] B. Bhanu and R. Holben. "Model-based segmentation of FLIR images." IEEE Transactions in Aerospace and Electronic System, vol. 26, pp.2-11, 1990.

[45] A. Danker and A. Rosenfeld. "Blob detection by relaxation." IEEE Transactions of Pattern Analysis and Machine Intelligence, vol. 3, pp.79-92, 1981.

[46] A. Yilmax, K. Shafique, and M. Shah. "Target tracking in airborne forward looking infrared imagery." in Image and Vision Computing, vol.21, pp.623-635, 2003.

[47] James W. Davis, Vinay Sharma, "Robust Background-Subtraction for Person Detection in Thermal Imagery", IEEE workshop on Object Tracking and Classification Beyond the Visible Spectrum, Washington DC, July 2, 2004.

[48] Ju Han and B. Bhanu. "Detecting moving humans using color and infrared video", IEEE International Conference on Multisensor Fusion and Integration for Intelligent Systems, vol.30, pp.228-233, 2003.

[49] Neeti A. Ogale, "A survey of techniques for human detection from video", M.S. thesis, University of Maryland, Maryland, MA, United States, 2006.

[50] Sang Min Yoon and Hyunwoo Kim. Real-time multiple people detection using skin color, motion and appearance information. International Workshop on Robot and Human Interactive Communication, pp.331-334, 2004. 
[51] Foster J. Provost, Tom Fawcett, Ron Kohavi, "The case against Accuracy Estimation for comparing Inductive Algorithms", Proceedings of the Fifteenth International Conference on Machine Learning, pp. 445 - 453, 1998.

[52] R.O. Duda, P.E.. Hart and D.G. Stork, Pattern classification and scene analysis. $2^{\text {nd }}$ ed. New York: Wiley, 2001.

[53] Babrauskas V. "Toxicity Assessment of Combustion Products" in The SFPE handbook of fire protection engineering, Third edition, chapter 2-6.

[54] The Engineering Toolbox, "Fuels, Chemicals and their ignition Temperature", web accessed September 2008, http://www.engineeringtoolbox.com/fuels-ignitiontemperatures-d 171.html.

[55] INNOVA AirTech Insturments, "Thermal Comfort", web accessed August 2008, http://www.blowtex-educair.it/DOWNLOADS/Thermal\%20Comfort.htm.

[56] Fanger, P.O, Thermal Comfort, McGraw-Hill, New York, USA, 1972.

[57] Wikipedia, "Equivalent temperature", web accessed October 2008, http://en.wikipedia.org/wiki/Equivalent temperature.

[58] Wikipedia, "Latent heat", web accessed October 2008, http://en.wikipedia.org/wiki/Latent heat.

[59] Wikipedia, "Humidity", web accessed October 2008, http://en.wikipedia.org/wiki/Mixing ratio.

[60] FLIR System LTD. "ThermoVision SDK 2.6", web accessed May 2008, www.FLIR.CA.

[61] Chef Geir, "Deep frying", web accessed July 2008, http://www.culinaryyours.com/frying oil.html.

[62] Wikipedia, "Smoke point", web accessed October 2008, http://en.wikipedia.org/wiki/Smoke point. 


\section{Appendix A - Experimental Procedures}

The experimental protocol followed for each experiment of three different types of stove tops is described below.

\section{A-1 Electric Coil Stove}

\begin{tabular}{|c|c|c|}
\hline Experiment(at Carleton University, top view) & $\begin{array}{c}\text { Seconds per frame } \\
\text { (SPF) }\end{array}$ & $\begin{array}{c}\text { Total } \\
\text { frames }\end{array}$ \\
\hline EC1 & 2 & 31 \\
\hline EC2 & 10 & 38 \\
\hline EC3 & 1 & 31 \\
\hline EC4 & 10 & 83 \\
\hline EC5 & 5 & 106 \\
\hline EC6 & 5 & 32 \\
\hline EC8 & 5 & 37 \\
\hline EC9 & 5 & 16 \\
\hline EC10 & & \\
\hline EC11 & 2 & 194 \\
\hline EC12 & 2 & 245 \\
\hline Experiment (at Mingye's apartment, top view) & 2 & 259 \\
\hline ECT4 & 2 & 132 \\
\hline ECT6 & 2 & \\
\hline
\end{tabular}

Table A.1. SPF and total frames for electrical coil stove experiments

\section{A-1.1 Two-burner experiments, top view}

- Place the camera directly on the top of the stove.

- This placement of the thermal camera also has advantages for image processing in that the burner will not be skewed by camera angle. 


\section{Experiment EC1}

\section{Goal:}

- To test the max temperature and how long it will take to max temperature

\section{Description:}

- Turn on both burners to Max and the experiment lasts for 60 seconds.

\section{Experiment EC2}

\section{Goal:}

- In order to get the cooling rate

\section{Description:}

- This experiment was taken after the experiment EC1.

- Turn off both burners at the beginning of the experiment.

\section{Experiment EC3}

\section{Goal:}

- Pick up one image from this experiment for calibration

\section{Description:}

- The burners are both off and they are at the room temperature at the beginning of the experiment.

- Wait for $5 \mathrm{~s}$ and turn on both burners on for $25 \mathrm{~s}$.

\section{Experiment EC4}

\section{Goal:}

- In order to detect human activity and pot boiling.

\section{Description:}


- The burners are both off and they are at the room temperature at the beginning of the experiment.

- A pot with half full water is on the front burner (burner 1). The other burner (burner 2) is empty at the beginning of the experiment.

- Turn on burner 1 and wait for 1 minute, remove pot, wait 30 seconds then replace the pot and wait for 1 minute. Hands on the handle for 20 seconds and then remove the burner. At 3.5 minutes (from the start of the experiment 4), put back the burner.

- At 7.5 minutes (from the start of the experiment 4), the pot on burner 1 reaches the boiling. Hands on handle for 20 seconds and remove the pot for 1 minute and put it back.

- At 8.5 minutes (from the start of the experiment 4), put hands again

- At 9 minutes (from the start of the experiment 4), remove the pot on burner 1

- At 10 minutes (from the start of the experiment 4) replace the pot on burner 1

- At 10 minutes and 45 seconds (from the start of the experiment 4 ), the pot reach boiling again. (END)

\section{Experiment EC5}

\section{Goal:}

- In order to get the pictures from boiling to boiling dry and human activity.

\section{Description:}

- Burner 1 starts from the boiling status with $1 / 8$ water full pot at the beginning of the experiment. 
- At 0 , the pot is boiling.

- At 30 seconds, hands on pot for 15 seconds

- At 2.5 minutes, the pot starts to boiling dry

- At 7.5 minutes, the pot is boiling dry (pot is at the same temperature as the burner at the moment).

- End at 8.5 minutes.

\section{Experiment EC6}

\section{Goal:}

- In order to distinguish lid on pot/ not on pot.

\section{Description:}

- A pot with water is on the front burner (burner 1 is at the max temperature), burner 2 is off at the beginning of the experiment.

- At 20 seconds, hand on the pot for 10 seconds.

- At 35 seconds, hand on the lid and the lid is removed on the pot.

- At 1 minute, put the lid back on the pot.

- At 1 minute and 30 seconds to 1 minute and 45 seconds, hand on the pot.

- At 1 minute and 50 seconds, hand off and the lid off the pot.

- At 2 minutes and 5 seconds, the hand on and the lid is back on the pot.

- At 2 minutes and 20 seconds, the hand off and the lid is still on the pot until the end of the experiment.

\section{Experiment EC7}

\section{Goal:}

- In order to test the temperature of the lid when the water is boiling inside the pot 


\section{Description:}

- A pot with water is on the front burner (burner 1 is at the max temperature), burner 2 is off at the beginning of the experiment.

- At 20-35 seconds, the hand is on the pot

- At 35-65 seconds, the hand is off and the lid is off the pot

- At 1 minute and 5 seconds - 1 minute and 20 seconds, the hand put on the pot again

- At 1 minute and 25 seconds, the hand is removed

- At 1 minute and 35 seconds, put the lid back on the pot until the end of the experiment

\section{Experiment EC8}

\section{Goal:}

- In order to test the temperature of two burners doesn't affect each other

\section{Description:}

- Both 2 burners are on and the pot is on the front burner (B1) at the beginning of the experiment.

- From beginning to 35 seconds, the pot is on the burner 1 .

- At 40 seconds, the pot is on the burner 2 until the end of the experiment.

\section{A-1.2 Four-burner experiments, front view}

- The thermal camera was placed directly in front of the stove. 
- The block view from hood vent prevents the thermal camera to shoot the fourburner top view, therefore, the front view was replaced.

- The placement of the camera is shown in the picture below:

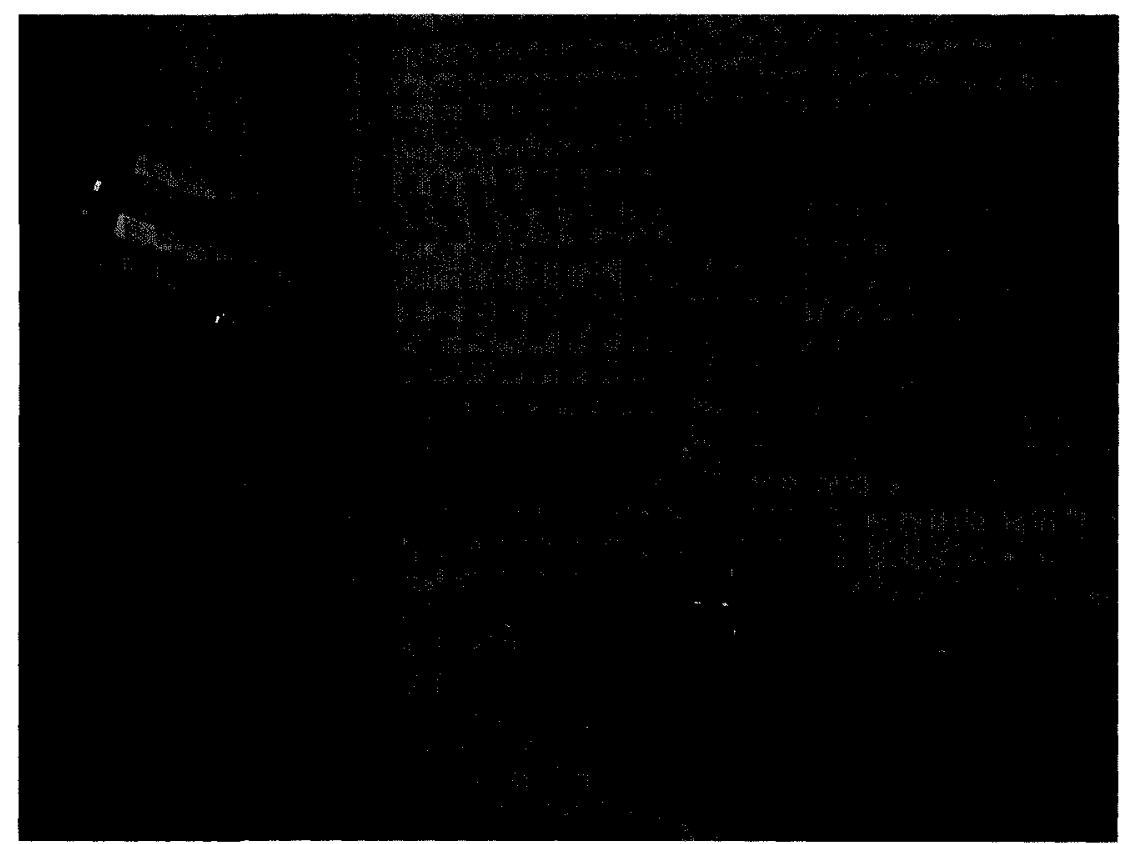

Figure A.1. How the thermal camera to be placed to shot the front view of the stove

\section{Experiment EC9}

\section{Goal:}

- Turn on four burners to maximum power at the same time

- It is used to get the calibration picture for all front view four-burner electric coil stove top

\section{Description:}

- 4-burner electric top stove (Mingye's )

- turn on all 4 burners, let them heat until no change visible on screen 


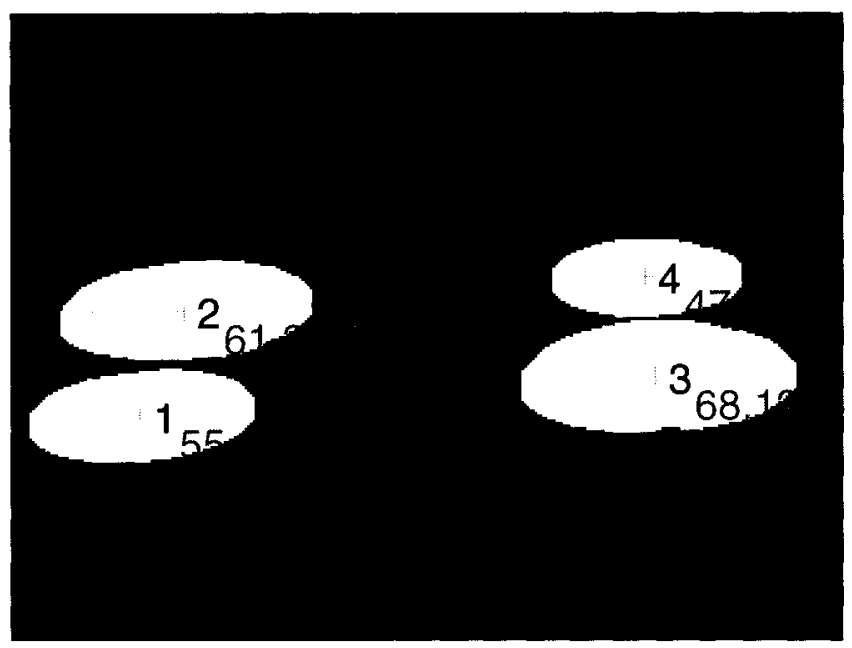

Figure A.1. Experiment 15 calibration picture extracted from the Exp15000278.mat

\section{Experiment EC10}

\section{Goal:}

- In order to test alert situations:

1. Turn on one burner and put the pot on the other burner (turn off),

2. Turn on burners without putting pot on any of them.

3. At the beginning part of the experiment, constant human activity, later on, no human activity, generate alerts when there is no constant human activity.

4. can also detect the burner temperature status if it is increasing or decreasing

\section{Description:}

- Turn on right front burner (burner 3), put pot on right behind burner(burner 4)

- Turn off burner 3, turn on burner 4 and put pot on burner 4

- Turn both burners 3 and 4 off, turn on burner 2 and 1 without putting any bur.

\section{Experiment EC11}




\section{Goal:}

- In order to test alter situations:

1. Turn on a burner without putting a pot on it

2. Put the pot on the on burner without human activity for 5 minutes, generate alert. ( 5 minutes or other time can be chosen as input)

\section{Description:}

- Turn on the burner 4 and put the pot until the $16^{\text {th }}$ frame

- The pot was on the burner 4 the entire experiment with some human activity at the beginning of the experiment and no human activity for last 5 minutes of the experiment

\section{Experiment EC12}

\section{Goal:}

- In order to test :

- Temperature profile when pot is boiling and boiling dry

- In order to distinguish the pot boiling and boiling dry temperature with lid and without lid

\section{Description:}

- Put milk into two pots to simulate the soup boiling and boiling dry situations, one is on burner 1 (without lid), the other one is on burner 4(with lid)

- Both pots are boiling on the $80^{\text {th }}$ frame at the same time

- Pot on burner 1 is boiling dry on the 121 st frame, the other pot is boiling dry on the $125^{\text {th }}$ frame. 


\section{A-1.3 Two-burner experiments, top view}

Due to the limited zoom factor of thermal camera, I can only record burner 1 and burner 2 top view videos.

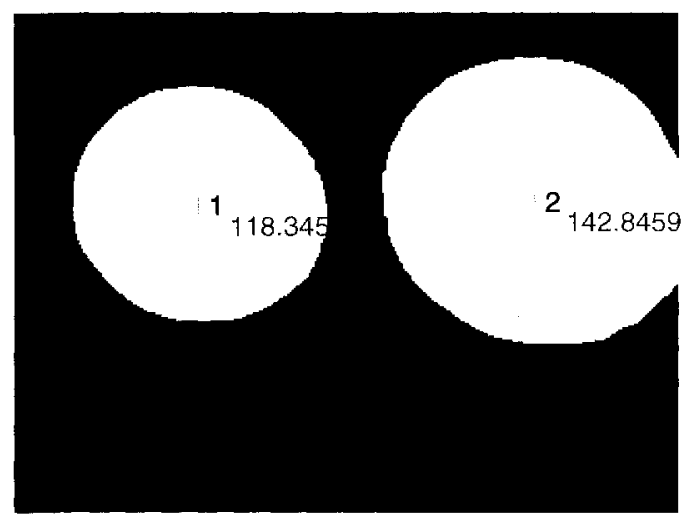

Figure A.2. Calibration picture from experiment 19, frame 40 (Top view with 2 burners)

\section{Experiment ECT1}

\section{Goal:}

- Calibration

\section{Description:}

- 2-burner electric top stove

- turn on all 2 burners, let them heat until no change visible on screen

- 2 seconds per frame, 41 frames in total

\section{Experiment ECT2}

\section{Goal:}

- To test if the system can detect wrong pot placement 
- Can we still detect the pot presence/absence by using a large pot (cover the burner entirely)

\section{Description:}

- turn on burner 1 , put pan on burner $2-\rightarrow$ generate alert

- after a while, put pan on burner 1, the size of the pan ( with a bit water inside) is much larger than the size of burner $1 \rightarrow$ we can still detect the pot absence/ presence use different algorithm

- the water is boiling at the $93^{\text {rd }}$ frame

- the water is boiling dry at the $117^{\text {th }}$ frame

\section{Experiment ECT3}

\section{Goal:}

- Test if the system can detect no constant human activity and generate alerts

\section{Description:}

- turn on burner 2 without putting pot on it, the burner 1 is off but still some temperature remain after experiment 20

- put a pot (with water) on burner 2

- remove pot to test pot absence/presence

- pot on burner 2 for a couple of minutes without human activity to test no human attended for a while situation

\section{Experiment ECT4}

\section{Goal:}

- Calibration 


\section{Description:}

- Turn on all two burners for 76 seconds until no visible heat difference shown on the screen

\section{Experiment ECT5}

\section{Goal:}

- This experiment was planned to test if the heating curve algorithm is the right one to detect pot presence or absence

- We can also use it to detect human activity

- Several pot presence/absence change in the experiment

\section{Description:}

- Turn on burner 1 for low heat level after the heat reaches 100 degrees Celsius.

- Turn the burner 1 to Maximum heat level, put a small pot with a little bit water inside (picture) on the burner 1

- Pot on the burner 1 without lid for a while then removes the pot.

- Put the pot again with lid this times and the pot is boiling at the $218^{\text {th }}$ frame

- Put a little bit more cold water inside the pot and the pot becomes boiling again at the $306^{\text {th }}$ frame

\section{Experiment ECT6}

\section{Goal:}

- This experiment was planned to test if the heating curve algorithm is the right one to detect pot presence or absence 
- Few human activity events

- Several pot replacement and removal for two different sizes of the pots.

\section{Description:}

- The burner 1 was off and the burner 2 was on low heat level at the beginning of the experiment.

- Turn the burner 2 at the Max heat level, and put the big pot with a little bit water inside on the burner 2 for a while. This big pot was with lid.

- Remove the big pot and replace with a medium pot without lid and occupied with a little bit water inside, heat until the end of the experiment.

\section{A-2 Ceramic Stove Experiments}

The following experiments were conducted on J. Green's ceramic stove top.

\begin{tabular}{|c|c|c|}
\hline Experiment(Front view) & Seconds per frame (SPF) & Total frames \\
\hline C0 & $\mathbf{5}$ & 21 \\
\hline C1 & 1 & 28 \\
\hline C2 & 1 & 454 \\
\hline C3 & 1 & 399 \\
\hline C4 & 10 & 143 \\
\hline Experiment (Top view) & & \\
\hline CT1 & 1 & 105 \\
\hline CT2 & 1 & 275 \\
\hline CT3 & 1 & 326 \\
\hline
\end{tabular}

Table A.2. SPF and total frames for ceramic stove experiments

\section{A-2.1 Four-burner ceramic experiments, front view}

\section{Experiment C0}

\section{Goal:}

- Calibration 


\section{Description:}

- 4-burner ceramic top stove

- Turn on all 4 burners, let them heat until no change visible on screen (90 seconds)

- $5 \mathrm{fps}$

\section{Experiment C1}

\section{Goal:}

- Test if the data fusion system will generate any false positive alerts when there are no true alerts occurring.

\section{Description:}

- 4-burner ceramic top stove

- Cooling stove top with ice cubes (fun)

\section{Experiment C2}

\section{Goal:}

- To test the human activity sub-system

- Burner 1 and 4 were occupied with pot at the beginning, could test the pot occupancy

\section{Description:}

- 4-burner ceramic top stove

- Tried to include some of counter-top

- Large pot on front-left burner. Small pot on back-right burner.

- Each pot $40 \%$ full of cool water. 
- Turn on burners to $50 \%$

- Record 1fps (can always drop frames later)

- Human activity every $10-30$ seconds

- Pot 1 , then 2 , etc

- Dwell on handle for 5-10 seconds

- $\quad$ Ran for 8 minutes

\section{Experiment C3}

\section{Goal:}

- To test the human activity sub-system

- Plan to see the temperature profile when the water is boiling dry

\section{Description:}

- 4-burner ceramic top stove

- Tried to include some of counter-top margin

- Large pot on front-left burner. Small pot on back-right burner.

- Each pot $40 \%$ full of warm-hot water.

- Turn on burners to $50 \%$

- Increase to $100 \%$

- Remove lid of small pot

- Remove $2 / 3$ of water

- Let boil dry. 


\section{Experiment C4}

Goal:

- For plotting cooling curve

\section{Description:}

- 4-burner ceramic top stove

- Tried to include some of counter-top

- Large pot on front-left burner. Small pot on back-right burner.

- Pots removed. Heat removed. Will be useful for plotting cooling curve.

- Need to know when burner is cooling since no longer check for human activity.

- Ran for about 15 minutes.

\section{A-2.2 Four-burner ceramic experiments, top view}

\section{Experiment CT1}

Goal:

- Calibration

\section{Description:}

- electric ceramic 4-burner stove top

- turn on all 4 burners, let them heat until no visible change can be seen on thermal imaging 


\section{Experiment CT2}

\section{Goal:}

- In order to test alert situations:

1. Turn on one burner and put the pot on the other burner (turn off),

2. Turn on burners without putting pot on any of them.

3. At the beginning part of the experiment, constant human activity, later on, no human activity, generate alerts when there is no constant human activity.

4. can also detect the burner temperature status if it is increasing or decreasing

\section{Description:}

- Time is 4 and $1 / 2$ minutes in total

- Turned on LR burner but put pot on UR burner.

- After 1 minute, moved pot to LR burner.

- After 2 minutes, removed pot, replaced again after 20 seconds.

- Removed pot again, left burner uncovered for 15 seconds.

- Turned burner off at 3:35. Continued to record for 30 seconds to see cooling effect.

\section{Experiment CT3}

\section{Goal:}

- If the system can distinguish the difference $b / w$ pot on/off at the beginning of the experiment 


\section{Description:}

- Repeated for left side burners (right burners still hot, will have to ignore)

- Note that burner turned itself off briefly at 3:40. Again at 4:00. Again at 4:22. On $90 \%$ power instead of "High" so stove is cycling power off every 20 seconds...

- Turned off at 4:40

- Stopped recording at 5:20.

- Did not include HA - you already have image sequences to test for HA. This new data is just to test your new pot presence algorithm.

\section{A-3 Gas Stove Experiments}

The following experiments were conducted on D. Lahey's and K. Dubinsky's 5-burner natural gas stove top.

\begin{tabular}{|c|c|c|}
\hline Experiment & Seconds per frame (SPF) & Total frame \\
\hline G1 & 1 & 164 \\
\hline G2 & 1 & 639 \\
\hline G3 & 1 & 68 \\
\hline
\end{tabular}

Table A.3. SPF and total frames for gas stove experiments

\section{Experiment G1}

\section{Goal:}

- Calibration

\section{Description:}

- All 5 burners on for approx 1 minute. Uncovered. 1fps. 


\section{Experiment G2}

\section{Goal:}

- To test the human activity detecting system

- Pot presence/absence change

\section{Description:}

- BR burner with pot of cold water. $1 \mathrm{fps}$. Burner on high flame.

- Human activity every 45 seconds. Pot boiled after $\sim 5 \mathrm{~min}$.

- Remove pot after 8 minutes, leave burner on.

- After approx 30 seconds with no pot, turn off burner.

- Stop after 10.5 minutes.

- Some slight camera shaking during experiment.

\section{Experiment G3}

\section{Goal:}

- Could use this experiment to test the dangerous situation: put the pot on the wrong burner

\section{Description:}

- Put pot on back-right, but turn on front right. 1fps. High heat. Run for approx 40 seconds. 